\title{
Differential impact of leverage on the default risk of small and large firms
}

Article

Accepted Version

Cathcart, L., Dufour, A., Rossi, L. and Varotto, S. (2020) Differential impact of leverage on the default risk of small and large firms. Journal of Corporate Finance, 60. 101541. ISSN 0929-1199 doi: https://doi.org/10.1016/j.jcorpfin.2019.101541 Available at https://centaur.reading.ac.uk/87142/

It is advisable to refer to the publisher's version if you intend to cite from the work. See Guidance on citing.

To link to this article DOI: http://dx.doi.org/10.1016/j.jcorpfin.2019.101541

Publisher: Elsevier

All outputs in CentAUR are protected by Intellectual Property Rights law, including copyright law. Copyright and IPR is retained by the creators or other copyright holders. Terms and conditions for use of this material are defined in the End User Agreement.

\section{www.reading.ac.uk/centaur}

\section{CentAUR}

Central Archive at the University of Reading

Reading's research outputs online 


\title{
Differential Impact of Leverage on the Default Risk of
}

\author{
Small and Large Firms*
}

Lara Cathcart $^{1} \quad$ Alfonso Dufour ${ }^{2} \quad$ Ludovico Rossi $^{3} \quad$ Simone Varotto ${ }^{2}$

\author{
${ }^{1}$ Imperial College Business School \\ ${ }^{2}$ ICMA Centre, Henley Business School, University of Reading \\ ${ }^{3}$ Department of Economics, CUNEF (Colegio Universitario de Estudios
}

Financieros)

October 31, 2019

\begin{abstract}
We analyse a sample of 6 million firm-year observations of large corporations and small and medium sized enterprises (SMEs) spanning 6 European countries from 2005 to 2015, to determine the impact of leverage and different sources of funding on default risk. We find that financial leverage has a greater impact on the probability of default of SMEs than of large corporations. The difference in default probability between the top and bottom leverage quartiles is $1.24 \%$ for large firms and $2.87 \%$ for SMEs. This difference may be explained by the greater exposure of SMEs to short-term debt and their consequently higher refinancing risk. Indeed, we find that SMEs that recover from the state of insolvency may have similar leverage to defaulted SMEs; however their liability structure is significantly altered towards long-term debt and away from short-term debt. Our findings have important implications not only for bank regulators and policy-makers but also for credit risk modelling.
\end{abstract}

JEL Codes: G01, G32, G33

Keywords: Default Risk, Leverage, Small and Medium Enterprises, Recovery Probabilities

${ }^{*}$ We thank Douglas Cumming (editor), Santiago Carbó-Valverde, Michael Clements, Anzhela Knyazeva, Raquel de Freitas Oliveira, Magdalena Pisa, Roberto Savona, Stephen Schaefer, Chardin Wese Simen, Nicholas Wilson, and $\mathrm{Ru}$ Xie, as well as participants at the Annual Meeting of the Annual Conference of Brunel Studies in Economics and Finance (2019), the Financial Management Association in San Diego (2018), the International Risk Management Conference in Paris (2018), the European Financial Management Association Annual Meetings in Milan (2018), the Annual Conference on Financial Stability and Banking in Sao Paulo (2018), the Annual Conference of the French Finance Association in Paris (2018), the Annual Congress of the European Accounting Association in Milan (2018), the British Accounting and Finance Association Annual Conference in London (2018), and the CREDIT Conference in Venice (2018) for useful comments and suggestions. 


\section{Introduction}

Since the seminal works of Beaver (1966) and Altman (1968), academic research has paid great attention to the determinants of corporate defaults. More recently, Traczynski (2017) has shown that the only two risk factors that can explain default risk across all industry sectors are financial leverage and market return volatility. This suggests that, for unlisted firms, for which stock returns cannot be computed, financial leverage may be the most important predictor of corporate distress. Indeed, leverage plays a central role in standard credit risk models used in academia and in industry (Merton, 1974, Collin-Dufresne and Goldstein, 2001, Vassalou and Xing, 2004 and Bharath and Shumway, 2008).

Although several papers have looked at the role of leverage specifically for large firms (Altman, 1968, Ohlson, 1980, Shumway, 2001, Chava and Jarrow, 2004, Campbell et al., 2008, Giordani et al., 2014 and Traczynski, 2017) and for small firms (Edmister, 1972, Altman and Sabato, 2005 and Altman and Sabato, 2007) none, to our knowledge, has investigated the differential impact of leverage and its components on the default risk of these two firm types. Yet the factors influencing capital structure decisions as well as resilience to adverse economic conditions and financing constraints may vary with firm size. For example, Beck et al. (2008), employing firm-level survey data that include both small and large firms across 48 countries, find that small firms use less external finance, especially bank loans. They also show that large credit-constrained firms can more easily increase external sources of finance than can small firms. The implication is that similar capital structures may result in different credit risk profiles for small and large firms. A better understanding of these issues can lead to more accurate default prediction models, improve lending decisions, and inform government policies aimed at promoting a healthy small and medium sized enterprise (SME) sector.

Our paper contributes to the literature in the following ways. First, we show that 
leverage has a greater impact on the default probability of SMEs than it does on that of large firms. To reach this conclusion, we employ a sample of more than 6 million firm-year observations of large corporations and SMEs spanning 6 European countries from 2005 to 2015. We estimate probabilities of default (PDs) using a discrete hazard model to control for common firm-specific and systematic factors. Our data source is Bureau van Dijk's Orbis for both types of firms, in order to ensure a degree a consistency across the balance sheet information used in the analysis. We find that the differential impact of leverage on PDs across companies of different size is economically important. The difference in PDs between first and fourth leverage quartiles for large firms is $1.24 \%$, whereas the difference is more than double, 2.87\%, for SMEs. Although higher leverage always causes higher default risk, the influence of leverage components on such risk varies between firm groups. Distressed SMEs exhibit higher leverage across all its components but particularly current liabilities, with a median increase of $15.4 \%$ of total assets. This is likely because current liabilities are a source of financing that may be more easily accessible to SMEs. The marked increase in short-term (current) liabilities substantially increases rollover risk and, with it, default risk. In contrast, large firms in distress tend to increase leverage mainly through non-current liabilities (12.8\% of total assets). Hence, the maturity structure of liabilities appears to explain the differential impact of leverage on the PDs of SMEs and large firms. Restricted access to longer-term financing for SMEs may be due to their perceived riskiness. However, this perception could act as a self-fulfilling prophecy. As a clear policy implication of our findings, regulators could attempt to prevent the vicious circle of excessive short-term borrowing leading to higher default rates by providing SMEs with easier access to longer-term financing.

Our second contribution is an analysis of the influence of leverage on the probability of recovery from the state of insolvency. Here, as in the Orbis database, "Insolvency" is used to refer to an intermediate state between the "Active" state and the "Bankrupt" or "In 
liquidation" state. Insolvent firms have the opportunity to restructure and become active again, thus avoiding liquidation. To date, this transition out of insolvency has been little investigated in corporate default studies. Indeed, corporate default is normally modelled as an absorbing state. Yet, understanding the factors that may help a firm's recovery has important economic implications.

We find that the maturity structure of liabilities of small firms that exit from insolvency is considerably different compared to that of defaulted SMEs. Small and medium enterprises that recover from insolvency appear to address rollover risk by borrowing more long term and less short term. As a result, the median non-current debt to total assets ratio is $15.6 \%$ higher, whereas the current debt and trade credit to total assets ratios decline by $7.3 \%$ and $8.4 \%$, respectively, relative to SMEs that remain in the insolvency state. Instead, large firms that recover from default appear to have lower non-current liabilities and higher current liabilities, which is exactly the opposite, though these changes are not statistically significant. The findings suggest that SMEs and large firms are subject to very different restructuring strategies, which may be the result of different bankruptcy procedures and/or creditors' bargaining power (Berkowitz and White, 2004 and Berger and Udell, 2006).

Until recently, the literature on predicting financial distress has mainly focused on large corporations. Our paper contributes to the expanding research that investigates default risk in SMEs by focusing specifically on the European market (Filipe et al., 2016 and McGuinness et al., 2018).

The finance literature has investigated firms' use of trade credit and the effect of regulatory restrictions on trade credit. ${ }^{1}$ Barrot (2016), for example, shows that after the introduction of maturity restrictions on trade credit extended by French trucking firms, the probability of a trucking firm filing for bankruptcy decreased substantially. Breza

\footnotetext{
${ }^{1}$ See, amongst others, Love et al. (2007), Klapper et al. (2012), Aktas et al. (2012), Fabbri and Menichini (2010), and Murfin and Njoroge (2014).
} 
and Liberman (2017), on the other hand, provide evidence that similar restrictions on the maturity of trade credit - such as that which a large buyer in Chile could obtain from small suppliers - lead to a reduction in trade with small firms. Abdulla et al. (2017) find that privately held firms rely more on trade credit than do publicly listed companies.

Our findings are in line with those of Molina and Preve (2012), who show that firms in financial distress tend to use more trade credit than do healthy firms. However, our findings do not support the conclusions in McGuinness et al. (2018), who suggest that trade finance may decrease SMEs' default risk. Instead, we show that trade finance has a positive and highly statistically significant impact on the default probability of small and medium firms. This may be because our larger sample enables us to test the impact of trade finance and other leverage components on defaulted firms directly, rather than indirectly, via the medium of the Z-score, as in McGuinness et al. (2018). ${ }^{2}$

Our findings are also related to recent studies that aim to explain capital structure decisions in European SMEs (e.g. Casey and O'Toole, 2014, Daskalakis et al., 2017, Mc Namara et al., 2017 and Carbó-Valverde et al., 2016) and earlier ones that focus on agency problems and information asymmetries in SME financing. For instance, Berger and Udell (1998) document that, to overcome agency problems, SMEs need to have a different capital structure to that of larger firms. Berger and Udell (2006) explain how financial institutions may employ different lending technologies to overcome information asymmetries when lending to SMEs. Similarly, Beck and Demirgüç-Kunt (2006) explain how different financing tools are needed to fund SMEs and show that SMEs financing opportunities depend on the development of financial institutions. Casey and O'Toole (2014) show that financially constrained SMEs use distinct sources of alternative external finance to replace bank credit; whereas trade credit is mainly used for working capital purposes, informal loans, company loans, market financing, and grants are prin-

\footnotetext{
${ }^{2}$ In Appendix A, we explore why our results differ from the those of McGuinness et al. (2018).
} 
cipally used for investment projects. The substitution effect is larger during economic downturns (Huang et al., 2011). Carbó-Valverde et al. (2016) show how trade creditors can function as lenders of last resort when SMEs are financially constrained and cannot access bank lending. This suggests that the different components of financial leverage may not have the same impact on firms' PD. Some companies may use trade credit to spur growth (Ferrando and Mulier, 2013), especially during the first years of a firm's life (Robb and Robinson, 2012). However, firms may not get the amount of trade credit they wish for. Indeed, supply of trade credit is affected by suppliers' competition (Chod et al., 2019), suppliers' bargaining power (Fabbri and Klapper, 2016), product market power (Goncalves et al., 2018), and supplier-customer relationships (Shenoy and Williams, 2017).

The remainder of this paper is organised as follows: in Section II we describe the data; in Section III we outline the empirical methodology and the variables used in our regressions; and in Section IV we present our results and robustness tests. Section V discusses the implications of our findings, and Section VI concludes.

\section{Data}

We collect firm-level data from Orbis. We also have access to the financial reports of firms from the sixteen Western European countries with the largest gross domestic product (GDP). We exclude financial firms, public sector firms and industries with poor representation across the countries in the sample. ${ }^{3}$ We also exclude all firms for which the industry sector is not provided. We construct the credit history of each firm using Orbis's fields "status" and "status date", which report default information. We exclude

\footnotetext{
${ }^{3}$ Specifically, we omit all firms that, according to the NACE Rev. 2 classification, operate in one of the following industries: financial and insurance activities; real estate activities; public administration and defence; compulsory social security; activities of households as employers; undifferentiated goods service producing activities of households for own use, and activities of extraterritorial organisations and bodies.
} 
all firm-year observations when information on the date on which the "status" is recorded or on the "status" itself is not available. ${ }^{4}$ Moreover, we omit all firm-year observations when accounting variables are not recorded, and we exclude countries in which the total number of firm-year observations is fewer than $5,000 .{ }^{5}$ We also exclude countries in which the percentage of active firm-year observations is higher than $99.99 \%$ of the total number of firm-year observations in that country. Such a high percentage is not plausible and most likely reflects issues with how Orbis records a firm's "status" or problems with the availability of defaulted firm data in that country. For instance, Orbis does not report the date of default for German firms. Finally, we winsorise all firm-level variables at the $1 \%$ and $99 \%$ level for each country. Our cleaned database consists of around 6.2 million observations from almost 1 million firms based in six countries (Belgium, Spain, France, the United Kingdom, Italy and Portugal) over the time period 2005-2015.

Table 1 reports the number of observations and firms for each country in the sample. We also differentiate between large corporations and SMEs. The latter are identified as firms with a value of total assets below $€ 43$ million, a threshold based on the European Commission's definition of an SME. ${ }^{6}$ The country with the highest number of firms and firm-year observations in our sample is Italy, with $34.97 \%$ of the total firm-year observations and $32.16 \%$ of firms; Portugal has the smallest number of firm-year observations $(3.85 \%)$ and firms (4.77\%). The United Kingdom has the largest number of large firms, and Italy has the largest number of SMEs. Table 1 also shows the percentages of active,

\footnotetext{
${ }^{4}$ We also exclude all firm-year observations with a 'status' that is active branch, active dormant, active reorganisation, dissolved demerger, dissolved merger, dissolved takeover, inactive branch, inactive no precision, non-profit organisations, or unknown situation.

${ }^{5}$ A subsample with such a low number of firms would not be representative of the country overall.

${ }^{6}$ The European Commission defines SMEs as firms with fewer than 250 employees. They should also have an annual turnover of up to $€ 50$ million or total assets below $€ 43$ million. Information on the number of employees and turnover is not complete in the Orbis database, so, for total assets, we use the latter indicator to identify SMEs. We do so to maximise the number of firms in our sample. Figure E.4 illustrates a robustness test in which we restrict the sample to satisfy the conditions in the European Commission definition. Even with the stricter definition, results remain qualitatively unchanged (see the discussion in Section IV.a.1).
} 
insolvent or bankrupt firms. Firms are active if the "status" field on Orbis is Active. They are insolvent if the "status" field in Orbis is Active default of payment, Active rescue plan or Active insolvency proceedings. Finally, firms are bankrupt if the "status" field in Orbis is Bankruptcy, In liquidation, Dissolved, Dissolved bankruptcy or Dissolved liquidation. Table B.1 provides firm status definitions. Percentages of insolvent and bankrupt firms vary by country. The heterogeneity is mainly due to the different percentages of large firms and SMEs in each country and the distribution of firm sizes. For instance, Italy has the largest cumulative SME bankruptcy rate over the whole sample period, with 14.03\%. The country also has a below-average bankruptcy rate for large firms (3.64\%). In contrast, the bankruptcy rate of small and large Spanish firms is remarkably similar, $8.82 \%$ and $8.23 \%$, respectively. Section IV.c discusses the possible causes of these country differences.

Table 2 shows transition rates from the Active and Insolvent states to the other states. Over 1 year, most of the firm-year observations classified as Active (97.88\%) do not migrate to another state. Only $0.36 \%$ go through insolvency procedures, and $1.77 \%$ go directly to bankruptcy. Only $1.01 \%$ of Insolvent firm-year observations manage to recover to the Active state, whereas a large share goes to the Bankrupt state (7.33\%). We also look at 5- and 10-year transition matrices to gain an idea of status changes at different intervals over the sample period. Multi-period transitions are derived from the 1-year matrix under the homogeneous Markov chain assumption. Table 3 reports the number of firms that default, namely, firms that become either insolvent or bankrupt, in each year of our sample period. Percentages are consistently higher for SMEs than for large corporations. The effect of the global financial crisis is particularly visible for SMEs. The peak of defaults for both SMEs (2.53\%) and large corporations $(1.52 \%)$ is in 2013 and is associated with the European sovereign debt crisis. From the global financial crisis onwards, the proportion of defaulted SMEs increases markedly relative to large 
corporations (see the last column of Table 3).

\section{Empirical Methodology}

\section{III.a Model Specification}

We estimate the default probability using a discrete hazard model in the form of a multi-period logit, as in Shumway (2001) and Campbell et al. (2008), which can be used to analyse unbalanced data, such as firm defaults. Bauer and Agarwal (2014) show that hazard models, which have time-varying covariates, provide superior performance compared with static, accounting-based models (e.g., Altman, 1968, Ohlson, 1980 and Zmijewski, 1984) and contingent claim models (e.g., Vassalou and Xing, 2004, Hillegeist et al., 2004 and Bharath and Shumway, 2008). Our logit model is given by:

$$
\begin{aligned}
P_{t}\left(y_{i, c, j, t+1}=1\right) & =\Phi\left(\alpha+\boldsymbol{X}_{i, t} \boldsymbol{\beta}+\boldsymbol{Z}_{i, \boldsymbol{c}, \boldsymbol{t}} \boldsymbol{\delta}+\gamma_{c}+\gamma_{j}\right) \\
& =\frac{1}{1+\exp \left[-\left(\alpha+\boldsymbol{X}_{\boldsymbol{i}, \boldsymbol{t}} \boldsymbol{\beta}+\boldsymbol{Z}_{\boldsymbol{i}, \boldsymbol{c}, \boldsymbol{t}} \boldsymbol{\delta}+\gamma_{c}+\gamma_{j}\right)\right]},
\end{aligned}
$$

where subscripts $i, c, j$, and $t$ vary according to firms, countries, industries and years, respectively. The $y$ variable is a dummy that indicates corporate default; it takes a value of 0 if the firm is active and a value of 1 if the firm is insolvent or bankrupt. Firms that remain in default for more than 1 year are retained in the sample used to estimate the model as depicted in Equation 1 until the year they first migrate to the default state. The parameter $\alpha$ is the constant; $\gamma_{c}$ and $\gamma_{j}$ are country and industry fixed effects, respectively; $\boldsymbol{X}$ is a vector of time-varying firm-level variables, and $\boldsymbol{Z}$ is a vector of time-varying control variables. Covariates are lagged and refer to the previous accounting year relative to the dependent variable.

For all regressions, we report McFadden's pseudo- $R^{2}$. We also report the percentage 
of correctly classified Insolvent and Bankrupt observations and the percentage of correctly classified Active observations. Thresholds to differentiate between correctly and incorrectly classified observations are derived like in Zhang et al. (2015).

\section{III.b Variables}

The firm-level variables include LEVERAGE or its components, that is, TRADE, CURRENT, and NONCURRENT. These are, respectively, the ratios of total leverage, trade payables, and current and non-current liabilities to total assets. In our analysis, we interact these variables with a dummy that identifies SMEs. The SME dummy takes the value of 1 if the firm has total assets below $€ 43$ million and 0 otherwise.

Controls that vary at the country level include a set of macroeconomic variables. ${ }^{7}$ We employ the natural logarithm of GDP growth (GDP), the yield of 3-month government bonds (GOVBOND) $)^{8}$ and the logarithm of sovereign credit default swap (CDS) spreads (SOVCDS) to capture the business cycle, interest rate effects, and sovereign risk, respectively. The information on GDP is from the Eurostat Database, interest rates are collected from the IMF-World Economic Outlook Database and CDS spreads are obtained from Markit. Firm-level control variables include the ratio of net income to total assets (NITA), the ratio of current assets to total assets (CATA), the number of years since a firm's incorporation (AGE), and the SME dummy.

Table 4 reports summary statistics for the independent variables. ${ }^{9}$ The median LEVERAGE is higher for SMEs (0.74) than it is for large corporations (0.69). Looking at the individual components of financial leverage, on the one hand, the median short-term

\footnotetext{
${ }^{7}$ Duffie et al. (2007) and Filipe et al. (2016) find that the economic environment influences the probability of default. The risk transmission channels from sovereign risk to corporate credit risk are government guarantees, domestic demand, and credit markets (Bedendo and Colla, 2015).

${ }^{8}$ The risk-free rate is a key ingredient in the Merton (1974) distance-to-default model.

${ }^{9}$ The minimum and maximum values of independent variables for large and small firms are the same because of the winsorisation process by means of which we replace tail observations with either the 1st or the 99th percentile.
} 
sources of finance (TRADE and CURRENT) are higher for SMEs (0.15 and 0.27) than for large firms (0.06 and 0.22). ${ }^{10}$ On the other hand, NONCURRENT is higher for large corporations. Table 5 describes the distribution of LEVERAGE, TRADE, CURRENT, and NONCURRENT at the country level. The table displays heterogeneous financing patterns which, apart from few exceptions, confirm the general trend observed in Table 4.

To understand the typical capital structure of active and defaulted firms, we check the levels of leverage and leverage components in the active and default states. Table 6 reports the results. Defaulted firms are always more levered than active ones, a fact that is true regardless of size. The difference between the median leverage for defaulted and active large firms is $21.2 \%$ and the difference between the median leverage for defaulted and active SMEs is $21.0 \%$ of total assets. The changes in leverage components do appear to be size dependent. Defaulted SMEs exhibit the largest median increase in current liabilities $(15.4 \%)$, followed by trade finance (5.6\%), relative to active SMEs. In contrast, large defaulted firms have the largest variation in non-current liabilities relative to large active companies (12.8\%), followed by current liabilities (7.7\%). This suggests that SMEs in distress are subject not only to higher debt levels but also to higher rollover risk. Indeed, SMEs in default have both higher trade finance and higher current liabilities than do large defaulted firms $(+15.7 \%$ and $+11.7 \%)$, whereas they have a lower non-current debt $(-14.2 \%)$ as a proportion of total assets. This difference in the maturity structure of liabilities and the resulting greater difficulties in refinancing for SMEs may help explain why the default rates for SMEs are much higher than they are for large firms even when controlling for total leverage.

\footnotetext{
${ }^{10}$ This evidence is in line with findings of Abdulla et al. (2017), who show that public firms maintain a lower level of trade credit than do private firms.
} 


\section{Results}

\section{IV.a Baseline Specification}

We estimate default probabilities according to Equation 1 and use four different specifications. Specification (1) is the benchmark model. In specification (2), we add an interaction term between leverage and the SME dummy to measure the differential impact of leverage on the default probabilities of SMEs. In specifications (3) and (4) leverage is broken down into three separate components: trade payables, (other) current liabilities and non-current liabilities. We also calculate the correlations between the regression variables which are presented in Table 7 . When considering the correlations between the independent variables and the dummy variables for the Insolvent and Bankrupt states, we observe that NITA has the largest negative correlation, while LEVERAGE has the largest positive correlation.

Table 8 presents the logit regression estimates for the four specifications. As expected, the coefficient of LEVERAGE is positive and strongly significant. When we look at the leverage components in specification (3), they are also positive and strongly significant. However, the coefficients of interaction terms with dummy variables, such as the SME dummy, cannot be directly interpreted in a logit model (Ai and Norton, 2003). Hence, for the sign and significance of leverage and leverage components interacted with SME, we examine the marginal effects. Appendix $\mathrm{C}$ details the calculations of the marginal effects and Table 9 reports the results. For large corporations, the marginal effect of LEVERAGE is 0.006. However, for small firms it is twice as much, at 0.012. This means that a one standard deviation increase in LEVERAGE leads to a 19 basis point increase in the default probability for large firms, and a 37 basis point increase for SMEs. These numbers and their differences are economically significant. According to Moody's, an increase in the average default rate from 0 to 9 basis points would cause a substantial 
downgrade from Aaa to A. The downgrade could go to Baa, the broad rating category that separates investment-grade from speculative-grade borrowers, with a 27 basis point default rate increase (Moody's Investors Service, 2017). Figure 1 shows the marginal effects of different levels of LEVERAGE on default probabilities and reveals that changes in leverage always have a greater impact on the probability of default of SMEs than that for large corporates. This finding is consistent with the evidence that large financially constrained firms are able to raise bank finances more easily than are small firms, especially during crisis periods (Gertler and Gilchrist, 1994 and Beck et al., 2008).

The default-risk literature indicates that short-term liabilities may have a greater influence on default risk than long-term financing. In the popular Merton-based KMV model (Vassalou and Xing, 2004), the default trigger comprises 100\% short-term debt and only $50 \%$ long-term debt, which highlights the relative importance of liabilities with different maturities. Table 9 confirms this idea, though for SMEs only. Specifically, a one standard deviation increase of trade payables and current liabilities increases the default probability by 57 and 66 basis points, respectively. If long-term financial debt instead increases by one standard deviation, the default probability would rise by 14 basis points only, which is considerably lower than the sensitivity observed for short-term financing. ${ }^{11}$ For the average large corporation, all sources of finance have similar importance, with marginal effects ranging from 7 to 8 basis points. The difference between large corporations and SMEs may be due to the better ability of large firms to obtain long-term financing which could flatten the impact of financial leverage of different maturities on default probabilities. For robustness, we check marginal effects at different quantiles of the leverage components, TRADE, CURRENT and NONCURRENT, to see whether their relative impact on the probability of default for SMEs and large firms is sensitive to the capital structure of the corporation. Table E.1 confirms our main findings. The

\footnotetext{
${ }^{11}$ The default probabilities were calculated using the marginal effect in Table 9 and the standard deviation of Table 6 .
} 
marginal effects of TRADE and CURRENT for SMEs are always larger than those for large firms across different levels of leverage.

In Table 8, for the McFadden pseudo- $R^{2}$, we obtain values of $8.90 \%$ and $8.91 \%$ for the first two specifications and values of $10.0 \%$ and $10.1 \%$ for specifications (3) and (4), respectively. The increment suggests that replacing LEVERAGE with TRADE, CURRENT, and NONCURRENT increases the model's goodness of fit. Although not high, these numbers are in line with previous findings on SMEs' survival probability. For instance, Faccio et al. (2011) estimate a logit model for SMEs' survival probability and report a McFadden pseudo- $R^{2}$ of about $9 \%$. It should be noted that the McFadden pseudo- $R^{2}$ cannot be interpreted in the same way as the standard $R^{2}$ in OLS regressions, that is, as the proportion of explained variance (Hemmert et al., 2018). This is because the former is based on the ratio of the log likelihood of the fitted model over a null model. For this reason, we provide additional metrics for the goodness of fit of our model by computing its accuracy in classifying default and non-default outcomes. For both outcomes, the classification accuracy is around $70 \%$ for all specifications.

For the other control variables used to estimate the PDs of large and small firms, Table 8 reports results consistent with expectations: better macroeconomic conditions, as indicated by a higher GDP growth rate, lower interest rates, and lower sovereign default risk decrease corporate default rates. For the impact of firm-specific control variables, first, as one would expect, higher profitability measured by NITA decreases the incidence of default. Second, firm age also causes a contraction of default probabilities since younger, less-established firms, are well known to be more prone to distress. Finally, CATA positively affects default risk. Indeed, some items in current assets can be reasonably associated with distress risk. For instance, difficulties in obtaining payments from customer sales will increase trade receivables, and rising inventory stocks may indicate a slowing demand for the company's products. Both occurrences would cause current as- 
sets and default risk to increase. However, higher cash holdings, which are also included in current assets, could indicate a healthier financial position and hence a lower default probability. To disentangle these effects, we rerun specification (1) on all the above components of current assets. Table B.3 shows the results, which confirm our expectations, with cash exhibiting a negative and statistically significant coefficient, whereas all the other components have a positive and significant impact on PDs.

A possible explanation for the differential impact of leverage on firms of different size may be offered by the findings in Campello and Gao (2017). The authors observe that firms with higher customer concentration face relatively higher interest rate spreads and/or more restrictive covenants in bank loan contracts. This may increase the riskiness of financial leverage. Small and medium enterprises are expected to have a higher customer concentration because they typically have more limited geographical reach and market penetration than do large firms. Hence, for the same amount of leverage, their default risk should be higher relative to large firms, as observed in our study.

To illustrate more clearly the effect of leverage on PDs, we calculate predicted PDs with our estimated logit model for different leverage quartiles; Table 10 reports the results. We can observe that an increase of leverage from the first to the last quartile generates a much larger rise in the PD of SMEs (2.87\%) than that of large corporations (1.24\%). For SMEs, the largest increase in the probability of default from the bottom to the top quartile is caused by current liabilities (2.12\%) and trade finance (1.20\%). This result is consistent with that of Cunat (2007), who shows that firms use trade credit as a marginal source of finance and that firms that rely on trade credit have to pay higher interest rates. On the other hand, in line with the previous findings reported in Table 6, trade credit has a relatively lower effect on the PDs of large firms, and this effect decreases slightly when moving from the bottom to the top trade-credit quartile.

A limitation of our analysis is that we do not account for loan contract features. 
Cumming et al. (2019) point out that loan features, such as collateral requirements and other covenants, are often used to reduce the riskiness of private loans and increase their marketability. This may attract more investors in the private loan market, lead to more competitive loan pricing, and perhaps reduce the riskiness of financial leverage.

\section{IV.a.1 Robustness}

We perform a battery of robustness tests on our main results by using specification (2) as a benchmark model. We check that our findings are not driven by zero or low-leverage firms. These firms have a different capital structure, profitability, dividend payout policy (Strebulaev and Yang, 2013), and corporate culture (El Ghoul et al., 2018). We run specification (2) excluding all observations in the bottom $10 \%$ of the LEVERAGE distribution. Figure E.1 reports the results, which are very similar to those reported in Figure 1, confirming that our conclusions are robust to the exclusion of low-leverage firms.

Furthermore, it is conceivable that the impact of LEVERAGE on default probabilities is non-linear (Giordani et al., 2014). For this reason, we also run specification (2) and include a quadratic term for LEVERAGE and its interaction with the SME dummy. Figure E.2 shows the resulting marginal effects, and, again, the differentiation between large firms and SMEs is consistent with previous findings.

We also consider insolvent and bankrupt firms separately, in contrast to the main analysis where they were bunched together as defaulted companies. We expect firms that will face bankruptcy, namely, those that will be liquidated and will not be able to recover from default, to be more sensitive to leverage. We use an ordered logit model; Figure E.3 shows the results. The lines in the figure relate to changes in the probability of retaining the Active state or migrating to the Insolvent or Bankrupt states when leverage changes. Bankrupt firms have the largest marginal effects, which are also statistically significantly different from those of insolvent firms. The marginal effects of the Active state decline 
as the probability of remaining active falls when leverage increases.

We also check that our results are not driven by our SME definition. The European Commission defines SMEs as those firms that have fewer than 250 employees and either no more than $€ 50$ million of turnover or no more than $€ 43$ million of total assets. To maximise the sample size, in our analysis, we have considered SMEs to be all firms with total assets below $€ 43$ million. This is because the Orbis database does not always report turnover and the number of employees. As a robustness test, we restrict the analysis to the subsample of firms for which turnover and the number of employees are available. Figure E.4 shows marginal effects computed on the restricted sample using specification (2). The results are qualitatively similar to those reported in Figure 1, where the full sample is used.

To check that our analysis is not driven by a dominant country or sector, we rerun our regressions excluding Italy and the retail sector, which have the largest number of observations. Figure E.5 shows the marginal effects when Italy is excluded, and Figure E.6 shows marginal effects when the retail sector is excluded. Our main conclusions remain unchanged.

In addition, we want to verify whether our findings are driven by a specifically sized subsample within the SME grouping. Thus, we run specification (2) interacting LEVERAGE with dummies that capture small and medium firms separately. ${ }^{12}$ Figure E.7 presents the results and confirms that the sensitivity of the default probability to leverage decreases monotonically with size.

Other factors can affect large corporation and SME defaults, potentially altering the effect of LEVERAGE. To control for Europe-wide changes in market conditions, we add time fixed effects to specification (2). Figure E.8 shows that the sensitivity of the default

\footnotetext{
${ }^{12}$ The small dummy takes a value of 1 if the firm has less than $€ 10$ million in total assets, and the medium dummy takes a value of 1 if total assets are between $€ 10$ and 43 million, based on the European commission definition.
} 
probability to leverage is not affected by time fixed effects.

Previous research has highlighted that the presence of public sector-sponsored credit guarantee schemes for small businesses affects firms' default risk (Mayordomo and RodríguezMoreno, 2018 and Wilcox and Yasuda, 2019). To capture this type of government intervention, we extend our analysis by considering the number of measures taken by each country and in each year of the sample to support local SMEs as a result of the EU's 2008 Small Business Act (SBA). One of the main objectives of the SBA has been to boost SMEs' funding opportunities by 'facilitating SMEs' participation in public procurement and ensuring better access to State Aid" and by "facilitating SMEs' access to finance" (European Commission, 2018, p. 158). Following the European Commission's report, we employ the number of SBA-related policy interventions enacted by each country in each year from 2011 as an indicator of government support for SMEs. We add a dummy to specification (2) to identify country-years when the number of interventions is above the median number of interventions across all country-years in the sample. We also interact the dummy with leverage. ${ }^{13}$ Figure E.9.a shows the marginal effects when the SBA dummy is taken into consideration. The results confirm that the sensitivity of the default probability to leverage is higher for SMEs than it is for large firms. Panel A of Table E.2 shows fitted probabilities of default for large corporations and SMEs in country-years with the number of SBA interventions below and above the median across all country-years. Firms in country-years with a high number of SBA interventions enjoy lower default probabilities, as one would expect. However, even when we control for this effect, the differential impact of leverage for large corporations and SMEs remains.

Cosh et al. (2009) show that corporations are more likely to seek external finance than are partnerships and sole proprietorships. To capture the different management propensities to increase leverage, we run specification (2) by adding a dummy variable that takes

\footnotetext{
${ }^{13}$ The time period is restricted to 2011-2015 like in table 35 of European Commission (2018).
} 
a value of 1 if the firm is a partnership or a sole trader, and 0 otherwise. We also add the interaction between the partnership/sole trader dummy and LEVERAGE. Figure E.9.b presents the marginal effects when partnerships and sole traders are differentiated from other firms. Again, the higher sensitivity of small firms to leverage holds. Moreover, Panel B of Table E.2 shows that, in line with our main findings, marginal effects on default probabilities increase with leverage and that the increase is higher for SMEs than for large companies. Furthermore, SMEs that are sole traders and partnerships exhibit a lower default probability than do other SMEs across different levels of leverage.

Not all firms obtain the amount of external finance they desire (Cosh et al., 2009). Leverage may play a different role in financially constrained firms. We perform a further robustness test to check whether financial constraints nullify the differential impact of leverage on the probability of default. We identify firms that are more likely to be financially constrained using a disequilibrium model (Carbó-Valverde et al., 2009 and Carbó-Valverde et al., 2016). ${ }^{14}$ Then, in specification (2), we insert a dummy that takes a value of 1 if the firm has a probability of being financially constrained above the sample median, and 0 otherwise. To capture constrained firms, we use the interaction term between the dummy and LEVERAGE. Table E.2 confirms our main results, and Panel $\mathrm{C}$ shows that fitted default probabilities increase with leverage. The increase is higher for SMEs than it is for large companies. These results are confirmed for both financially constrained and unconstrained firms, though the former group of firms, as expected, has a higher default probability. Figure E.9.c reports marginal effects, which are obtained by controlling for the probability of being financially constrained. The marginal effects are in line with the previous findings.

Finally, for fast-growing firms, external debt finance might not be preferred over

\footnotetext{
${ }^{14}$ The only difference between our estimation and that of Carbó-Valverde et al. (2016) (Table 2, column 1 ) is that we substitute Sales/Total Assets with EBIT/Total Assets. We do so because the Orbis database does not provide information on sales for UK firms.
} 
equity-type instruments (Cumming, 2005). Therefore, LEVERAGE may not have the same impact on firms that are quickly expanding their activities. We perform two robustness tests to determine whether the differential impact of leverage on default risk is present in both fast- and slow-growing firms. In the tests, we add a dummy to specification (2) to identify firms that have above-median growth and an interaction term between the growth dummy and LEVERAGE. As growth proxies, we alternatively use the rate of change of net income and the rate of change in total assets. Our main results are confirmed. Panels D and E of Table E.2 show that fitted default probabilities increase with leverage and the increase is higher for SMEs than it is for large companies. These results hold for both slow- and fast-growing companies. In addition, fast-growing companies have lower default probabilities, as expected. Figures E.9.d and E.9.e report marginal effects that are also consistent with previous inferences.

\section{IV.b Sector Variation}

In this section, we investigate how financial leverage affects probabilities of default in different industries. We group our observations into five sectors: production, retail, services, construction, and transportation. ${ }^{15}$ We run specification (2) separately for each sector. Figure 2 shows that marginal effects ${ }^{16}$ vary by sector, although the effect for SMEs is always higher than the effect for large corporations. In the production, retail, and transportation sectors, marginal effects for large corporations do not exhibit much

\footnotetext{
${ }^{15}$ We assign firms to (1) the production sector if the NACE Rev. 2 code is agriculture, forestry and fishing; mining and quarrying; manufacturing or electricity, gas, steam, and air conditioning supply; (2) the retail sector if the NACE Rev. 2 code is wholesale and retail trade; repair of motor vehicles and motorcycles; (3) the services sector if the NACE Rev. 2 code is water supply; sewerage, waste management, and remediation activities; accommodation and food service activities; information and communication; professional, scientific, and technical activities; administrative and support service activities; education; human health, and social work activities; arts, entertainment, and recreation or other service activities; (4) the construction sector if the NACE Rev. 2 code is construction; and (5) the transportation sector if the NACE Rev. 2 code is transportation and storage.

${ }^{16}$ The estimated coefficients of logit regressions for each sector, country and time period are available on request.
} 
sensitivity to the level of LEVERAGE, whereas for SMEs marginal effects exhibit a clear positive slope. In contrast, in the construction sector, marginal effects sharply increase with LEVERAGE for both firm types. At the opposite end of the spectrum lies the services industry, in which marginal effects are low and do not significantly change with LEVERAGE.

\section{IV.c Country Heterogeneity}

Figure 3 shows the marginal effects computed with specification (2) estimated separately for each country in our sample. The results are highly heterogeneous across countries. In France and Portugal, LEVERAGE increases the probability of default of both SMEs and large corporations, but the latter not as strongly. In Italy and Spain, LEVERAGE increases the probability of defaults for both SMEs and large firms in a similar manner, though the effect for both types of firms is more pronounced in Italy for high levels of leverage. Oddly, in the United Kingdom, LEVERAGE appears to have a small impact on probabilities of default regardless of firm size. Interestingly, large Belgian firms exhibit a negative relationship between leverage and PDs, with higher leverage leading to a decrease in PDs (though the decrease is lower as leverage increases). Bruggeman and Van Nieuwenhuyze (2013) discuss the peculiar resilience of Belgium during both the Great Recession and the European sovereign debt crisis and offer clues that may explain this puzzling result. Specifically, they illustrate that a substantial increase of corporate leverage was not the result of funding needs but rather of financial flows from Belgian multinational companies to local firms for tax-saving purposes. ${ }^{17}$ This explains why an

\footnotetext{
${ }^{17}$ Bruggeman and Van Nieuwenhuyze (2013), pp. 65-66, state that "the debt accumulation of Belgian firms is also determined partly by various specific factors attributable to the tax environment. For instance, in Belgium there are considerable funding flows between non-financial corporations, on account of the activities of non-financial holding companies and finance companies of multinationals based in Belgium. These companies were previously attracted by the tax concessions available to coordination centres and, since 2006, by the notional interest allowance. Since 2005, the loans granted by related foreign firms to firms based in Belgium have risen by 17 percentage points of GDP to 37\% of GDP at the end of 2012, accounting for much of the rise in the consolidated debt ratio, up by 26 percentage points of
} 
increase of leverage did not affect default risk. In fact, rather the opposite, because debt accumulation took place when Belgian companies were performing well.

One of the possible sources of this observed heterogeneity is the variability of the capital structure of SMEs and large corporations across the countries in our sample (see Table 5). Moreover, heterogeneities may be due to the fact that the relative importance of industry sectors changes across countries. Indeed, as discussed in Section IV.b, firms in different industries exhibit rather different default patterns (Nickell et al., 2000) and different marginal effects of leverage on default probabilities (see Figure 2). This evidence may help explain the variations in the marginal effect of leverage across countries (see Figure 3). For instance, the graph with the marginal effects of leverage for the United Kingdom may reflect the prominence of the service sector, for which default probabilities may react less to changes in LEVERAGE.

Another explanation for the heterogeneous link between default probabilities and financial leverage may be traced to different bankruptcy codes, degrees of creditors' protection (Davydenko and Franks, 2008), and different degrees of investors' legal protection (La Porta et al., 1998). The same holds true for SMEs (Mc Namara et al., 2017). There is conflicting evidence regarding the impact of creditor protection laws on financial leverage and credit risk. For instance, Claessens and Klapper (2005) claim that the number of bankruptcies increases in countries with stronger creditor rights and greater judicial efficiency. In contrast, Acharya et al. (2011) find that firms in countries with stronger creditor rights have lower cash flow risk and lower financial leverage. ${ }^{18}$ To reconcile these different observations, Heitz and Narayanamoorthy (2018) point out that different creditor-right laws, such as that assuring that secured creditors are paid first in case of

GDP during that period. Rather than being due to an actual demand for funding on the part of firms, that debt accumulation therefore originates from financial flows aimed at optimum tax efficiency."

${ }^{18}$ Other recent contributions include Qian and Strahan (2007), Bae and Goyal (2009), Ferrando et al. (2017), Sautner and Vladimirov (2017), Shah et al. (2017), Boyd et al. (2018), Fernández et al. (2018), and Houston et al. (2010). 
default and that creditors have the power to restrict reorganisation, have different effects on default probabilities and recovery rates.

We perform two new robustness tests following Djankov et al. (2007) and Heitz and Narayanamoorthy (2018) to distinguish countries with strong creditor rights from those with weaker rights. In the first test, we insert a dummy in specification (2) to identify firms in countries where absolute priority is respected, that is, where secured creditors are paid first, and an interaction term between the creditor rights dummy and LEVERAGE. In the second robustness, test we redefine the dummy to identify firms in countries where creditors can impose restrictions on reorganisation, for instance, when reorganisation is subject to creditors' consent. Table E.2, Panels F and G, confirms our original results. With both indicators of creditor rights, default probabilities increase with leverage, and the increase is steeper for SMEs than for large firms. In countries in which secured creditors are paid first, the probability of default may go up, as (a) secured creditors may be willing to lend to riskier borrowers, and (b) secured creditors have an incentive to initiate bankruptcy procedures as their claims are better protected in those countries (Heitz and Narayanamoorthy, 2018). Indeed, our findings suggest that PDs are higher in countries where secured creditors are paid first, but only when leverage is low. At a high level of leverage, we find the opposite result. This suggests that firms with higher leverage may reduce risk if they are based in countries with strongly secured creditors in order to decrease the chances of being forced into bankruptcy by such creditors. This incentive to reduce risk would be stronger for high leverage firms because, all else being equal, they would be closer to default than lower leverage firms. The lower risk of borrowers in countries with higher creditor rights has been documented by Acharya et al. (2011).

In terms of the right of creditors to restrict reorganisation, the expectation is that PDs will be lower in countries that warrant that right. This is because debtors will put more effort into avoiding default as they would be more likely to face liquidation rather 
than reorganisation. This is in line with our findings but only for higher leverage firms. At lower leverage, countries with reorganisation restrictions have higher PDs. A possible explanation of this puzzling result is that creditors in those countries might strategically preclude reorganisation to force the borrower into liquidation which is more likely to increase the amount recovered by the creditors when leverage is lower.

\section{IV.d The Financial Crisis}

The 2007-2008 financial crisis affected the availability of credit in European countries. During this period, financially constrained firms increased trade credit (Garcia-Appendini and Montoriol-Garriga, 2013, Carbó-Valverde et al., 2016). Trade credit is a short-term source of finance and, therefore, tends to be riskier (Vassalou and Xing, 2004, He and Xiong, 2012). Campello et al. (2010) also show that firms that experienced financial constraints because of the 2007-2008 crisis reduced investments and were forced to cut planned projects. Daskalakis et al. (2017) show that SMEs adjust their long-term debt ratios more slowly during crisis periods. Hence, financial crises may affect firms' debt management. Thus, it is interesting to investigate whether there have been significant changes in the sensitivity of default probabilities to financial leverage during crisis periods.

We run specification (2) for three sub-periods: the pre-crisis (2005-2006), Great Recession (2007-2009) and European sovereign debt crisis and recovery (2010-2014) periods. Figure 4 presents the results. The marginal effects suggest that the difference between large firms and SMEs with regard to their PD sensitivity to leverage becomes more pronounced as we move from the pre-crisis period to the Great Recession. This is mainly because of SMEs' PDs becoming more sensitive to leverage, while the marginal effects of large firms remain rather flat. In contrast, in the European sovereign debt crisis, both marginal effects are upward sloping and higher than in previous periods. 


\section{IV.e Recovery Probabilities}

In this section, we investigate the capital structure of firms that become insolvent and then recover relative to those that do not recover. Hence, we explore the determinants of the probability of recovery from the state of Insolvency. A clear pattern emerges from Table 11: whereas defaulted and recovered SMEs have similar levels of leverage, those that do recover exhibit markedly lower short-term debt and substantially higher long-term debt. Specifically, when firms move from Insolvent to Recovered, trade credit falls by $8.4 \%$ and current liabilities fall by $7.3 \%$, while non-current liabilities increase by 15.6\% (Panel B). All of the results are highly statistically significant. This suggests that a recipe for recovery is to seek more stable sources of funding and not necessarily decrease leverage, which may not always be possible. Hence, decreasing rollover risk may be key to restoring viable operating conditions.

The results for large firms have either no or low statistical significance due to the small sample of large recovered firms (only 17). For this reason, we restrict the subsequent analysis of the determinants of the recovery probabilities to SMEs. Table 12 reports the estimation results. Specification (1a) includes leverage as an independent variable. It shows that leverage contributes positively to the chances of a firm's recovery. In specification (2a) leverage is broken down into three separate components: trade payables, (other) current liabilities and non-current liabilities. Specification (2a) confirms that recovery is more likely when non-current liabilities increase. The stability and maturity structure of liabilities appear to make a difference between remaining in or exiting the default state. An alternative explanation is that a small firm that is able to raise long-term finance will have a higher probability of surviving an insolvency procedure. This may be because SMEs with longer-term financing have gone through strict screening procedures.

Considering the other determinants, a better economic and financial environment, as indicated by higher GDP and lower interest rates, improves recovery probabilities. In- 
terestingly, higher sovereign risk (SOVCDS) also appears to help recoveries. This may simply indicate that following the height of a crisis, when the economy has bottomed out and sovereign spreads are still larger than normal, SMEs may find better conditions to emerge from distress. This also would be reinforced by typical post-crisis governments' and regulators' policies aimed at supporting the SME sector (OECD, 2009, Bergthaler et al., 2015, Mayordomo and Rodríguez-Moreno, 2018).

Finally, using the estimated recovery probability models, we derive predicted recovery probabilities for different quartiles of leverage and its components. The results reported in Table 13 confirm the above conclusions and show that an increase in long-term debt (NONCURRENT) from the bottom to the top quartile improves the probability of recovery of SMEs by $2.24 \%$. In contrast, higher short-term debt (TRADE and CURRENT) causes the recovery probability to decrease.

\section{Applications in Banking}

In this section, we explore possible applications of our estimated default probability models. Specifically, we look at the differential impact of leverage on bank capital requirements and loan pricing for large versus small and medium borrowers.

\section{V.a Basel III Capital Requirements}

We derive capital requirements using the internal rating-based approach in Basel III (see Appendix D) for a 1-year pure discount loan worth $\$ 1$ at maturity. Other than maturity and loan exposure, the capital requirement depends on the loan PD, its expected loss-given default (LGD), and borrower size. We consider average PDs for the first and tenth decile of our sample of firms ranked according to leverage. The LGD is taken from Moody's Investors Service (2017) which provides bank loan recoveries. We compute the 
LGD as 1 minus the average corporate loan ultimate recovery over the period 1987-2016 (80.6\%), which gives an LGD of 19.4\% (see exhibit 8 in Moody's Investors Service, 2017).

Firm size is measured using annual sales. The Basel III assumption is that the smaller the firm, the lower its correlation with the rest of the bank portfolio. The maximum correlation difference between large and small firms is $4 \%$, which is achieved for SMEs with annual sales below $€ 5$ million. Table 14, Panel A, reports the minimum capital requirements calculated using the above assumptions. In line with our previous results, the PD of SMEs is greater than that of large firms and the difference increases with leverage. For low leverage (first decile), the SME default probability (0.76\%) is 1.23 times that of large firms $(0.62 \%)$. When leverage is high (tenth decile), the factor increases by 2.25 times, from $2.55 \%$ to $5.74 \%$.

When we hold the correlation constant across large firms and SMEs so that only the PD effect is present, regulatory capital also rises, as one would expect, but with lower multiples (1.11 and 1.34 for low and high leverage, respectively). However, when we consider the correlation discount given to small SMEs as defined by Basel (on average, the SMEs in our sample belong to this category), the capital requirement of SMEs becomes smaller than or similar to the capital requirement of large firms (the multiples are now 0.87 and 1 , respectively). This is clearly at odds with the evidence presented in Table 3 , where we show that default rates for SMEs are larger than for large firms in each year of the sample. Those rates represent the combined effect of default risk (PD) and correlation as they indicate the aggregate default risk of the portfolio of firms in our sample.

Our results are intuitive and highlight a potentially serious drawback of the current regulations. Although it might be defensible to assume that portfolio correlation declines with firm size in normal market conditions, this assumption clearly does not hold in crisis periods, when SMEs are more likely to experience distress, for example, because of restricted access to credit (see, for instance, Ferrando et al., 2017). Indeed, the results 
in Table 3 show that since 2008, the ratio of SME defaults to large firm defaults has increased and has remained higher than in the pre-crisis period.

\section{V.b Loan Pricing}

To illustrate the effect of leverage on the pricing of loans to SMEs and large firms, we adopt an approach similar to that of Resti and Sironi (2007). ${ }^{19}$ The loan spread is decomposed into an expected loss component $\left(d_{e l}\right)$ and an "unexpected loss" component $\left(d_{u l}\right)$. The former, for a 1-year pure discount loan worth $\$ 1$ at maturity, is obtained from the following equation:

$$
\frac{1-L G D \cdot P D}{1+r_{f}}=\frac{1}{1+r_{f}+d_{e l}}
$$

We assume that the unexpected loss component of the spread is driven by the risk premium $\left(r_{e}-r_{f}\right)$ paid by the bank for the regulatory capital allocated to the loan, as a percentage of the loan exposure (RegCap). The term "unexpected loss" is derived from the Basel III regulations, where equity capital requirements for credit exposures are meant as to act as buffers to absorb the value-at-risk of the loan not already covered by the loan loss provisions (Basel Committee on Banking Supervision, 2017). Details of the capital requirement calculations are shown in Appendix D. $d_{u l}$ can be derived from the following equation:

$$
\frac{1-L G D \cdot P D}{\left(1+r_{f}\right)+\operatorname{Reg} \operatorname{Cap}\left(r_{e}-r_{f}\right)}=\frac{1}{1+r_{f}+d_{e l}+d_{u l}}
$$

We normalise the risk-free rate $\left(r_{f}\right)$ to $0 . r_{e}$ is the bank's cost of capital and is set to $13.66 \%$. This is computed as the average cost of equity capital of the four main banks for each country in our sample as of 31 December, 2014. Bank-specific costs of equity have been sourced from Bloomberg.

\footnotetext{
${ }^{19}$ See Chapter 15, pp. 451-457.
} 
We divide our sample into deciles based on leverage and compute loan spreads and their components for the first and tenth deciles. Table 15 reports the results. We can see that, at low leverage, the spread differential between large firms and SMEs is close to zero. However, the spread difference increases to 63 basis points at high leverage, with the SME spread (1.65\%) 1.62 times that of large firms (1.02\%). Another way to look at this is to check the leverage effect for the two types of firms separately. We can observe that, in large firms, loan spreads at high leverage are 2.49 times those at low leverage, a difference of $0.61 \%$. However, the jump for SMEs is much more pronounced, with a multiple of 4.13 and a difference of $1.25 \%$. This evidence reinforces the importance of the leverage effect and firm size for lending rates.

As a robustness test, in Table E.3 we present a sensitivity analysis based on alternative values for the cost of capital. The results are broadly in line with our previous findings.

\section{Conclusion}

We focus on the role of financial leverage and its differential effect on the probability of default of SMEs and large corporations. We find that leverage and each of its components, including trade finance, current, and non-current liabilities, positively affect default probabilities. However, this impact is stronger for SMEs, especially in relation to short-term financing. The implication is that the rollover risk associated with short-term financing and restricted access to other sources of debt funding make SMEs more prone to default than are large firms. In addition, we observe that, to recover from default, SMEs need to rely less on short-term debt and more on longer-term liabilities. The upshot is that the maturity structure of liabilities appears to be a key ingredient to the health and stability of SMEs. Therefore, a clear direction from our research for future government policies aimed at increasing the resilience of SMEs, particularly during crisis 
periods, would be to create incentives for banks to extend longer-term credit to the SME sector. Indeed, SMEs' perceived higher default risk may be partly the result of short-term lending policies that create the pre-conditions for that very risk to materialise. 


\section{References}

Abdulla, Y., Dang, V. A., and Khurshed, A. (2017). Stock market listing and the use of trade credit: Evidence from public and private firms. Journal of Corporate Finance, $46: 391-410$.

Acharya, V. V., Amihud, Y., and Litov, L. (2011). Creditor rights and corporate risktaking. Journal of Financial Economics, 102(1):150 - 166.

Ai, C. and Norton, E. C. (2003). Interaction terms in logit and probit models. Economics Letters, 80(1):123-129.

Aktas, N., Bodt, E. d., Lobez, F., and Statnik, J.-C. (2012). The information content of trade credit. Journal of Banking \& Finance, 36(5):1402 - 1413.

Altman, E. (1993). Corporate Financial Distress and Bankruptcy: A complete Guide to predicting and avoiding distress and profiting from bankruptcy. New York, Wiley \& Sons.

Altman, E. (2000). Predicting Financial Distress of Companies: Revisiting the Z-Score and ZETATM Models. Working Paper.

Altman, E. I. (1968). Financial ratios, discriminant analysis and the prediction of corporate bankruptcy. The Journal of Finance, 23(4):589-609.

Altman, E. I., Haldeman, R. G., and Narayanan, P. (1977). ZETATM analysis A new model to identify bankruptcy risk of corporations. Journal of Banking $\mathscr{G}$ Finance, $1(1): 29-54$

Altman, E. I. and Sabato, G. (2005). Effects of the New Basel Capital Accord on Bank Capital Requirements for SMEs. Journal of Financial Services Research, 28(1):15-42. 
Altman, E. I. and Sabato, G. (2007). Modelling Credit Risk for SMEs: Evidence from the U.S. Market. Abacus, 43(3):332-357.

Bae, K.-H. and Goyal, V. K. (2009). Creditor Rights, Enforcement, and Bank Loans. The Journal of Finance, 64(2):823-860.

Barrot, J.-N. (2016). Trade Credit and Industry Dynamics: Evidence from Trucking Firms. The Journal of Finance, 71(5):1975-2016.

Basel Committee on Banking Supervision (2017). Basel III: Finalising post-crisis reforms.

Bauer, J. and Agarwal, V. (2014). Are hazard models superior to traditional bankruptcy prediction approaches? A comprehensive test. Journal of Banking $\&$ Finance, 40:432442.

Beaver, W. H. (1966). Financial Ratios As Predictors of Failure. Journal of Accounting Research, 4:71-111.

Beck, T. and Demirgüç-Kunt, A. (2006). Small and medium-size enterprises: Access to finance as a growth constraint. Journal of Banking 83 Finance, 30(11):2931-2943.

Beck, T., Demirgüç-Kunt, A., and Maksimovic, V. (2008). Financing patterns around the world: Are small firms different? Journal of Financial Economics, 89(3):467-487.

Bedendo, M. and Colla, P. (2015). Sovereign and corporate credit risk: Evidence from the Eurozone. Journal of Corporate Finance, 33:34-52.

Berger, A. N. and Udell, G. F. (1998). The economics of small business finance: The roles of private equity and debt markets in the financial growth cycle. Journal of Banking E Finance, 22(6-8):613-673.

Berger, A. N. and Udell, G. F. (2006). A more complete conceptual framework for SME finance. Journal of Banking \& Finance, 30(11):2945-2966. 
Bergthaler, W., Kang, K., Liu, Y., and Monaghan, D. (2015). Tackling Small and Medium Sized Enterprise Problem Loans in Europe. IMF Staff Discussion Note.

Berkowitz, J. and White, M. J. (2004). Bankruptcy and small firms' access to credit. The Rand Journal of Economics, 35(1):69-84.

Bharath, S. T. and Shumway, T. (2008). Forecasting Default with the Merton Distance to Default Model. The Review of Financial Studies, 21(3):1339-1369.

Boyd, J. H., Hakenes, H., and Heitz, A. (2018). The Effects of Creditor Rights and Bank Information Sharing on Borrower Behavior: Theory and Evidence. Working Paper.

Breza, E. and Liberman, A. (2017). Financial Contracting and Organizational Form: Evidence from the Regulation of Trade Credit. The Journal of Finance, 72(1):291324.

Bruggeman, A. and Van Nieuwenhuyze, C. (2013). Size and dynamics of debt positions in Belgium and in the euro area. National Bank of Belgium Economic Review.

Campbell, J. Y., Hilscher, J., and Szilagyi, J. (2008). In Search of Distress Risk. The Journal of Finance, 63(6):2899-2939.

Campello, M. and Gao, J. (2017). Customer concentration and loan contract terms. Journal of Financial Economics, 123(1):108 - 136.

Campello, M., Graham, J. R., and Harvey, C. R. (2010). The real effects of financial constraints: Evidence from a financial crisis. Journal of Financial Economics, 97(3):470-487.

Carbó-Valverde, S., Rodríguez-Fernández, F., and Udell, G. F. (2009). Bank Market Power and SME Financing Constraints. Review of Finance, 13(2):309-340. 
Carbó-Valverde, S., Rodríguez-Fernández, F., and Udell, G. F. (2016). Trade Credit, the Financial Crisis, and SME Access to Finance. Journal of Money, Credit and Banking, 48(1):113-143.

Casey, E. and O'Toole, C. M. (2014). Bank lending constraints, trade credit and alternative financing during the financial crisis: Evidence from European SMEs. Journal of Corporate Finance, 27:173-193.

Chava, S. and Jarrow, R. A. (2004). Bankruptcy Prediction with Industry Effects. Review of Finance, 8(4):537-569.

Chod, J., Lyandres, E., and Yang, S. A. (2019). Trade credit and supplier competition. Journal of Financial Economics, 131(2):484 - 505.

Claessens, S. and Klapper, L. F. (2005). Bankruptcy around the World: Explanations of Its Relative Use. American Law and Economics Review, 7(1):253-283.

Collin-Dufresne, P. and Goldstein, R. S. (2001). Do Credit Spreads Reflect Stationary Leverage Ratios? The Journal of Finance, 56(5):1929-1957.

Cosh, A., Cumming, D. J., and Hughes, A. (2009). Outside Enterpreneurial Capital. The Economic Journal, 119(540):1494-1533.

Cumming, D., Fleming, G., and Liu, Z. F. (2019). The Returns to Private Debt: Primary Issuances vs. Secondary Acquisitions. Financial Analysts Journal, 75(1):48-62.

Cumming, D. J. (2005). Capital structure in venture finance. Journal of Corporate Finance, 11(3):550 - 585.

Cunat, V. (2007). Trade Credit: Suppliers as Debt Collectors and Insurance Providers. The Review of Financial Studies, 20(2):491-527. 
Daskalakis, N., Balios, D., and Dalla, V. (2017). The behaviour of SMEs' capital structure determinants in different macroeconomic states. Journal of Corporate Finance, 46:248260.

Davydenko, S. A. and Franks, J. R. (2008). Do Bankruptcy Codes Matter? A Study of Defaults in France, Germany, and the U.K. The Journal of Finance, 63(2):565-608.

Djankov, S., McLiesh, C., and Shleifer, A. (2007). Private credit in 129 countries. Journal of Financial Economics, 84(2):299 - 329.

Duffie, D., Saita, L., and Wang, K. (2007). Multi-period corporate default prediction with stochastic covariates. Journal of Financial Economics, 83(3):635-665.

Edmister, R. O. (1972). An Empirical Test of Financial Ratio Analysis for Small Business Failure Prediction. Journal of Financial and Quantitative Analysis, 7(2):1477-1493.

El Ghoul, S., Guedhami, O., Kwok, C., and Zheng, X. (2018). Zero-Leverage Puzzle: An International Comparison. Review of Finance, 22(3):1063-1120.

European Commission (2018). Annual Report on European SMEs 2017/2018.

Fabbri, D. and Klapper, L. F. (2016). Bargaining power and trade credit. Journal of Corporate Finance, 41:66 - 80 .

Fabbri, D. and Menichini, A. M. C. (2010). Trade credit, collateral liquidation, and borrowing constraints. Journal of Financial Economics, 96(3):413 - 432.

Faccio, M., Marchica, M.-T., and Mura, R. (2011). Large Shareholder Diversification and Corporate Risk-Taking. The Review of Financial Studies, 24(11):3601-3641.

Fernández, A. I., González, F., and Suárez, N. (2018). Bank supply shocks and the substitution between bank and nonbank debt. Journal of Corporate Finance, 48:122147. 
Ferrando, A. and Mulier, K. (2013). Do firms use the trade credit channel to manage growth? Journal of Banking $\&$ Finance, 37(8):3035 - 3046.

Ferrando, A., Popov, A., and Udell, G. F. (2017). Sovereign stress and SMEs' access to finance: Evidence from the ECB's SAFE survey. Journal of Banking ES Finance, 81:65 $-80$.

Filipe, S. F., Grammatikos, T., and Michala, D. (2016). Forecasting distress in European SME portfolios. Journal of Banking \& Finance, 64:112-135.

Garcia-Appendini, E. and Montoriol-Garriga, J. (2013). Firms as liquidity providers: Evidence from the 2007-2008 financial crisis. Journal of Financial Economics, 109(1):272291.

Gertler, M. and Gilchrist, S. (1994). Monetary Policy, Business Cycles, and the Behavior of Small Manufacturing Firms. The Quarterly Journal of Economics, 109(2):309-340.

Giordani, P., Jacobson, T., Schedvin, E. v., and Villani, M. (2014). Taking the Twists into Account: Predicting Firm Bankruptcy Risk with Splines of Financial Ratios. Journal of Financial and Quantitative Analysis, 49(4):1071-1099.

Goncalves, A. B., Schiozer, R. F., and Sheng, H. H. (2018). Trade credit and product market power during a financial crisis. Journal of Corporate Finance, 49:308 - 323.

He, Z. and Xiong, W. (2012). Rollover Risk and Credit Risk. The Journal of Finance, $67(2): 391-430$.

Heitz, A. R. and Narayanamoorthy, G. (2018). Creditor Rights and Bank Losses: A Cross-Country Comparison. Working Paper. 
Hemmert, G. A. J., Schons, L. M., Wieseke, J., and Schimmelpfennig, H. (2018). Loglikelihood-based Pseudo-R2 in Logistic Regression: Deriving Sample-sensitive Benchmarks. Sociological Methods $\&$ Research, 47(3):507-531.

Hillegeist, S. A., Keating, E. K., Cram, D. P., and Lundstedt, K. G. (2004). Assessing the Probability of Bankruptcy. Review of Accounting Studies, 9(1):5-34.

Houston, J. F., Lin, C., Lin, P., and Ma, Y. (2010). Creditor rights, information sharing, and bank risk taking. Journal of Financial Economics, 96(3):485 - 512.

Huang, H., Shi, X., and Zhang, S. (2011). Counter-cyclical substitution between trade credit and bank credit. Journal of Banking \& Finance, 35(8):1859 - 1878.

Klapper, L., Laeven, L., and Rajan, R. (2012). Trade Credit Contracts. The Review of Financial Studies, 25(3):838-867.

La Porta, R., Lopez-de Silanes, F., Shleifer, A., and Vishny, R. W. (1998). Law and Finance. Journal of Political Economy, 106(6):1113-1155.

Love, I., Preve, L. A., and Sarria-Allende, V. (2007). Trade credit and bank credit: Evidence from recent financial crises. Journal of Financial Economics, 83(2):453 469.

Mayordomo, S. and Rodríguez-Moreno, M. (2018). Did the bank capital relief induced by the Supporting Factor enhance SME lending? Journal of Financial Intermediation.

Mc Namara, A., Murro, P., and O'Donohoe, S. (2017). Countries lending infrastructure and capital structure determination: The case of European SMEs. Journal of Corporate Finance, 43:122-138.

McGuinness, G., Hogan, T., and Powell, R. (2018). European trade credit use and SME survival. Journal of Corporate Finance, 49:81-103. 
Merton, R. C. (1974). On the Pricing of Corporate Debt: The Risk Structure of Interest Rates. The Journal of Finance, 29(2):449-470.

Molina, C. A. and Preve, L. A. (2012). An Empirical Analysis of the Effect of Financial Distress on Trade Credit. Financial Management, 41(1):187-205.

Moody's Investors Service (2017). Annual Default Study: Corporate Default and Recovery Rates, 1920 - 2016.

Murfin, J. and Njoroge, K. (2014). The Implicit Costs of Trade Credit Borrowing by Large Firms. The Review of Financial Studies, 28(1):112-145.

Nickell, P., Perraudin, W., and Varotto, S. (2000). Stability of rating transitions. Journal of Banking $\&$ Finance, 24(1):203-227.

OECD (2009). The Impact of the Global Crisis on SME and Entrepreneurship Financing and Policy Responses.

Ohlson, J. A. (1980). Financial Ratios and the Probabilistic Prediction of Bankruptcy. Journal of Accounting Research, 18(1):109-131.

Qian, J. and Strahan, P. E. (2007). How Laws and Institutions Shape Financial Contracts: The Case of Bank Loans. The Journal of Finance, 62(6):2803-2834.

Resti, A. and Sironi, A. (2007). Risk Management and Shareholders'Value in Banking: From Risk Measurement Models to Capital Allocation Policies. John Wiley \& Sons.

Robb, A. M. and Robinson, D. T. (2012). The Capital Structure Decisions of New Firms. The Review of Financial Studies, 27(1):153-179.

Sautner, Z. and Vladimirov, V. (2017). Indirect Costs of Financial Distress and Bankruptcy Law: Evidence from Trade Credit and Sales*. Review of Finance, 22(5):1667-1704. 
Shah, A., Shah, H. A., Smith, J. M., and Labianca, G. J. (2017). Judicial efficiency and capital structure: An international study. Journal of Corporate Finance, 44:255 - 274.

Shenoy, J. and Williams, R. (2017). Trade credit and the joint effects of supplier and customer financial characteristics. Journal of Financial Intermediation, 29:68 - 80.

Shumway, T. (2001). Forecasting Bankruptcy More Accurately: A Simple Hazard Model. The Journal of Business, 74(1):101-124.

Strebulaev, I. A. and Yang, B. (2013). The mystery of zero-leverage firms. Journal of Financial Economics, 109(1):1-23.

Traczynski, J. (2017). Firm Default Prediction: A Bayesian Model-Averaging Approach. Journal of Financial and Quantitative Analysis, 52(3):1211-1245.

Vassalou, M. and Xing, Y. (2004). Default Risk in Equity Returns. The Journal of Finance, 59(2):831-868.

Wilcox, J. A. and Yasuda, Y. (2019). Government guarantees of loans to small businesses: Effects on banks' risk-taking and non-guaranteed lending. Journal of Financial Intermediation, $37: 45-57$.

Zhang, Q., Vallascas, F., Keasey, K., and Cai, C. X. (2015). Are Market-Based Measures of Global Systemic Importance of Financial Institutions Useful to Regulators and Supervisors? Journal of Money, Credit and Banking, 47(7):1403-1442.

Zmijewski, M. E. (1984). Methodological Issues Related to the Estimation of Financial Distress Prediction Models. Journal of Accounting Research, 22:59-82. 


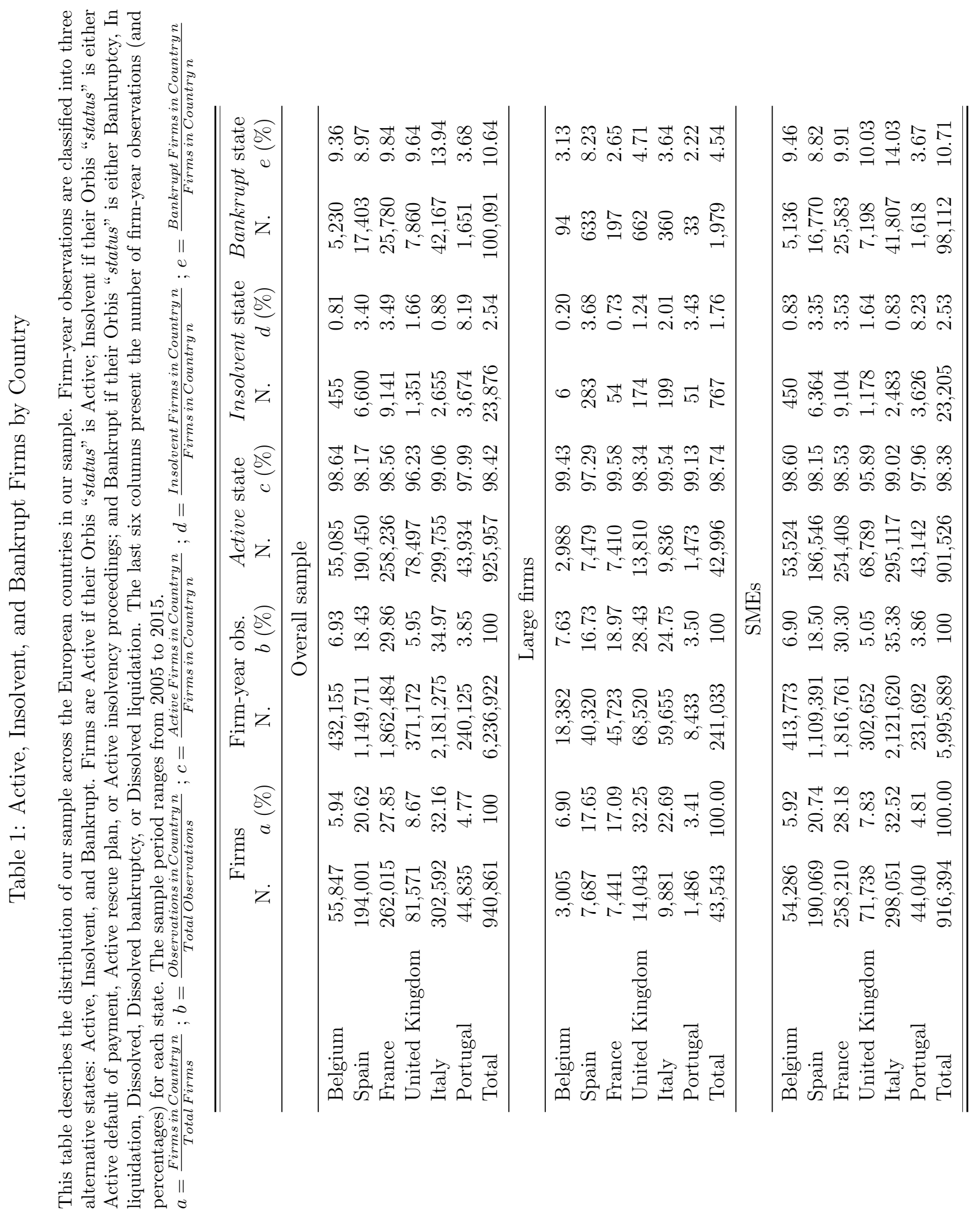




\section{Table 2: Transition Matrix}

The table shows transition probabilities for Active and Insolvent states to Active, Insolvent, and Bankrupt states over 1 (Panel A), 5 (Panel B) and 10 years (Panel C). Firms are Active if their Orbis "status" is Active; Insolvent if their Orbis "status" is Active default of payment, Active rescue plan, or Active insolvency proceedings; and Bankrupt if their Orbis "status" is Bankruptcy, In liquidation, Dissolved, Dissolved bankruptcy, or Dissolved liquidation. Values in the table are expressed as a percentage. The sample period ranges from 2005 to 2015.

\begin{tabular}{lccc}
\hline \hline state $_{t} \backslash$ state $_{t+n}$ & Active & Insolvent & Bankrupt \\
\hline \hline \multicolumn{4}{c}{ Panel A: $\mathrm{n}=1$ year } \\
\hline Active & 97.876 & 0.358 & 1.766 \\
Insolvent & 1.012 & 91.657 & 7.331 \\
\hline \multicolumn{4}{c}{ Panel B: $\mathrm{n}=5$ years } \\
\hline Active & 89.852 & 1.448 & 8.700 \\
Insolvent & 4.089 & 64.718 & 31.19 \\
\hline \multicolumn{4}{c}{ Panel C: $\mathrm{n}=10$ years } \\
\hline Active & 80.793 & 2.239 \\
Insolvent & 6.320 & 41.944 & 16.968 \\
\hline \hline
\end{tabular}


Table 3: Number of Defaults

This table reports the number (and percentage) of insolvent and bankrupt firms for each year of the sample. The percentages (in parentheses) are computed for the total number of firms in each year. Sample firms are then split into two sub-samples: SMEs and large corporations. If the value of a firm's total assets is no greater than $€ 43$ million, the firm is classified as an SME; otherwise, it is classified as a large corporation. The table displays the number (and percentage for each sub-sample) of insolvent and bankrupt firms that are SMEs and large corporations. The last column is the ratio of the percentage of defaulted SMEs to the percentage of defaulted large corporations.

$a=\frac{\% \text { SMEs }}{\% \text { LargeCorporations }}$.

\begin{tabular}{cccccccc}
\hline \hline \multirow{2}{*}{ Years } & \multicolumn{2}{c}{ Overall sample } & \multicolumn{3}{c}{ SMEs } & \multicolumn{3}{c}{ Large firms } & \multirow{2}{*}{$a$} \\
& $\mathrm{~N}$. & $(\%)$ & $\mathrm{N}$. & $(\%)$ & $\mathrm{N}$. & $(\%)$ & \\
\hline 2006 & 7,159 & 1.359 & 6,906 & 1.362 & 253 & 1.284 & 1.061 \\
2007 & 8,146 & 1.395 & 7,879 & 1.404 & 267 & 1.166 & 1.204 \\
2008 & 11,702 & 1.894 & 11,393 & 1.920 & 309 & 1.263 & 1.521 \\
2009 & 14,731 & 2.316 & 14,486 & 2.370 & 245 & 0.980 & 2.418 \\
2010 & 13,276 & 2.061 & 12,972 & 2.095 & 304 & 1.216 & 1.723 \\
2011 & 14,030 & 2.131 & 13,763 & 2.175 & 267 & 1.049 & 2.073 \\
2012 & 16,196 & 2.428 & 15,934 & 2.484 & 262 & 1.024 & 2.425 \\
2013 & 16,617 & 2.491 & 16,232 & 2.530 & 385 & 1.516 & 1.669 \\
2014 & 13,674 & 2.082 & 13,380 & 2.119 & 294 & 1.158 & 1.829 \\
2015 & 7,516 & 1.339 & 7,389 & 1.369 & 127 & 0.586 & 2.334 \\
Total & 123,047 & 13.078 & 120,334 & 13.132 & 2,713 & 6.233 & 2.107 \\
\hline \hline
\end{tabular}


Table 4: Summary Statistics for the Regression Variables

This table shows summary statistics for the independent variables used in our regression analysis. The first three are country-specific variables: GDP is the 1-year GDP growth rate; GOVBOND is the 3month government bond interest rate; SOVCDS is the logarithm of the government CDS spread; NITA is the ratio of net income to total assets; CATA is the ratio of current assets to total assets; AGE is the number of days since incorporation divided by 365; LEVERAGE is the ratio of total liabilities to total assets; TRADE is the ratio of trade payables to total assets; CURRENT is the ratio of current liabilities (minus trade payables) to total assets; and NONCURRENT is the ratio of non-current liabilities to total assets. GDP, GOVBOND and SOVCDS are reported for the whole sample of firm-year observations. NITA, CATA, AGE, LEVERAGE, TRADE, CURRENT, and NONCURRENT are reported for large corporations and SMEs. A firm-year observation is classified as an SME if a firm's total assets are worth no more than $€ 43$ million. The total number of firm-year observations is $6,236,922$. The number of firm-year observations for large corporations is 241,033 . The number of firm-year observations for SMEs is $5,995,889$. The sample period ranges from 2005 to 2015 .

\begin{tabular}{lrrrrr}
\hline \hline & Mean & Median & SD & Min & Max \\
\hline GDP (\%) & 0.309 & 0.652 & 2.497 & -7.101 & 4.223 \\
GOVBOND (\%) & 1.759 & 1.244 & 1.571 & -0.073 & 6.750 \\
SOVCDS (\%) & -0.776 & -0.359 & 1.647 & -4.375 & 2.443 \\
\hline \multicolumn{5}{c}{ Large firms } & \\
\hline NITA & 0.022 & 0.015 & 0.102 & -0.973 & 0.631 \\
CATA & 0.533 & 0.554 & 0.322 & 0.001 & 1.000 \\
AGE & 25.656 & 20.066 & 20.736 & 0.427 & 104.849 \\
LEVERAGE & 0.664 & 0.691 & 0.321 & 0.002 & 4.470 \\
TRADE & 0.122 & 0.064 & 0.154 & 0.000 & 0.917 \\
CURRENT & 0.290 & 0.224 & 0.251 & 0.000 & 1.927 \\
NONCURRENT & 0.249 & 0.135 & 0.287 & 0.000 & 2.616 \\
\hline & \multicolumn{7}{c}{ SMEs } & & & \\
\hline NITA & 0.026 & 0.017 & 0.108 & -0.973 & 0.631 \\
CATA & 0.689 & 0.775 & 0.279 & 0.001 & 1.000 \\
AGE & 17.349 & 14.238 & 13.618 & 0.427 & 104.849 \\
LEVERAGE & 0.709 & 0.739 & 0.306 & 0.002 & 4.470 \\
TRADE & 0.205 & 0.151 & 0.204 & 0.000 & 0.917 \\
CURRENT & 0.320 & 0.266 & 0.245 & 0.000 & 1.927 \\
NONCURRENT & 0.182 & 0.096 & 0.229 & 0.000 & 2.616 \\
\hline \hline
\end{tabular}




\section{Table 5: Sources of Finance across Countries}

This table shows summary statistics for the variables representing the alternative sources of finance across the countries represented in the sample. LEVERAGE is the ratio of total liabilities to total assets; TRADE is the ratio of trade payables to total assets; CURRENT is the ratio of current liabilities (minus trade payables) to total assets; and NONCURRENT is the ratio of non-current liabilities to total assets. Bold numbers are the maximum mean values of LEVERAGE, TRADE, CURRENT, and NONCURRENT across countries in the overall sample for large corporations and for SMEs. The sample period ranges from 2005 to 2015.

\begin{tabular}{|c|c|c|c|c|c|c|}
\hline & & LEVERAGE & TRADE & CURRENT & NONCURRENT & N. observations \\
\hline \multirow[t]{4}{*}{ Belgium } & Mean (Large firms) & 0.546 & 0.127 & 0.234 & 0.184 & 18,382 \\
\hline & Median (Large firms) & 0.592 & 0.058 & 0.154 & 0.063 & \\
\hline & Mean (SMEs) & 0.629 & 0.182 & 0.274 & 0.168 & 413,773 \\
\hline & Median (SMEs) & 0.657 & 0.113 & 0.211 & 0.080 & \\
\hline \multirow[t]{4}{*}{ Spain } & Mean (Large firms) & 0.670 & 0.097 & 0.276 & 0.292 & 40,320 \\
\hline & Median (Large firms) & 0.710 & 0.040 & 0.213 & 0.198 & \\
\hline & Mean (SMEs) & 0.671 & 0.118 & 0.308 & 0.242 & $1,109,391$ \\
\hline & Median (SMEs) & 0.703 & 0.034 & 0.247 & 0.158 & \\
\hline \multirow[t]{4}{*}{ France } & Mean (Large firms) & 0.640 & 0.174 & 0.288 & 0.171 & 45,723 \\
\hline & Median (Large firms) & 0.657 & 0.130 & 0.229 & 0.082 & \\
\hline & Mean (SMEs) & 0.671 & 0.234 & 0.319 & 0.113 & $1,816,761$ \\
\hline & Median (SMEs) & 0.669 & 0.196 & 0.274 & 0.040 & \\
\hline \multirow[t]{4}{*}{ United Kingdom } & Mean (Large firms) & 0.710 & 0.063 & 0.308 & 0.334 & 68,520 \\
\hline & Median (Large firms) & 0.710 & 0.015 & 0.216 & 0.193 & \\
\hline & Mean (SMEs) & 0.748 & 0.131 & 0.334 & 0.263 & 302,652 \\
\hline & Median (SMEs) & 0.667 & 0.074 & 0.249 & 0.096 & \\
\hline \multirow[t]{4}{*}{ Italy } & Mean (Large firms) & 0.658 & 0.163 & 0.302 & 0.192 & 59,655 \\
\hline & Median (Large firms) & 0.709 & 0.123 & 0.260 & 0.127 & \\
\hline & Mean (SMEs) & 0.771 & 0.239 & 0.341 & 0.191 & $2,121,620$ \\
\hline & Median (SMEs) & 0.840 & 0.186 & 0.291 & 0.122 & \\
\hline \multirow[t]{4}{*}{ Portugal } & Mean (Large firms) & 0.693 & 0.127 & 0.247 & 0.314 & 8,433 \\
\hline & Median (Large firms) & 0.710 & 0.066 & 0.188 & 0.226 & \\
\hline & Mean (SMEs) & 0.723 & 0.211 & 0.247 & 0.262 & 231,692 \\
\hline & Median (SMEs) & 0.730 & 0.169 & 0.199 & 0.194 & \\
\hline
\end{tabular}


Table 6: Sources of Finance for Active and Defaulted SMEs and Large Firms

This table shows summary statistics for the variables representing the alternative sources of finance for active and defaulted SMEs and large firms. LEVERAGE is the ratio of total liabilities to total assets; TRADE is the ratio of trade payables to total assets; CURRENT is the ratio of current liabilities (minus trade payables) to total assets; and NONCURRENT is the ratio of non-current liabilities to total assets. Panel B reports the difference between median values of active and defaulted SMEs and large firms. Statistical significance is calculated using the Wilcoxon test. The number of firm-year observations per group is 237,825 for Active large corporations; 3,208 for Insolvent and Bankrupt large corporations; $5,858,702$ for Active SMEs; and 137,187 for Insolvent and Bankrupt SMEs. The sample period ranges from 2005 to 2015 . *** $\mathrm{p}<0.01 ;{ }^{* *} \mathrm{p}<0.05 ;{ }^{*} \mathrm{p}<0.1$.

\begin{tabular}{|c|c|c|c|c|c|}
\hline \multicolumn{6}{|c|}{ Panel A } \\
\hline & Mean & Median & $\mathrm{SD}$ & Min & $\operatorname{Max}$ \\
\hline \multicolumn{6}{|c|}{ Active large } \\
\hline LEVERAGE & 0.661 & 0.689 & 0.318 & 0.002 & 4.470 \\
\hline TRADE & 0.122 & 0.064 & 0.154 & 0.000 & 0.917 \\
\hline CURRENT & 0.289 & 0.223 & 0.250 & 0.000 & 1.927 \\
\hline NONCURRENT & 0.247 & 0.134 & 0.286 & 0.000 & 2.616 \\
\hline \multicolumn{6}{|c|}{ Defaulted large } \\
\hline LEVERAGE & 0.868 & 0.901 & 0.424 & 0.002 & 4.470 \\
\hline TRADE & 0.121 & 0.049 & 0.172 & 0.000 & 0.917 \\
\hline CURRENT & 0.372 & 0.300 & 0.319 & 0.000 & 1.927 \\
\hline NONCURRENT & 0.370 & 0.262 & 0.373 & 0.000 & 2.616 \\
\hline \multicolumn{6}{|c|}{ Active SMEs } \\
\hline LEVERAGE & 0.703 & 0.734 & 0.301 & 0.002 & 4.470 \\
\hline TRADE & 0.203 & 0.150 & 0.202 & 0.000 & 0.917 \\
\hline CURRENT & 0.316 & 0.263 & 0.242 & 0.000 & 1.927 \\
\hline NONCURRENT & 0.180 & 0.096 & 0.227 & 0.000 & 2.616 \\
\hline \multicolumn{6}{|c|}{ Defaulted SMEs } \\
\hline LEVERAGE & 0.965 & 0.943 & 0.390 & 0.002 & 4.470 \\
\hline TRADE & 0.267 & 0.206 & 0.252 & 0.000 & 0.917 \\
\hline CURRENT & 0.470 & 0.417 & 0.317 & 0.000 & 1.927 \\
\hline NONCURRENT & 0.235 & 0.120 & 0.294 & 0.000 & 2.616 \\
\hline \multicolumn{6}{|c|}{ Panel B: Median differences } \\
\hline & Large firms & SMEs & \multicolumn{2}{|c|}{ SMEs - Large } & \\
\hline & Defaulted - Active & Defaulted - Active & Active & Defaulted & \\
\hline LEVERAGE & $0.212^{* * *}$ & $0.210^{* * *}$ & $0.045^{* * *}$ & $0.043^{* * *}$ & \\
\hline TRADE & $-0.015^{* * *}$ & $0.056^{* * *}$ & $0.086^{* * *}$ & $0.157^{* * *}$ & \\
\hline CURRENT & $0.077 * * *$ & $0.154^{* * *}$ & $0.040 * * *$ & $0.117 * * *$ & \\
\hline NONCURRENT & $0.128 * * *$ & $0.024^{* * *}$ & $-0.038^{* * *}$ & $-0.142^{* * *}$ & \\
\hline
\end{tabular}




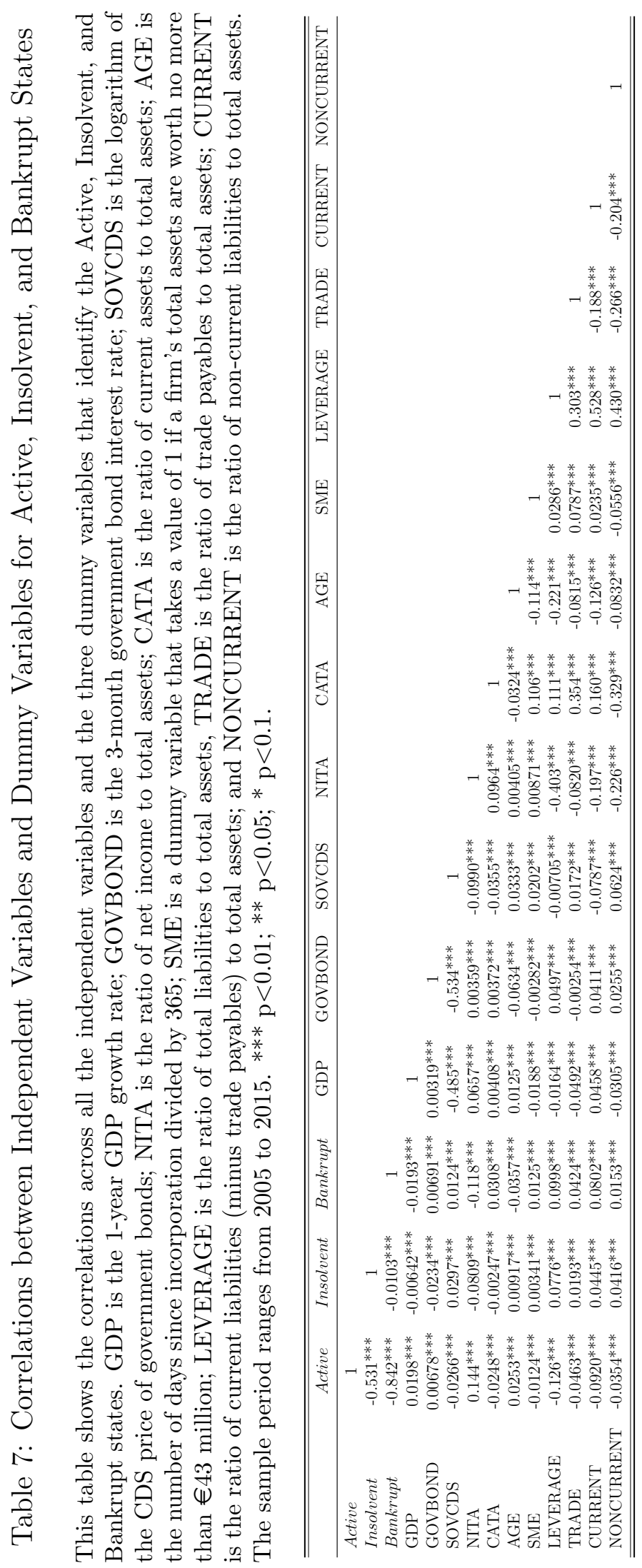


Table 8: Default Probability: Regression Results

This table reports the estimated coefficients for the logit regressions and their robust standard errors clustered at the firm level (in parentheses). The bottom of the table reports the number of observations, number of clusters (i.e., firms), McFadden's $R^{2}$, and the percentage of correctly classified observations. The dependent variable takes a value of 0 if the firm is Active and a value of 1 if it is either Insolvent or Bankrupt. GDP is the 1-year GDP growth rate; GOVBOND is the 3-month government bond interest rate; SOVCDS is the logarithm of the CDS price of government bonds; NITA is the ratio of net income to total assets; CATA is the ratio of current assets to total assets; AGE is the number of days since incorporation divided by 365; SME is a dummy variable that takes a value of 1 if a firm's total assets are worth no more than $€ 43$ million; LEVERAGE is the ratio of total liabilities to total assets; TRADE is the ratio of trade payables to total assets; CURRENT is the ratio of current liabilities (minus trade payables) to total assets; and NONCURRENT is the ratio of non-current liabilities to total assets. Independent variables are lagged. The sample period ranges from 2005 to 2015 . ${ }^{* * *} \mathrm{p}<0.01 ;{ }^{* *} \mathrm{p}<0.05 ;{ }^{*} \mathrm{p}<0.1$.

\begin{tabular}{|c|c|c|c|c|}
\hline Specification & (1) & (2) & (3) & (4) \\
\hline LEVERAGE & $\begin{array}{c}0.640^{* * *} \\
(0.015)\end{array}$ & $\begin{array}{c}0.422^{* * *} \\
(0.053)\end{array}$ & & \\
\hline LEVERAGE*SME & & $\begin{array}{c}0.224^{* * *} \\
(0.055)\end{array}$ & & \\
\hline TRADE & & & $\begin{array}{c}1.521^{* * *} \\
(0.017)\end{array}$ & $\begin{array}{c}0.613^{* * *} \\
(0.145)\end{array}$ \\
\hline TRADE*SME & & & & $\begin{array}{c}0.921^{* * *} \\
(0.146)\end{array}$ \\
\hline CURRENT & & & $\begin{array}{c}1.447^{* * *} \\
(0.015)\end{array}$ & $\begin{array}{c}0.666^{* * *} \\
(0.074)\end{array}$ \\
\hline CURRENT*SME & & & & $\begin{array}{c}0.805^{* * *} \\
(0.075)\end{array}$ \\
\hline NONCURRENT & & & $\begin{array}{c}0.349^{* * *} \\
(0.020)\end{array}$ & $\begin{array}{c}0.657^{* * *} \\
(0.063)\end{array}$ \\
\hline NONCURRENT*SME & & & & $\begin{array}{c}-0.324^{* * *} \\
(0.065)\end{array}$ \\
\hline SME & $\begin{array}{c}0.348^{* * *} \\
(0.021)\end{array}$ & $\begin{array}{c}0.163^{* * *} \\
(0.046)\end{array}$ & $\begin{array}{c}0.334^{* * *} \\
(0.021)\end{array}$ & $\begin{array}{l}-0.014 \\
(0.052)\end{array}$ \\
\hline GDP & $\begin{array}{c}-0.023^{* * *} \\
(0.001)\end{array}$ & $\begin{array}{c}-0.023^{* * *} * \\
(0.001)\end{array}$ & $\begin{array}{c}-0.023^{* * *} \\
(0.001)\end{array}$ & $\begin{array}{c}-0.023^{* * *} \\
(0.001)\end{array}$ \\
\hline GOVBOND & $\begin{array}{c}0.068^{* * *} \\
(0.002)\end{array}$ & $\begin{array}{c}0.068^{* * *} \\
(0.002)\end{array}$ & $\begin{array}{c}0.067^{* * *} \\
(0.002)\end{array}$ & $\begin{array}{c}0.067^{* * *} \\
(0.002)\end{array}$ \\
\hline SOVCDS & $\begin{array}{c}0.125^{* * *} \\
(0.003)\end{array}$ & $\begin{array}{c}0.125^{* * *} \\
(0.003)\end{array}$ & $\begin{array}{c}0.133^{* * *} \\
(0.003)\end{array}$ & $\begin{array}{c}0.133^{* * *} \\
(0.003)\end{array}$ \\
\hline NITA & $\begin{array}{c}-4.237^{* * *} \\
(0.026)\end{array}$ & $\begin{array}{c}-4.236^{* * *} \\
(0.026)\end{array}$ & $\begin{array}{c}-3.692^{* * * *} \\
(0.027)\end{array}$ & $\begin{array}{c}-3.688^{* * *} \\
(0.027)\end{array}$ \\
\hline CATA & $\begin{array}{c}0.567^{* * *} \\
(0.013)\end{array}$ & $\begin{array}{c}0.567^{* * *} \\
(0.013)\end{array}$ & $\begin{array}{c}0.197^{* * *} \\
(0.014)\end{array}$ & $\begin{array}{c}0.205^{* * *} \\
(0.014)\end{array}$ \\
\hline AGE & $\begin{array}{c}-0.012^{\text {*** }} \\
(0.000)\end{array}$ & $\begin{array}{c}-0.012^{* * *} \\
(0.000)\end{array}$ & $\begin{array}{c}-0.010^{* * *} \\
(0.000)\end{array}$ & $\begin{array}{c}-0.010^{* * *} \\
(0.000)\end{array}$ \\
\hline Constant & $\begin{array}{c}-5.863^{* * *} \\
(0.043) \\
\end{array}$ & $\begin{array}{c}-5.683^{* * *} \\
(0.057)\end{array}$ & $\begin{array}{c}-6.090^{* * *} \\
(0.043)\end{array}$ & $\begin{array}{c}-5.760^{* * *} * \\
(0.062)\end{array}$ \\
\hline Observations & $6,219,574$ & $6,219,574$ & $6,219,574$ & $6,219,574$ \\
\hline Country FE & Yes & Yes & Yes & Yes \\
\hline Industry FE & Yes & Yes & Yes & Yes \\
\hline Clusters & 940,861 & 940,861 & 940,861 & 940,861 \\
\hline Pseudo- $R^{2}$ & 0.0890 & 0.0891 & 0.100 & 0.101 \\
\hline \% Insolvent and Bankrupt correctly classified & 68.133 & 68.121 & 68.996 & 68.951 \\
\hline$\%$ Active correctly classified & 69.757 & 69.795 & 69.960 & 70.048 \\
\hline
\end{tabular}


Table 9: Default Probability: Average Marginal Effects

The table shows average marginal effects of LEVERAGE, TRADE, CURRENT, and NONCURRENT for both SMEs and large corporations (Panel A). Standard errors are reported in parentheses. Standard errors of marginal effects are calculated using the delta method. LEVERAGE is the ratio of total liabilities to total assets; TRADE is the ratio of trade payables to total assets; CURRENT is the ratio of current liabilities (minus trade payables) to total assets; and NONCURRENT is the ratio of non-current liabilities to total assets. Average marginal effects of LEVERAGE are computed using specification (2). Average marginal effects of TRADE, CURRENT, and NONCURRENT are computed using specification (4) of Table 8. Panel B reports differences in average marginal effects between SMEs and large firms. Statistical significance is calculated using the Wald test.

\begin{tabular}{lccccc}
\hline \hline & LEVERAGE & TRADE & CURRENT & NONCURRENT & N. observations \\
\hline \multirow{5}{*}{ Large firms } & $0.006^{* * *}$ & $0.007^{* * *}$ & $0.008^{* * *}$ & $0.008^{* * *}$ & 240,538 \\
& $(0.001)$ & $(0.002)$ & $(0.001)$ & $(0.001)$ & \\
SMEs & $0.012^{* * *}$ & $0.028^{* * *}$ & $0.027^{* * *}$ & $0.006^{* * *}$ & $5,979,036$ \\
& $(0.000)$ & $(0.000)$ & $(0.000)$ & $(0.000)$ & \\
\hline \multicolumn{5}{c}{ Panel B: SMEs - Large firms } \\
\hline \hline
\end{tabular}


Table 10: Predicted Default Probabilities

This table reports average predicted probabilities of default expressed as a percentage computed using specification (4). Predicted probabilities are sorted according to different quartiles of LEVERAGE, TRADE, CURRENT, and NONCURRENT. LEVERAGE is the ratio of total liabilities to total assets; TRADE is the ratio of trade payables to total assets; CURRENT is the ratio of current liabilities (minus trade payables) to total assets; and NONCURRENT is the ratio of non-current liabilities to total assets. The last column reports a Wald test on the difference between means of the fourth and the first quartiles. *** $\mathrm{p}<0.01 ;{ }^{* *} \mathrm{p}<0.05 ;{ }^{*} \mathrm{p}<0.1$.

\begin{tabular}{|c|c|c|c|c|c|}
\hline & First quartile & Second quartile & Third quartile & Fourth quartile & $\Delta_{\text {Fourth-First }}$ \\
\hline \multicolumn{6}{|c|}{ LEVERAGE } \\
\hline All sample & $0.90 * * *$ & $1.38 * * *$ & $1.91^{* * *}$ & $3.72^{* * *}$ & $2.82^{* * *}$ \\
\hline Large firms & $0.65^{* * *}$ & $0.85^{* * *}$ & $1.11^{* * *}$ & $1.90^{* * *}$ & $1.24^{* * *}$ \\
\hline SMEs & $0.91^{* * *}$ & $1.40^{* * *}$ & $1.94^{* * *}$ & $3.79^{* * *}$ & $2.87^{* * *}$ \\
\hline \multicolumn{6}{|c|}{ TRADE } \\
\hline All sample & $1.67 * * *$ & $1.54^{* * *}$ & $1.86^{* * *}$ & $2.85^{* * *}$ & $1.18^{* * *}$ \\
\hline Large firms & $1.23^{* * *}$ & $1.08^{* * *}$ & $1.06^{* * *}$ & $1.14^{* * *}$ & $-0.08^{* * *}$ \\
\hline SMEs & $1.69^{* * *}$ & $1.57^{* * *}$ & $1.89^{* * *}$ & $2.89^{* * *}$ & $1.20^{* * *}$ \\
\hline \multicolumn{6}{|c|}{ CURRENT } \\
\hline All sample & $1.28^{* * *}$ & $1.47^{* * *}$ & $1.82^{* * *}$ & $3.34^{* * *}$ & $2.06^{* * *}$ \\
\hline Large firms & $0.98^{* * *}$ & $0.96^{* * *}$ & $1.07^{* * *}$ & $1.50^{* * *}$ & $0.52^{* * *}$ \\
\hline SMEs & $1.30 * * *$ & $1.49^{* * *}$ & $1.85^{* * *}$ & $3.41^{* * *}$ & $2.12^{* * *}$ \\
\hline \multicolumn{6}{|c|}{ NONCURRENT } \\
\hline All sample & $2.07^{* * *}$ & $1.94^{* * *}$ & $1.86^{* * *}$ & $2.05^{* * *}$ & $-0.03^{* * *}$ \\
\hline Large firms & $0.92 * * *$ & $0.96^{* * *}$ & $1.04^{* * *}$ & $1.59^{* * *}$ & $0.67^{* * *}$ \\
\hline SMEs & $2.11^{* * *}$ & $1.98 * * *$ & $1.89^{* * *}$ & $2.08^{* * *}$ & $-0.03^{* * *}$ \\
\hline
\end{tabular}


Table 11: Sources of Finance for Recovered and Defaulted SMEs and Large Firms

This table shows summary statistics for the variables representing the alternative sources of finance for Insolvent firms at $t-1$. Panel A reports summary statistics for recovered and defaulted SMEs and large firms. LEVERAGE is the ratio of total liabilities to total assets; TRADE is the ratio of trade payables to total assets; CURRENT is the ratio of current liabilities (minus trade payables) to total assets and NONCURRENT is the ratio of non-current liabilities to total assets. Panel B reports the difference between median values of active and defaulted SMEs and large firms. Statistical significance is calculated with the Wilcoxon test. The number of firm-year observations for recovered large firms; Insolvent and Bankrupt large corporations; recovered SMEs; and Insolvent and Bankrupt SMEs is 17; 495; 313; and 16,885, respectively. The sample period ranges from 2005 to 2015 . ${ }^{* * *} \mathrm{p}<0.01 ;{ }^{* *} \mathrm{p}<0.05$; $* \mathrm{p}<0.1$.

\begin{tabular}{|c|c|c|c|c|c|}
\hline \multicolumn{6}{|c|}{ Panel A } \\
\hline & Mean & Median & S. & Min & Max \\
\hline \multicolumn{6}{|c|}{ Recovered large } \\
\hline LEVERAGE & 1.092 & 1.055 & 0.328 & 0.584 & 1.580 \\
\hline TRADE & 0.049 & 0.016 & 0.076 & 0.000 & 0.280 \\
\hline CURRENT & 0.513 & 0.495 & 0.384 & 0.009 & 1.022 \\
\hline NONCURRENT & 0.435 & 0.300 & 0.371 & 0.003 & 1.006 \\
\hline \multicolumn{6}{|c|}{ Defaulted large } \\
\hline LEVERAGE & 0.946 & 0.917 & 0.317 & 0.002 & 2.169 \\
\hline TRADE & 0.109 & 0.041 & 0.166 & 0.000 & 0.917 \\
\hline CURRENT & 0.410 & 0.354 & 0.313 & 0.000 & 1.160 \\
\hline NONCURRENT & 0.428 & 0.402 & 0.320 & 0.000 & 1.847 \\
\hline \multicolumn{6}{|c|}{ Recovered SMEs } \\
\hline LEVERAGE & 1.061 & 0.986 & 0.339 & 0.158 & 1.893 \\
\hline TRADE & 0.175 & 0.096 & 0.209 & 0.000 & 0.893 \\
\hline CURRENT & 0.395 & 0.321 & 0.316 & 0.002 & 1.216 \\
\hline NONCURRENT & 0.470 & 0.430 & 0.337 & 0.000 & 1.006 \\
\hline \multicolumn{6}{|c|}{ Defaulted SMEs } \\
\hline LEVERAGE & 1.055 & 0.971 & 0.385 & 0.031 & 4.470 \\
\hline TRADE & 0.248 & 0.180 & 0.236 & 0.000 & 0.917 \\
\hline CURRENT & 0.469 & 0.394 & 0.336 & 0.000 & 1.927 \\
\hline NONCURRENT & 0.346 & 0.274 & 0.306 & 0.000 & 2.616 \\
\hline \multicolumn{6}{|c|}{ Panel B: Comparisons } \\
\hline & Large firms & SMEs & \multicolumn{2}{|c|}{ SMEs - Large } & \\
\hline & Defaulted - Recovered & Defaulted - Recovered & Recovered & Defaulted & \\
\hline LEVERAGE & $-0.137^{*}$ & -0.015 & -0.069 & $0.054^{* * *}$ & \\
\hline TRADE & $0.025^{*}$ & $0.084^{* * *}$ & $0.080^{* * *}$ & $0.139^{* * *}$ & \\
\hline CURRENT & -0.141 & $0.073^{* * *}$ & -0.174 & $0.040^{* * *}$ & \\
\hline NONCURRENT & 0.103 & $-0.156^{* * *}$ & 0.131 & $-0.128^{* * *}$ & \\
\hline
\end{tabular}


Table 12: Recovery Probability for SMEs: Regression Results

This table shows the estimated coefficients of logit regressions run on the sub-sample of Insolvent or Bankrupt SME firms to estimate their recovery probability, that is, the probability that these firms migrate to the Active state. Robust standard errors clustered at the firm level are shown in parentheses. The bottom of the table reports the number of observations, the number of clusters (i.e., firms), McFadden's $R^{2}$, and the percentage of correctly classified observations. The dependent variable takes a value of 0 if the firm is either Insolvent or Bankrupt and a value of 1 if it is Active. The regression is estimated on the sub-sample of Insolvent SMEs at $t-1$. GDP is the 1-year GDP growth rate; GOVBOND is the 3-month government bond interest rate; SOVCDS is the logarithm of the CDS price of government bonds; NITA is the ratio of net income to total assets; CATA is the ratio of current assets to total assets; AGE is the number of days since incorporation divided by 365; LEVERAGE is the ratio of total liabilities to total assets; TRADE is the ratio of trade payables to total assets; CURRENT is the ratio of current liabilities (minus trade payables) to total assets; and NONCURRENT is the ratio of non-current liabilities to total assets. Independent variables are lagged. The sample period ranges from 2005 to 2015. *** $\mathrm{p}<0.01 ;{ }^{* *} \mathrm{p}<0.05 ;{ }^{*} \mathrm{p}<0.1$.

\begin{tabular}{lcc}
\hline \hline Specification & $(1 \mathrm{a})$ & $(2 \mathrm{a})$ \\
\hline \hline LEVERAGE & $0.787^{* * *}$ & \\
TRADE & $(0.215)$ & \\
& & 0.586 \\
CURRENT & $(0.395)$ \\
NONCURRENT & 0.162 \\
& & $(0.254)$ \\
GDP & & $0.877^{* * *}$ \\
& & $(0.241)$ \\
GOVBOND & $0.303^{* * *}$ & $0.303^{* * *}$ \\
& $(0.049)$ & $(0.049)$ \\
SOVCDS & $-1.003^{* * *}$ & $-1.023^{* * *}$ \\
& $(0.165)$ & $(0.169)$ \\
NITA & $1.418^{* * *}$ & $1.401^{* * *}$ \\
& $(0.154)$ & $(0.154)$ \\
CATA & -0.203 & -0.629 \\
& $(0.459)$ & $(0.482)$ \\
AGE & $-1.104^{* * *}$ & $-0.921^{* * *}$ \\
& $(0.225)$ & $(0.237)$ \\
Constant & $0.018^{* * *}$ & $0.018^{* * *}$ \\
& $(0.005)$ & $(0.005)$ \\
Observations & $-2.104^{* * *}$ & $-1.840^{* * *}$ \\
Country FE & $(0.499)$ & $(0.459)$ \\
Industry FE & 14,406 & 14,406 \\
Clusters & Yes & Yes \\
\% correctly classified Insolvent and Bankrupt SMEs & 80.331 & 80.338 \\
\% correctly classified Active firms & 92.121 & 92.121 \\
\hline \hline
\end{tabular}


Table 13: Predicted Recovery Probabilities for SMEs

This table reports average predicted probabilities of recovery for SMEs expressed as a percentage computed using specification (2a) of Table 12. Predicted probabilities of recovery are sorted for different quartiles of LEVERAGE, TRADE, CURRENT, and NONCURRENT. LEVERAGE is the ratio of total liabilities to total assets; TRADE is the ratio of trade payables to total assets; CURRENT is the ratio of current liabilities (minus trade payables) to total assets; and NONCURRENT is the ratio of non-current liabilities to total assets. The last column reports a Wald test on the difference between means of the fourth and the first quartiles. ${ }^{* * *} \mathrm{p}<0.01 ;{ }^{*} \mathrm{p}<0.05 ;{ }^{*} \mathrm{p}<0.1$.

\begin{tabular}{lcccc}
\hline \hline First quartile & Second quartile & Third quartile & Fourth quartile & $\Delta_{\text {Fourth-First }}$ \\
\hline \multirow{2}{*}{$2.02^{* * *}$} & $2.01^{* * *}$ & LEVERAGE & \\
& & $2.33^{* * *}$ & $2.33^{* * *}$ & $0.31^{* *}$ \\
$3.51^{* * *}$ & $1.99^{* * *}$ & TRADE & & \\
& & $1.67^{* * *}$ & $1.52^{* * *}$ & $-1.99^{* * *}$ \\
$2.89^{* * *}$ & $2.11^{* * *}$ & CURRENT & & \\
& & $1.97^{* * *}$ & $1.71^{* * *}$ & $-1.18^{* * *}$ \\
$0.93^{* * *}$ & $1.93^{* * *}$ & NONCURRENT & & \\
& & $2.66^{* * *}$ & $3.17^{* * *}$ & $2.24^{* * *}$ \\
\hline \hline
\end{tabular}




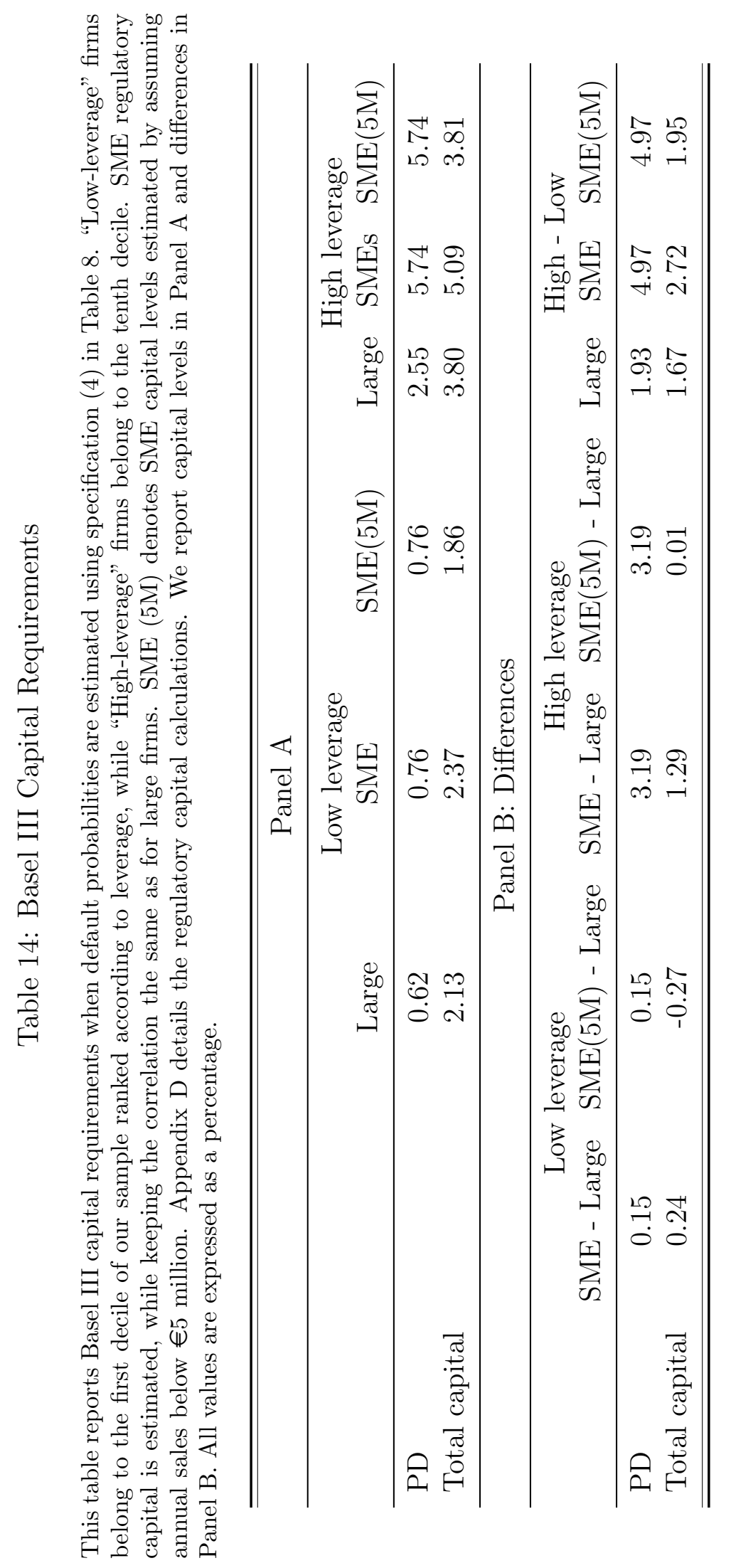




\section{Table 15: Loan Spreads}

This table reports loan spreads when default probabilities are estimated using specification (4) in Table 8. "Low leverage" firms belong to the first decile of our sample ranked according to leverage, whereas "High-leverage" firms belong to the tenth decile. SME (5M) denotes SMEs with annual sales below $€ 5$ million. "PDs" refers to the probability of default; $d_{e l}$ is the expected loss component of the spread; $d_{u l}$ is the unexpected loss component of the spread; and $d_{e l}+d_{u l}$ is the total loan spread. All values are expressed as a percentage.

\begin{tabular}{lcccccccc}
\hline \hline & \multicolumn{3}{c}{ Low Leverage } & \multicolumn{3}{c}{ High Leverage } & \multicolumn{2}{c}{$\Delta_{\text {High-Low }}$} \\
& Large & SME(5M) & $\Delta$ & Large & SME(5M) & $\Delta$ & Large & SME(5M) \\
\hline $\mathrm{PD}$ & 0.62 & 0.76 & 0.15 & 2.55 & 5.74 & 3.19 & 1.93 & 4.97 \\
$d_{e l}$ & 0.12 & 0.15 & 0.03 & 0.50 & 1.13 & 0.63 & 0.38 & 0.98 \\
$d_{u l}$ & 0.29 & 0.25 & -0.04 & 0.52 & 0.53 & 0.00 & 0.23 & 0.27 \\
$d_{e l}+d_{u l}$ & 0.41 & 0.40 & -0.01 & 1.02 & 1.65 & 0.63 & 0.61 & 1.25 \\
\hline \hline
\end{tabular}


Figure 1: Marginal Effects of Leverage

This figure presents the marginal effects of LEVERAGE on the default probability of both large corporations and SMEs computed using specification (2). Vertical lines represent average LEVERAGE values for large corporations (dash-dotted line) and SMEs (solid line). LEVERAGE is the ratio of total liabilities to total assets. Confidence intervals are reported at the $99 \%$ level.

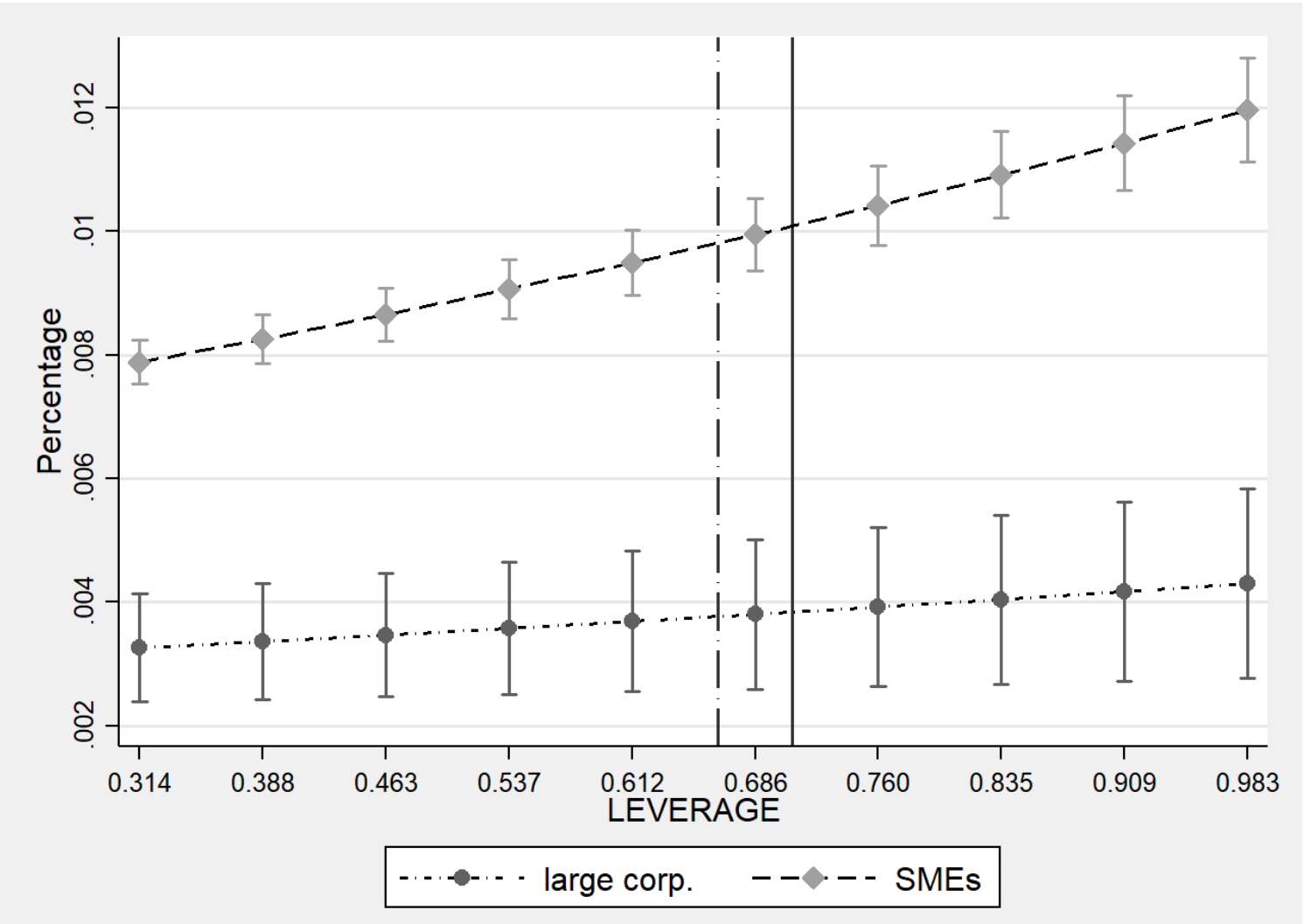


Figure 2: Marginal Effects of Leverage across Sectors

This figure presents the marginal effects of LEVERAGE on the default probability of both large corporations and SMEs for different sectors computed using specification (2). Vertical lines represent average LEVERAGE values for large corporations (dash-dotted line) and SMEs (solid line). LEVERAGE is the ratio of total liabilities to total assets. Confidence intervals are reported at the $99 \%$ level.

(a) Production

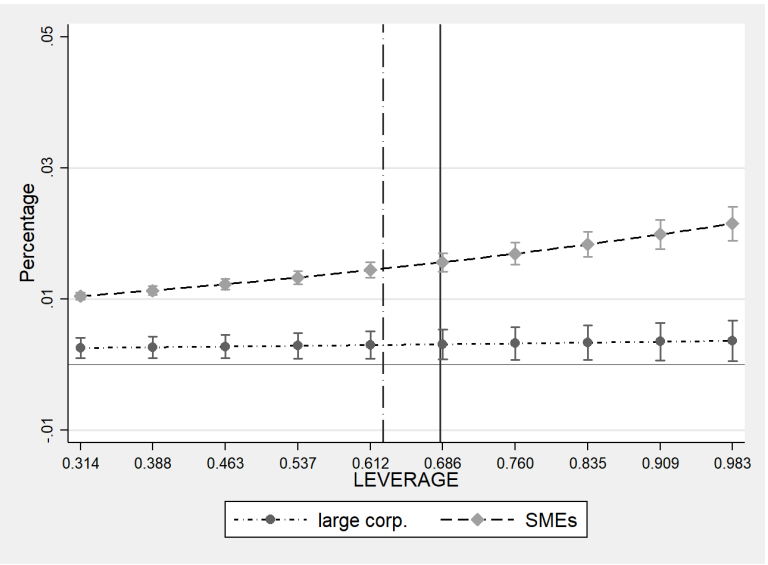

(c) Retail

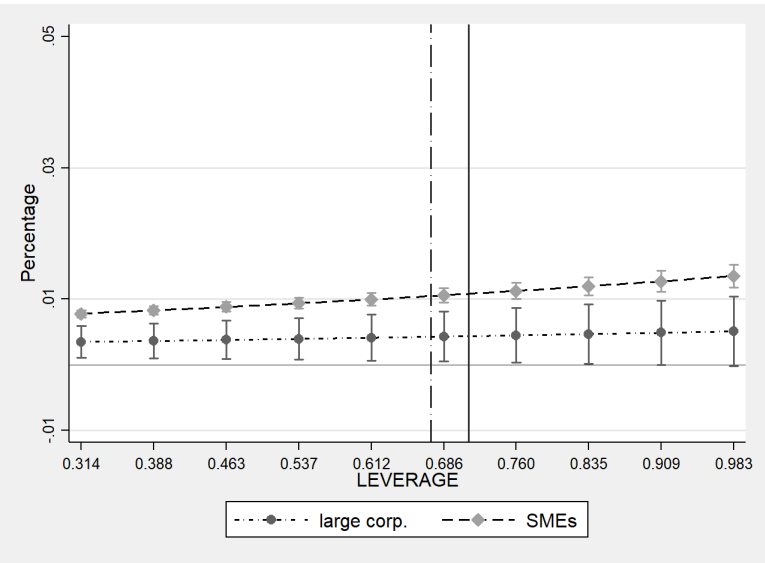

(b) Services

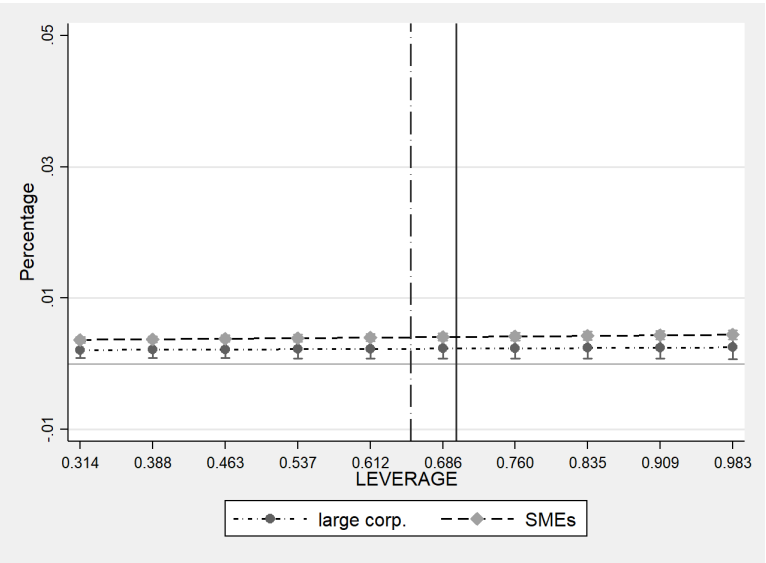

(d) Construction

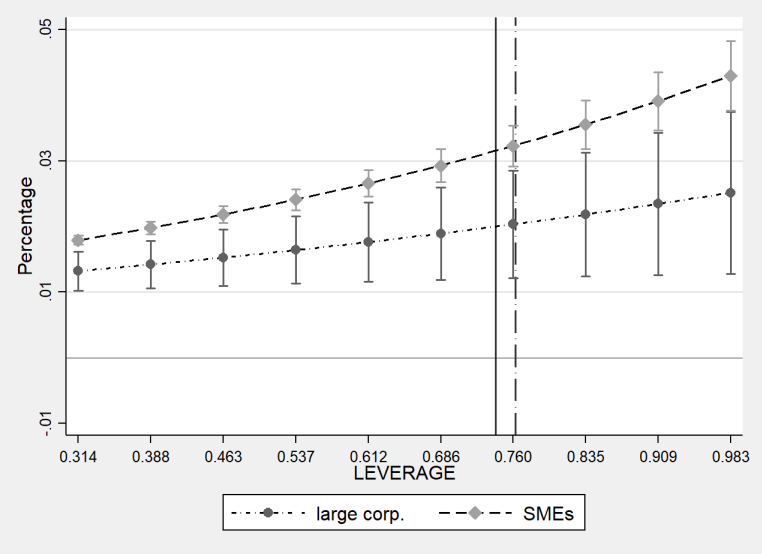

(e) Transportation

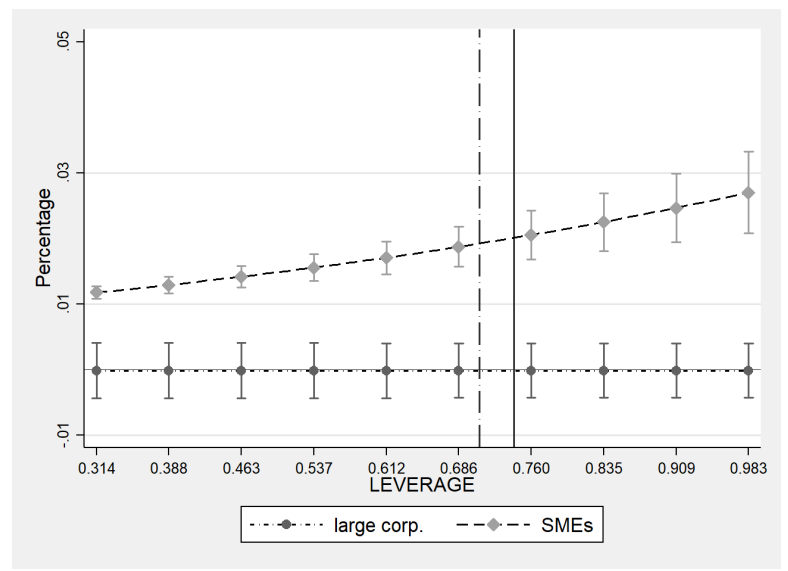


Figure 3: Marginal Effects of Leverage across Countries

This figure presents the marginal effects of LEVERAGE on the default probability of both large corporations and SMEs for different countries computed using specification (2). Vertical lines represent average LEVERAGE values for large corporations (dash-dotted line) and SMEs (solid line). LEVERAGE is the ratio of total liabilities to total assets. Confidence intervals are reported at the $99 \%$ level.

(a) Belgium

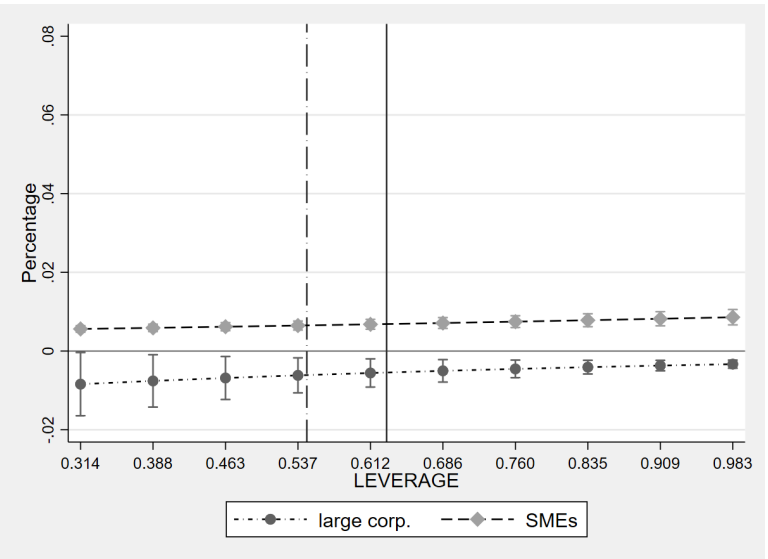

(c) France

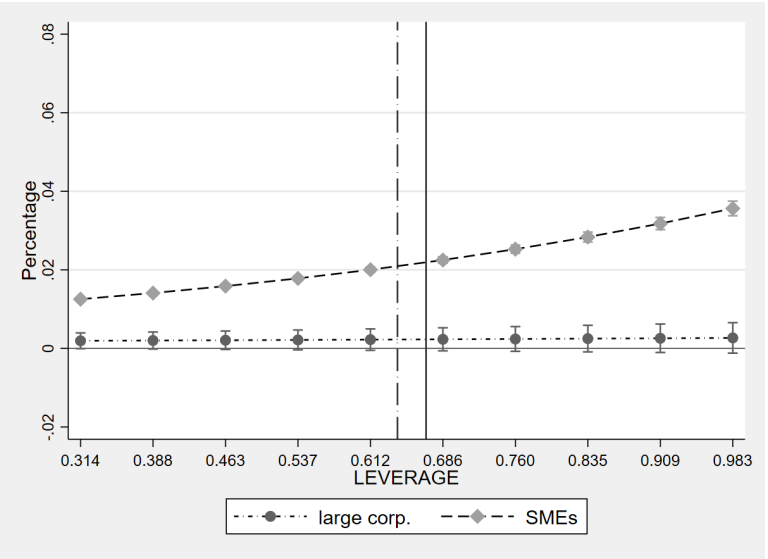

(e) Italy

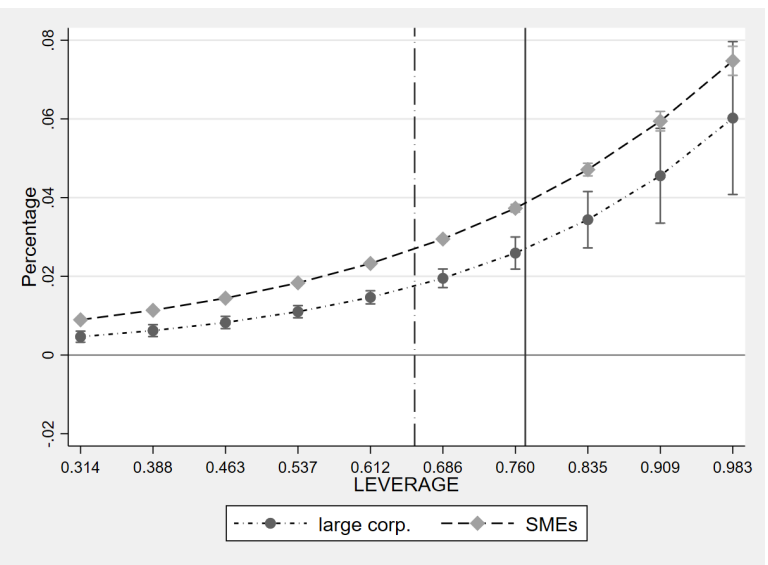

(b) Spain

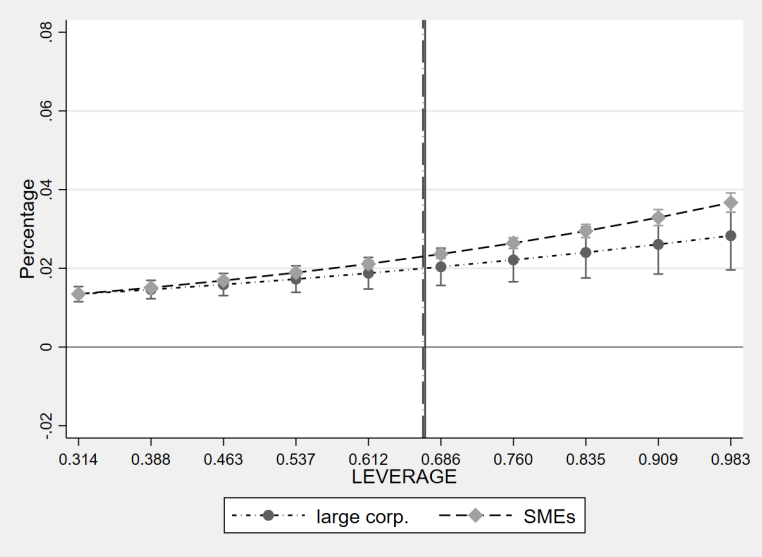

(d) United Kingdom

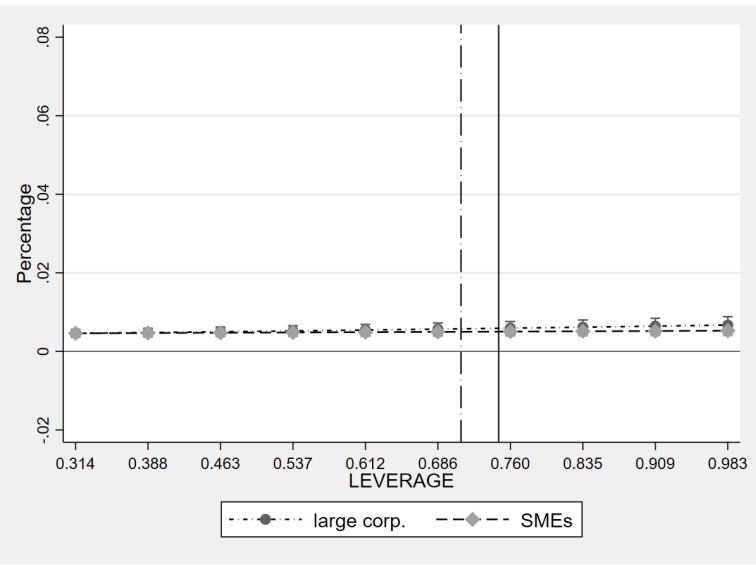

(f) Portugal

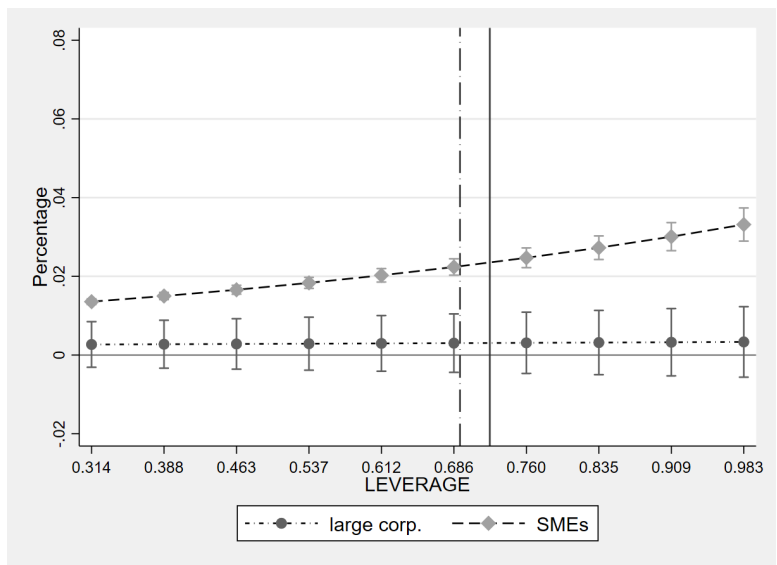


Figure 4: Marginal Effects of Leverage over Time

This figure presents the marginal effects of LEVERAGE on the default probability of both large corporations and SMEs for three different time periods computed using specification (2). Vertical lines represent average LEVERAGE values for large corporations (dash-dotted line) and SMEs (solid line). LEVERAGE is the ratio of total liabilities to total assets. Confidence intervals are reported at the $99 \%$ level.

(a) $2005-2006$

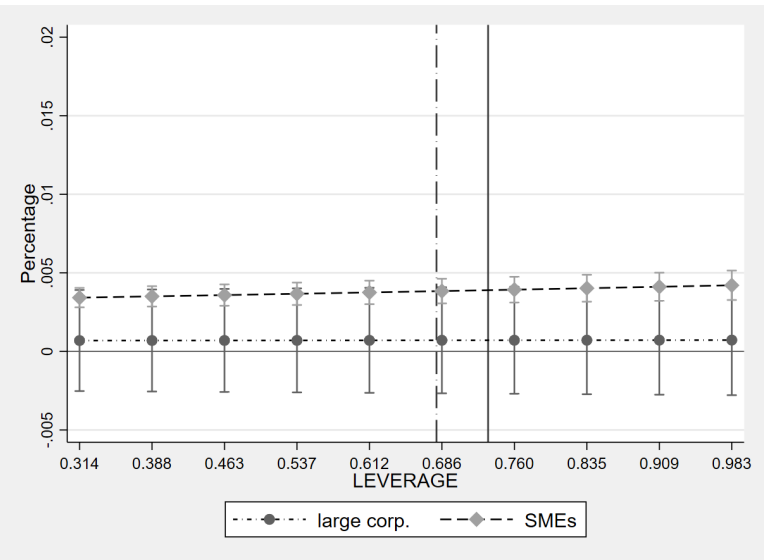

(b) 2007-2009

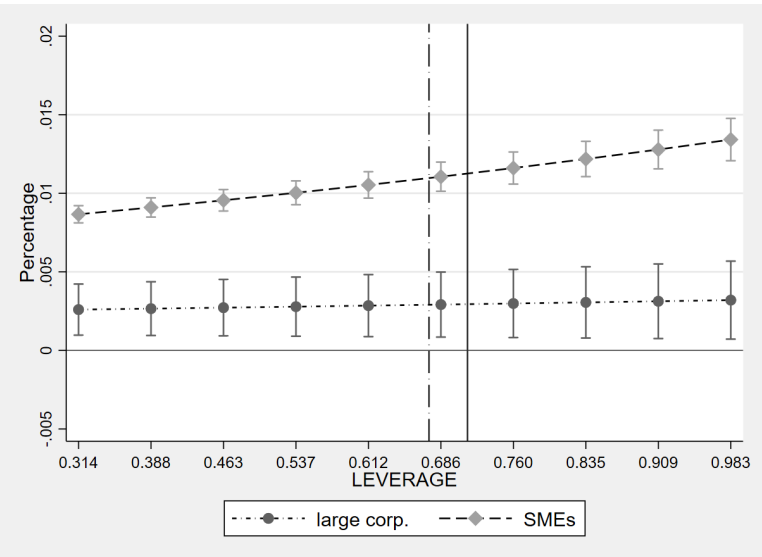

(c) $2010-2014$

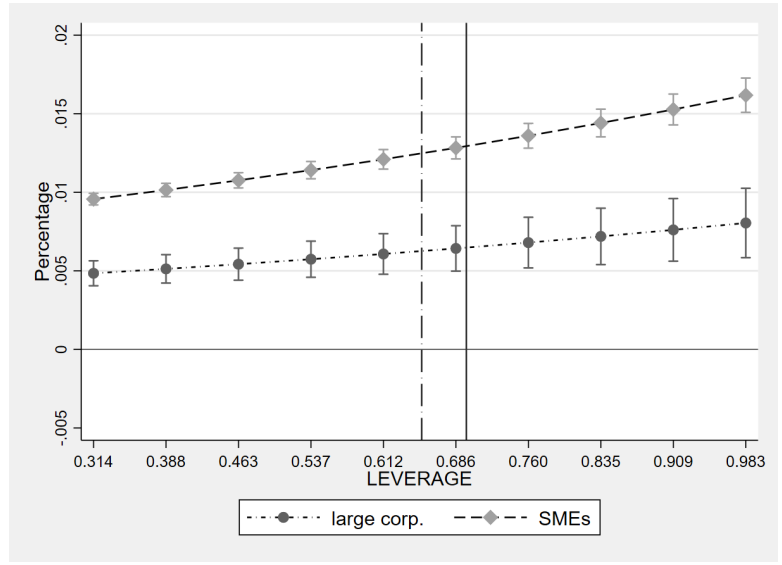




\section{Appendices}

\section{A Trade Credit and Default Risk}

In this appendix, we seek to reconcile our finding of a positive relationship between trade credit and default risk with the findings of McGuinness et al. (2018), who reach the opposite conclusion and suggest that trade credit is negatively related to default risk. We conclude that the result in McGuinness et al. (2018) may follow because they indirectly identify bankruptcy through an "unconditional" Z-score rather than directly and in a model-free manner, as we do, by assigning a default status to companies when they are actually insolvent or bankrupt.

Although the Z-score has been proven to be an accurate default predictor (Altman, 1968, Altman et al., 1977, Altman, 2000 and Altman and Sabato, 2007), its ability to discriminate between active and defaulted companies may deteriorate with an unconditional version of the score, that is, when the weights of its risk factors and the score's default threshold have not been adjusted for country, industry, and time effects. Indeed, default risk is sensitive to all such effects (Nickell et al., 2000); these effects are implicitly accounted for in our model where observed insolvent and bankrupt firms are employed.

On the other hand, the Z-score in McGuinness et al. (2018) was estimated by Altman (1993) using a sample of U.S. private firms. As a result, that score may not be well calibrated for the sample of European firms from 2003 to 2012 analysed in McGuinness et al. (2018).

To test whether the switch in the sign of trade finance is due to the specification of the default prediction model, we use the same set of independent variables to predict both our default indicator derived with actual insolvency/bankruptcy observations and the 1993 Z-score-based default indicator in McGuinness et al. (2018). Table A.1 presents 
the results of our comparison. Trade credit exhibits opposite signs when the two default indicators (actual vs. estimated) are used and is highly statistically significant in both cases. Trade credit is positive when we employ actual insolvent and bankrupt firms to identify companies in distress, which confirms our main findings in Table 8. It is negative when the 1993 Altman Z-score is used. As robustness tests, we restrict the period of our original sample to 2005-2012 to match, as closely as possible, that in McGuinness et al. (2003-2012). Furthermore, we extend our country coverage by adding Finland, Germany, Greece, and Ireland, as in McGuinness et al. (2018), but excluding Hungary, Latvia, and Poland, for which data are either not available or of poor quality. For the added countries (Finland, Germany, Greece, and Ireland), we have incomplete firm status data. ${ }^{20}$ Our robustness tests confirm the switched sign for trade finance from positive to negative when the Z-score is used. Table A.2 further illustrates this sign switch. The table shows that the average ratio of trade credit to total assets falls (from $23.2 \%$ to 16.2\%) as firms enter the Z-score default area, that is, when the Z-score takes a value below 1.23. In contrast, average trade credit over total assets increases (from $21.3 \%$ to $27.4 \%$ ) when active firms become distressed.

The results can be explained by the poor discriminative power of an unconditional Z-score. Table A.3 shows that, although the proportion of insolvent companies in the distress area of the Z-score is higher than in the non-distress area, it is still rather small, at $5.05 \%$. Furthermore, the distress area of the Z-score can only capture $52.1 \%$ of the insolvent firms in our sample. This means that $47.9 \%$ of the insolvent firms are incorrectly classified as active by the Z-score.

\footnotetext{
${ }^{20}$ This is the reason we exclude those countries from our main analysis.
} 


\section{Table A.1: Trade Finance and Actual versus Estimated Default Indicators}

This table reports logit regressions using the sample in our paper and the SME definition in McGuinness et al. (2018). The sample has been restricted to include only firms for which all the dependent and independent variables in McGuinness et al.'s (2018) model 5 in their Table 6 are available. In columns (1) and (2) the sample period is 2005-2015, and the countries included are Belgium, Spain, France, Italy, Portugal, and the United Kingdom, as in our previous analysis. In columns (3) and (4), the sample period is restricted to 2005-2012. In columns (5) and (6), the sample period is restricted to 2005-2012, and we add Finland, Germany, Greece, and Ireland to the pool of countries. In columns (1), (3), and (5), the dependent variable takes a value of 0 if the firm is Active and a value of 1 if it is either Insolvent or Bankrupt, as in our previous analysis. In columns (2), (4), and (6), the dependent variable takes a value of 0 if the firm has a Z-score equal or above 1.23 and a value of 1 if the firm has a Z-score below 1.23 , as in McGuinness et al. (2018). Independent variables are lagged. Robust standard errors (in parentheses) are clustered at the firm level. ${ }^{* * *} \mathrm{p}<0.01 ;{ }^{* *} \mathrm{p}<0.05 ;{ }^{*} \mathrm{p}<0.1$.

\begin{tabular}{|c|c|c|c|c|c|c|}
\hline & (1) & $(2)$ & (3) & (4) & (5) & (6) \\
\hline & \multicolumn{2}{|c|}{$2005-2014$} & \multicolumn{2}{|c|}{$2005-2012$} & \multicolumn{2}{|c|}{ Additional Countries - 2005-2012 } \\
\hline & Actual Default & Estimated Default & Actual Default & Estimated Default & Actual Default & Estimated Default \\
\hline \multirow[t]{2}{*}{ TRADE } & $1.535^{* * *}$ & $-1.755^{* * *}$ & $1.507 * * *$ & $-1.865^{* * *}$ & $1.515^{* * *}$ & $-1.901^{* * *}$ \\
\hline & $(0.026)$ & $(0.018)$ & $(0.029)$ & $(0.019)$ & $(0.029)$ & $(0.019)$ \\
\hline \multirow[t]{2}{*}{ Ln(ASSETS) } & $-0.066^{* * *}$ & $0.460^{* * *}$ & $-0.078 * * *$ & $0.460^{* * *}$ & $-0.076^{* * *}$ & $0.464^{* * *}$ \\
\hline & $(0.005)$ & $(0.003)$ & $(0.005)$ & $(0.003)$ & $(0.005)$ & $(0.003)$ \\
\hline \multirow[t]{2}{*}{ SALES GROWTH } & $-0.311^{* * *}$ & $0.022^{* * *}$ & $-0.183^{* * *}$ & $0.030^{* * *}$ & $-0.179 * * *$ & $0.032^{* * *}$ \\
\hline & $(0.027)$ & $(0.001)$ & $(0.019)$ & $(0.002)$ & $(0.018)$ & $(0.002)$ \\
\hline \multirow[t]{2}{*}{ CASH } & $-3.796^{* * *}$ & $-7.174^{* * *}$ & $-4.240 * * *$ & $-6.831^{* * *}$ & $-4.200 * * *$ & $-6.766^{* * *}$ \\
\hline & $(0.064)$ & $(0.046)$ & $(0.076)$ & $(0.047)$ & $(0.075)$ & $(0.046)$ \\
\hline \multirow[t]{2}{*}{ AGE } & $-0.041^{* * *}$ & $-0.032^{* * *}$ & $-0.045^{* * *}$ & $-0.035^{* * *}$ & $-0.040 * * *$ & $-0.033^{* * *}$ \\
\hline & $(0.001)$ & $(0.001)$ & $(0.001)$ & $(0.001)$ & $(0.001)$ & $(0.001)$ \\
\hline \multirow[t]{2}{*}{$\mathrm{AGE}^{2}$} & $0.001 * * *$ & $0.000 * * *$ & $0.001^{* * *}$ & $0.000^{* * *}$ & $0.000 * * *$ & $0.000 * * *$ \\
\hline & $(0.000)$ & $(0.000)$ & $(0.000)$ & $(0.000)$ & $(0.000)$ & $(0.000)$ \\
\hline \multirow[t]{2}{*}{ Lerner Index } & $7.634^{* * *}$ & $-4.719 * * *$ & $6.473^{* * *}$ & $-5.121 * * *$ & $6.124^{* * *}$ & $-3.177^{* * *}$ \\
\hline & $(0.834)$ & $(0.407)$ & $(0.891)$ & $(0.458)$ & $(0.876)$ & $(0.442)$ \\
\hline \multirow[t]{2}{*}{ Constant } & $-11.271^{* * *}$ & $1.401 * * *$ & $-9.957^{* * *}$ & $1.837 * * *$ & $-9.665^{* * *}$ & -0.102 \\
\hline & $(0.814)$ & $(0.398)$ & $(0.868)$ & $(0.448)$ & $(0.853)$ & $(0.434)$ \\
\hline Observations & $2,520,133$ & $2,520,133$ & $1,842,015$ & $1,842,015$ & $1,931,011$ & $1,931,011$ \\
\hline Country FE & Yes & Yes & Yes & Yes & Yes & Yes \\
\hline Industry FE & Yes & Yes & Yes & Yes & Yes & Yes \\
\hline Year FE & Yes & Yes & Yes & Yes & Yes & Yes \\
\hline Clusters & 573,834 & 573,834 & 520,805 & 520,805 & 549,719 & 549,719 \\
\hline Pseudo- $R^{2}$ & 0.0464 & 0.214 & 0.0507 & 0.215 & 0.0525 & 0.216 \\
\hline
\end{tabular}


Table A.2: Average Trade Credit for Active and Defaulted Firms: Actual versus Estimated

This table reports the average value of trade credit over total assets (TRADE) for active and defaulted firms, when firm status (default/active) is observed and when it is estimated using a Z-score as in McGuinness et al. (2018). The sample period is 2005-2014, and the countries included are Belgium, Spain, France, Italy, Portugal, and the United Kingdom.

\begin{tabular}{ccc}
\hline \hline & $\begin{array}{c}\text { Estimated active firms } \\
\text { Z-score } \geq 1.23\end{array}$ & $\begin{array}{c}\text { Estimated defaulted firms } \\
\text { Z-score }<1.23\end{array}$ \\
\hline TRADE (\%) & 23.2 & 16.2 \\
\hline & Active firms - actual & Defaulted firms - actual \\
\hline TRADE (\%) & 21.3 & 27.4 \\
\hline \hline
\end{tabular}


Table A.3: The "Unconditional" Z-Score's Discriminant Ability

This table describes the ability of the "unconditional" Z-score used in McGuinness et al. (2018) to discriminate between active and defaulted companies. The sample period is 2005-2015, and the countries included are Belgium, Spain, France, Italy, Portugal, and the United Kingdom.

$a=\frac{\text { Defaulted }}{\text { Total Estimated Active or Defaulted Firms }} ; b=\frac{\text { Defaulted }}{\text { Total Defaulted }}$

\begin{tabular}{lcc}
\hline \hline & $\begin{array}{c}\text { Estimated active firms } \\
\text { Z-score } \geq 1.23\end{array}$ & $\begin{array}{c}\text { Estimated defaulted firms } \\
\text { Z-score }<1.23\end{array}$ \\
\hline Active (actual) & $1,879,688$ & 581,213 \\
Defaulted (actual) & 28,349 & 30,883 \\
$a(\%)$ & 1.49 & 5.05 \\
$b(\%)$ & 47.86 & 52.14 \\
\hline \hline
\end{tabular}




\section{B Additional Tables}

Table B.1: Definition of Status Field

This table reports definitions of Orbis's "status" field. We define firm-year observations as Active if the "status" is "Active"; as Insolvent if the "status" is "Active default of payment", "Active rescue plan", or "Active insolvency proceedings"; and as Bankrupt if the "status" is "Bankruptcy", "In liquidation" or "Dissolved".

\begin{tabular}{ll}
\hline \hline Orbis Definition of Status & Description \\
\hline Active & The company has not defaulted. \\
Active default of payment & The company has defaulted, but it is still a going concern. \\
Active rescue plan & The company is active and has not defaulted but sought \\
& protection from its creditors to have time to reorganise. \\
& There are no formal insolvency proceedings. Typical in \\
& France ("Procedure de sauvegarde"). \\
Active insolvency proceedings & The company is insolvent but is still active. Similar to \\
& Chapter 11 in the United States. \\
Bankruptcy & The company is declared bankrupt. \\
In liquidation & The company is under liquidation, not necessarily because \\
& of bankruptcy. A company may be liquidated because of \\
& voluntary dissolution, for instance. \\
Dissolved & The company has been liquidated and no longer exists as \\
& a legal entity. \\
\hline \hline
\end{tabular}




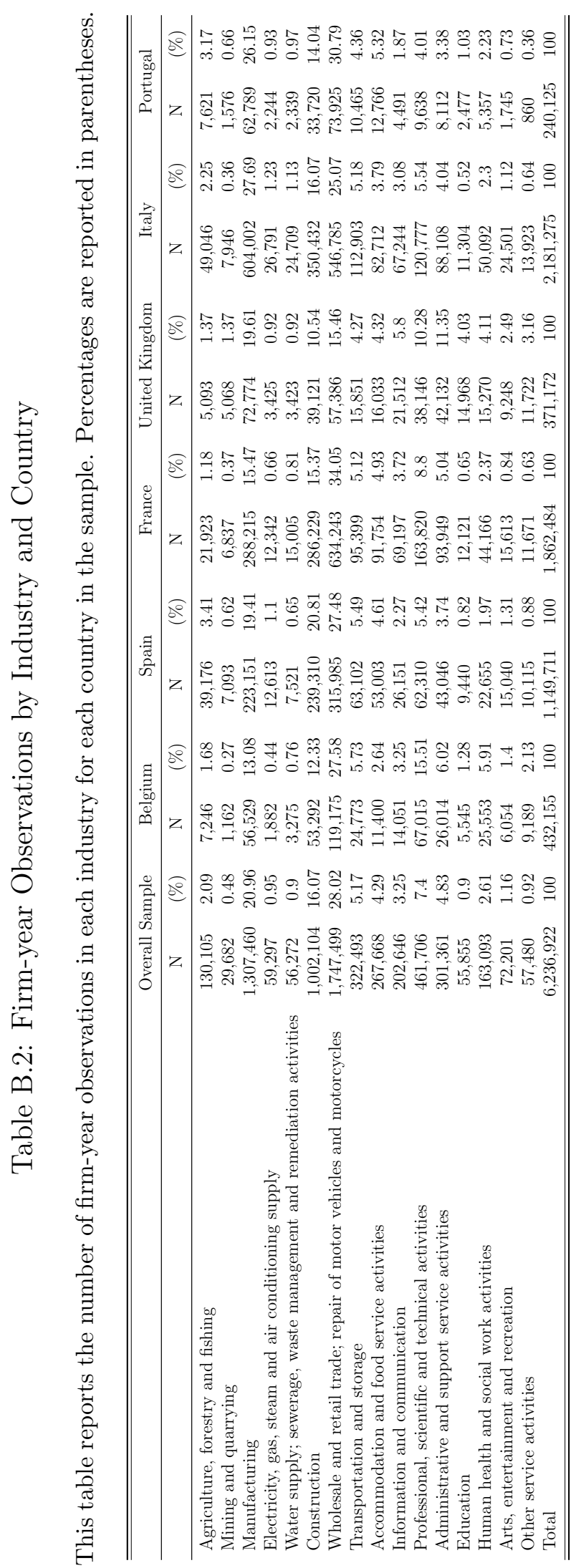




\section{Table B.3: Default Probability: Effect of Current Assets}

This table reports the estimated coefficients of logit regressions and their robust standard errors clustered at the firm level (in parentheses). The bottom of the table reports the number of observations, number of clusters (i.e., firms), McFadden's $R^{2}$, and the percentage of correctly classified observations. The dependent variable takes a value of 0 if the firm is Active and a value of 1 if it is either Insolvent or Bankrupt. GDP is the 1-year GDP growth rate; GOVBOND is the 3-month government bond interest rate; SOVCDS is the logarithm of the CDS price of government bonds; NITA is the ratio of net income to total assets; STOCKTA is the ratio of inventories to total assets; DEBTORSTA is the ratio of trade receivable to total assets; CASHTA is the ratio of cash and cash equivalent to total assets; OTHERCATA is the ratio of all current assets not included in STOCKTA, DEBTORSTA, and CASHTA to total assets; AGE is the number of days since incorporation divided by 365; SME is a dummy variable that takes a value of 1 if a firm's total assets are worth no more than $€ 43$ million; and LEVERAGE is the ratio of total liabilities to total assets. Independent variables are lagged. The sample period ranges from 2005 to 2015 . *** $\mathrm{p}<0.01 ;{ }^{* *} \mathrm{p}<0.05$; $^{*} \mathrm{p}<0.1$.

\begin{tabular}{lc}
\hline \hline Specification & $(1)$ \\
\hline \hline LEVERAGE & $0.606^{* * *}$ \\
& $(0.016)$ \\
SME & $0.445^{* * *}$ \\
& $(0.022)$ \\
GDP & $-0.020^{* * *}$ \\
& $(0.001)$ \\
GOVBOND & $0.062^{* * *}$ \\
& $(0.002)$ \\
SOVCDS & $0.120^{* * *}$ \\
& $(0.003)$ \\
NITA & $-4.392^{* * *}$ \\
& $(0.028)$ \\
STOCKTA & $0.522^{* * *}$ \\
& $(0.017)$ \\
DEBTORSTA & $1.239^{* * *}$ \\
& $(0.019)$ \\
CASHTA & $-1.984^{* * *}$ \\
& $(0.041)$ \\
OTHERCATA & $0.924^{* * *}$ \\
& $(0.016)$ \\
AGE & $-0.013^{* * *}$ \\
& $(0.000)$ \\
Constant & $-5.871^{* * *}$ \\
& $(0.044)$ \\
\hline Observations & $6,044,014$ \\
Country FE & Yes \\
Industry FE & Yes \\
Clusters & 929,785 \\
Pseudo- $R^{2}$ & 0.101 \\
\hline \hline &
\end{tabular}




\section{Marginal Effects}

We calculate the marginal effects of LEVERAGE, TRADE, CURRENT, and NONCURRENT on the probabilities of default across different levels of the independent variables as our estimated logistic function is non-linear in nature. In addition, we cannot directly interpret the sign, magnitude, and statistical significance of coefficients of terms interacted with dummy variables (Ai and Norton, 2003).

Marginal effects in specifications (1) and (3) of Table 8, where there is no interaction term with the SME dummy are:

$$
\frac{\partial P_{t}\left(y_{i, c, j, t+1}=1\right)}{\partial x}=\beta_{x} \Phi^{\prime}\left(\alpha+\boldsymbol{X}_{\boldsymbol{i}, \boldsymbol{t}} \boldsymbol{\beta}+\boldsymbol{Z}_{\boldsymbol{i}, \boldsymbol{c}, \boldsymbol{t}} \boldsymbol{\delta}+\gamma_{c}+\gamma_{j}\right)
$$

Marginal effects in specifications (3) and (4), where variables of interest interact with the SME dummy are:

$$
\frac{\partial P_{t}\left(y_{i, c, j, t+1}=1\right)}{\partial x}=\left(\beta_{x}+\beta_{x \cdot S M E} S M E\right) \Phi^{\prime}\left(\alpha+\boldsymbol{X}_{i, t} \boldsymbol{\beta}+\boldsymbol{Z}_{i, c, t} \boldsymbol{\delta}+\gamma_{c}+\gamma_{j}\right)
$$

where $x$ is the variable of interest (LEVERAGE, TRADE, CURRENT, or NONCURRENT). In non-linear models, independent variables affect marginal effects of the variable of interest. We choose to evaluate marginal effects at the mean values of the two subgroups (SMEs and large corporations). 


\section{Basel III Formula}

In this appendix, we report the Basel III capital requirement calculations that we employ in Sections V.a and V.b.

$$
\begin{gathered}
R=0.12 \frac{\left(1-e^{-50 P D}\right)}{\left(1-e^{-50}\right)}+0.24 \frac{\left[1-\left(1-e^{-50 P D}\right)\right]}{\left(1-e^{-50}\right)} \\
b=(0.11852-0.05478 \ln (P D))^{2} \\
M A=\frac{1+(M-2.5) b}{1-1.5 b} \\
K=\left[L G D \cdot N\left[\left(\frac{1}{1-R}\right)^{0.5} G(P D)+\left(\frac{R}{1-R}\right)^{0.5} G(0.999)\right]-P D \cdot L G D\right] M A \\
K=12.5 \cdot K \cdot 1.06 \cdot E A D,
\end{gathered}
$$

where $R$ stands for correlation; $P D$ is the probability of default; $b$ is a calibrated parameter; $M A$ is the maturity adjustment; $M$ is the "effective" maturity of the loan estimated as its Macaulay duration with the discount rate set to $0 ; K$ is the capital requirement; $L G D$ is the loss given default; and $E A D$ is the exposure at default. $N$ is the normal cumulative function, and $G$ is its inverse. 


\section{E Robustness Tests}

Figure E.1: Marginal Effects of Leverage, Excluding Low Leverage Firms

This figure presents the marginal effects of LEVERAGE on the default probability of both large corporations and SMEs computed using specification (2). We exclude observations in the bottom $10 \%$ of the LEVERAGE distribution. Vertical lines represent average LEVERAGE values for large corporations (dash-dotted line) and SMEs (solid line). LEVERAGE is the ratio of total liabilities to total assets. Confidence intervals are reported at the $99 \%$ level.

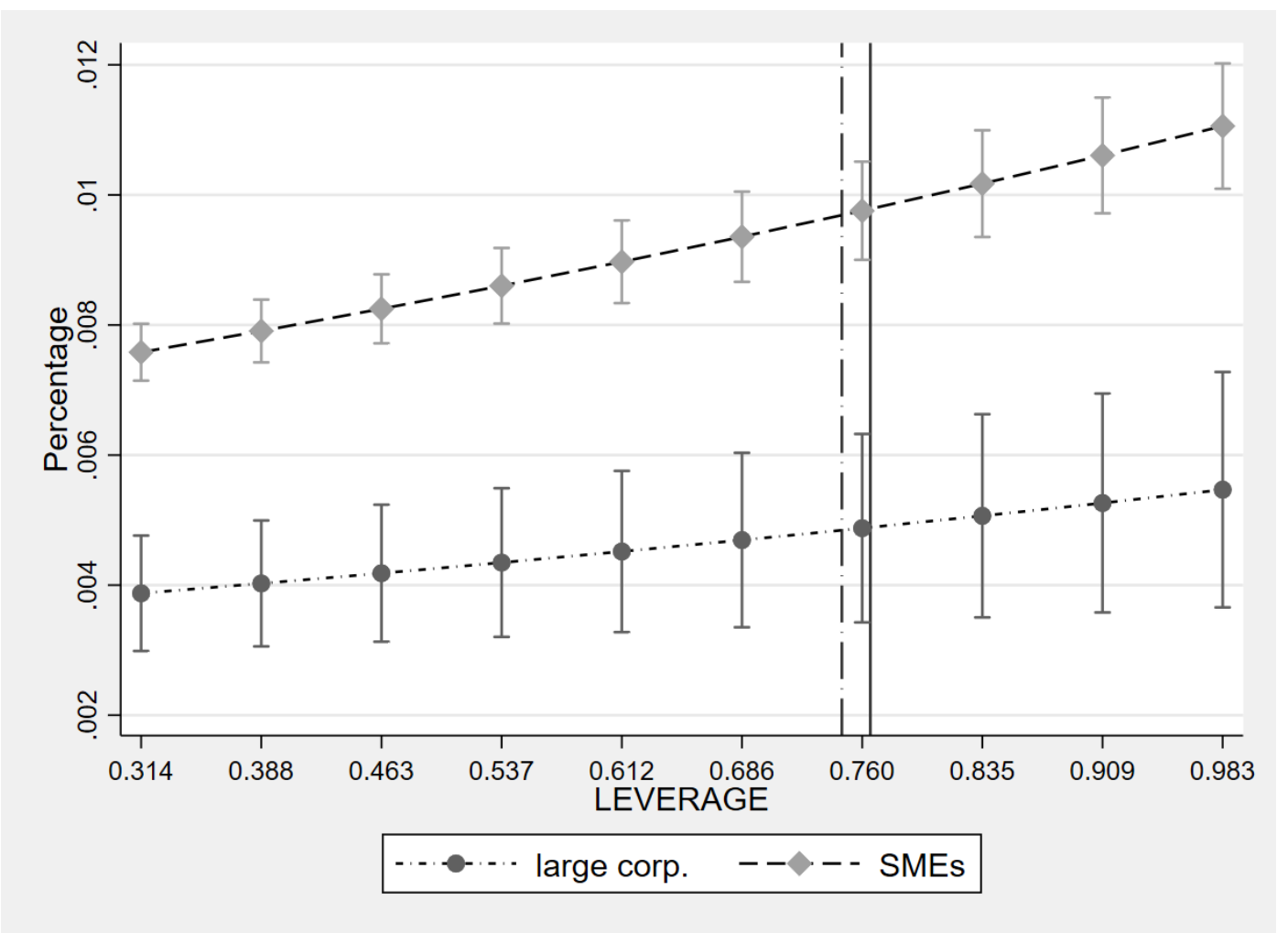


Figure E.2: Marginal Effects of Leverage with a Quadratic Term

This figure presents the marginal effects of LEVERAGE on the default probability of both large corporations and SMEs computed using specification (2). We include a LEVERAGE quadratic term and a LEVERAGE quadratic term interacted with the SMEs dummy. Vertical lines represent average LEVERAGE values for large corporations (dash-dotted line) and SMEs (solid line). LEVERAGE is the ratio of total liabilities to total assets. Confidence intervals are reported at the $99 \%$ level.

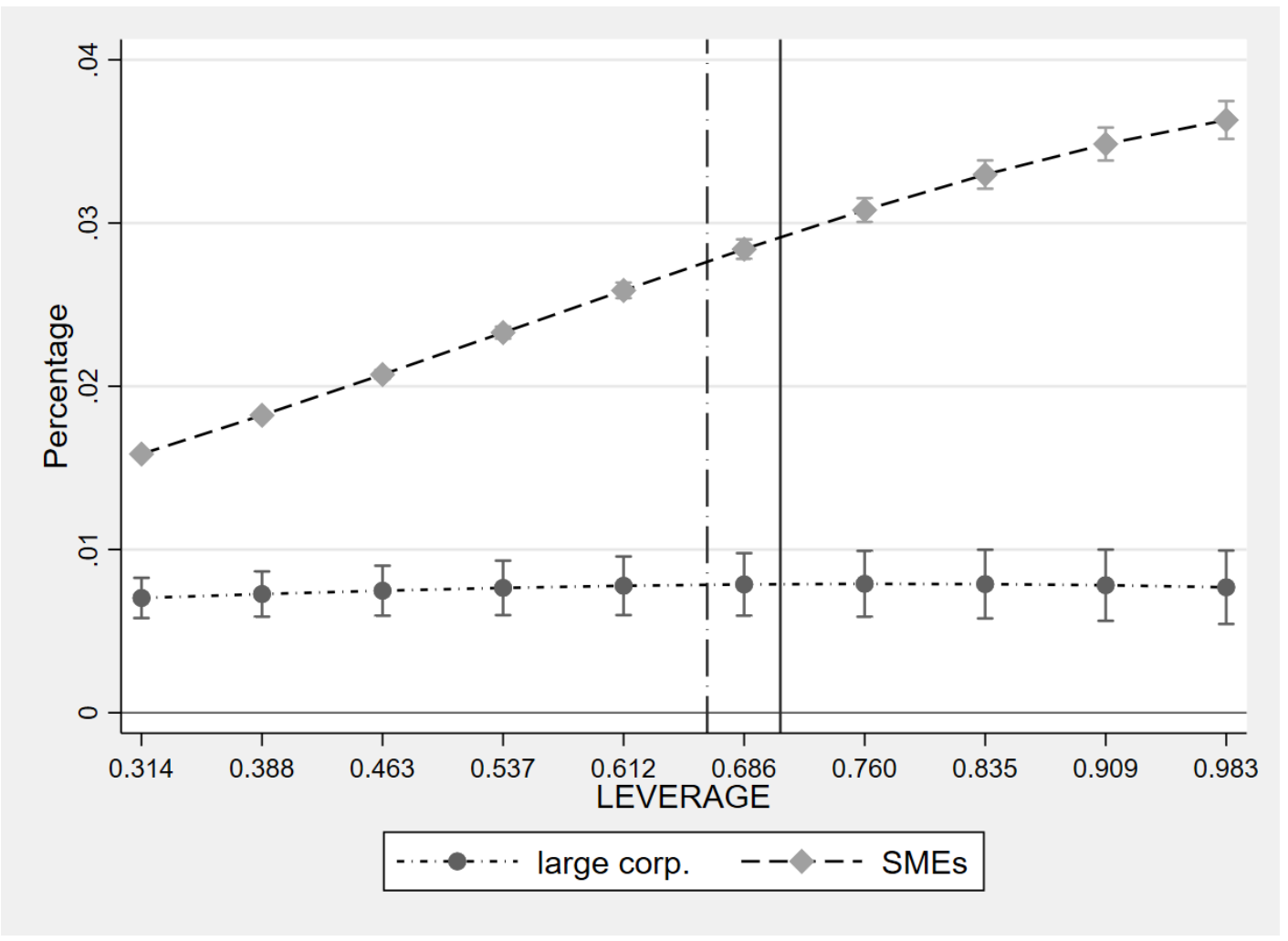


Figure E.3: Marginal Effects of Leverage with an Ordered Logit Model

This figure presents the marginal effects of LEVERAGE on the default probability of large corporations and SMEs computed using specification (2). We use an ordered logit model, which distinguishes between Active, Insolvent, and Bankrupt observations. Vertical lines represent the average LEVERAGE values for large corporations (dash-dotted line) and SMEs (solid line). LEVERAGE is the ratio of total liabilities to total assets. Confidence intervals are reported at the $99 \%$ level.

(a) Large Corporations

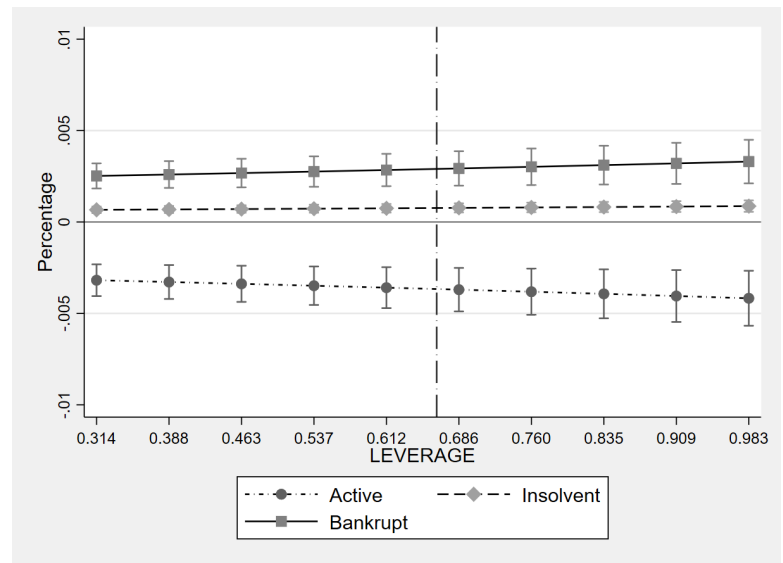

(b) SMEs

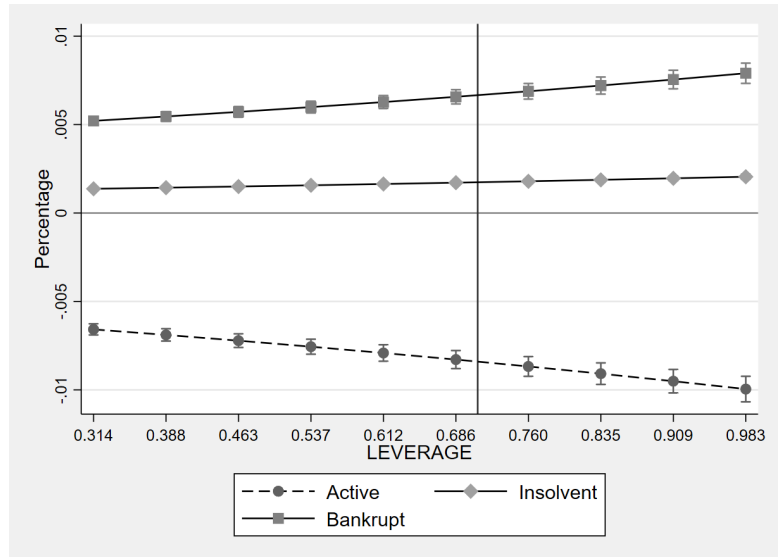


Figure E.4: Marginal Effects of Leverage Using the European Commission's SME Definition

This figure presents the marginal effects of LEVERAGE on the default probability of large corporations and SMEs computed using specification (2). SMEs are defined according to the European Commission's definition. LEVERAGE is the ratio of total liabilities to total assets. Vertical lines represent average LEVERAGE values for large corporations (dash-dotted line) and SMEs (solid line). Confidence intervals are reported at the $99 \%$ level.

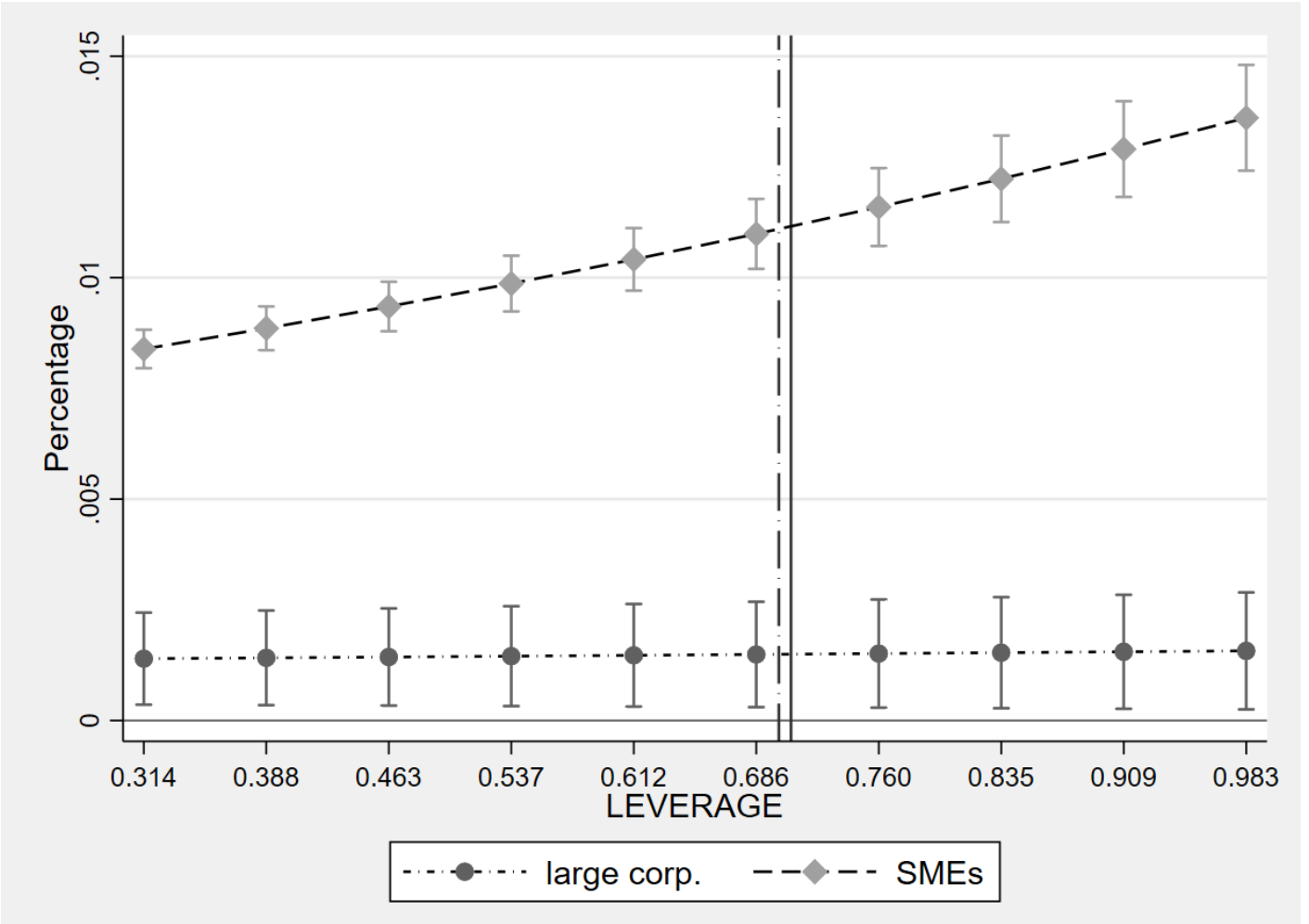


Figure E.5: Marginal Effects of Leverage, Excluding Italy

This figure presents the marginal effects of LEVERAGE on the default probability of large corporations and SMEs computed using specification (2). Observations from Italy are excluded. LEVERAGE is the ratio of total liabilities to total assets. Vertical lines represent average LEVERAGE values for large corporations (dash-dotted line) and SMEs (solid line). Confidence intervals are reported at the $99 \%$ level.

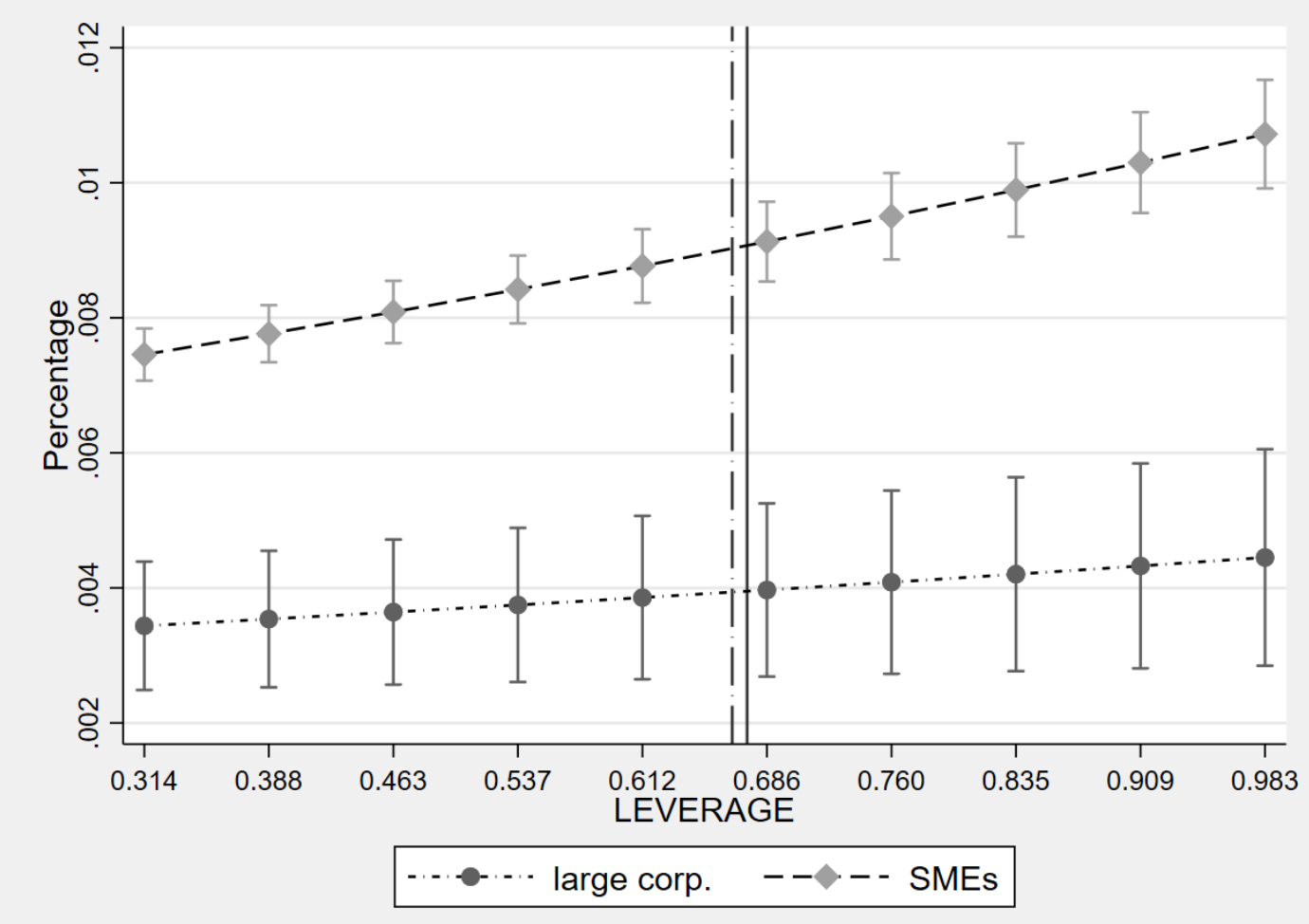


Figure E.6: Marginal Effects of Leverage, Excluding the Retail Sector

This figure presents the marginal effects of LEVERAGE on the default probability of large corporations and SMEs computed using specification (2). Observations from the retail sector are excluded. LEVERAGE is the ratio of total liabilities to total assets. Vertical lines represent average LEVERAGE values for large corporations (dash-dotted line) and SMEs (solid line). Confidence intervals are reported at the $99 \%$ level.

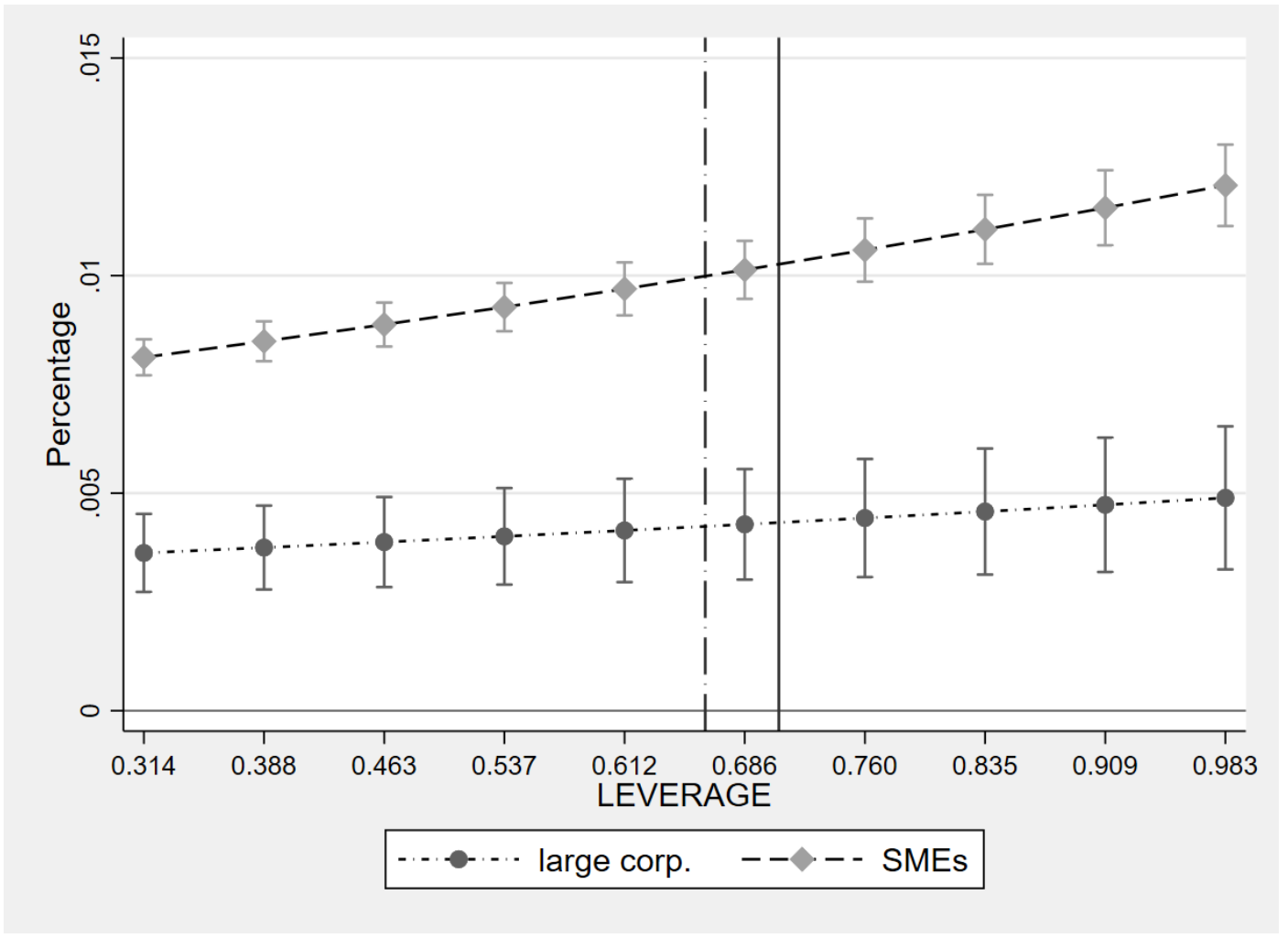


Figure E.7: Marginal Effects of Leverage along Firm Dimensions

This figure presents the marginal effects of LEVERAGE on the default probability of large corporations medium, and small firms computed using specification (2). LEVERAGE is the ratio of total liabilities to total assets. Vertical lines represent average LEVERAGE values for large corporations (dash-dotted line), medium firms (solid line), and SMEs (dotted line). Confidence intervals are reported at the 99\% level.

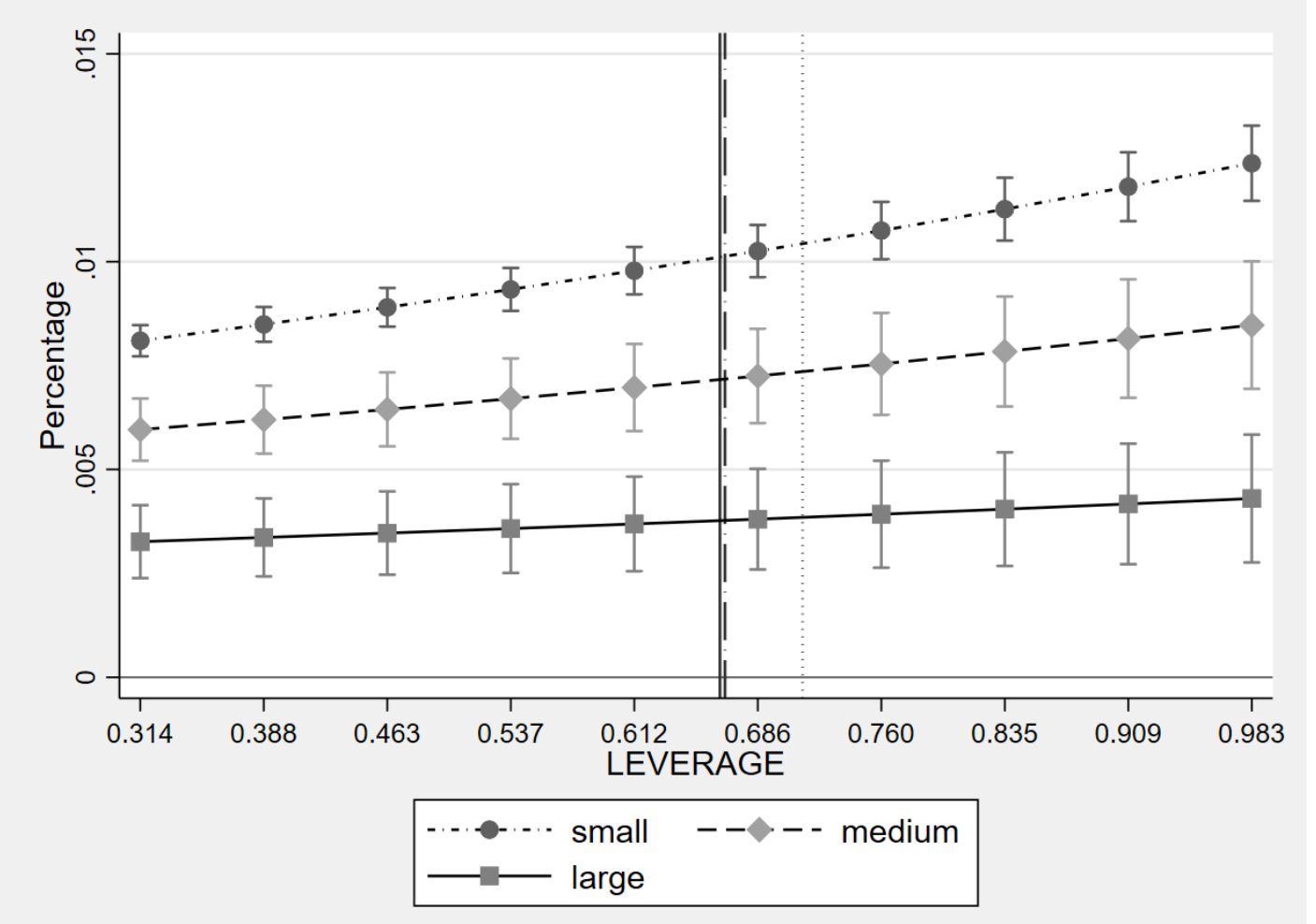


Figure E.8: Marginal Effects of Leverage and Time Fixed Effects

This figure presents the marginal effects of LEVERAGE on default probability with specification (2) and time fixed effects. LEVERAGE is the ratio of total liabilities to total assets. Vertical lines represent average LEVERAGE values for large corporations (dash-dotted line) and SMEs (solid line). Confidence intervals are reported at the $99 \%$ level.

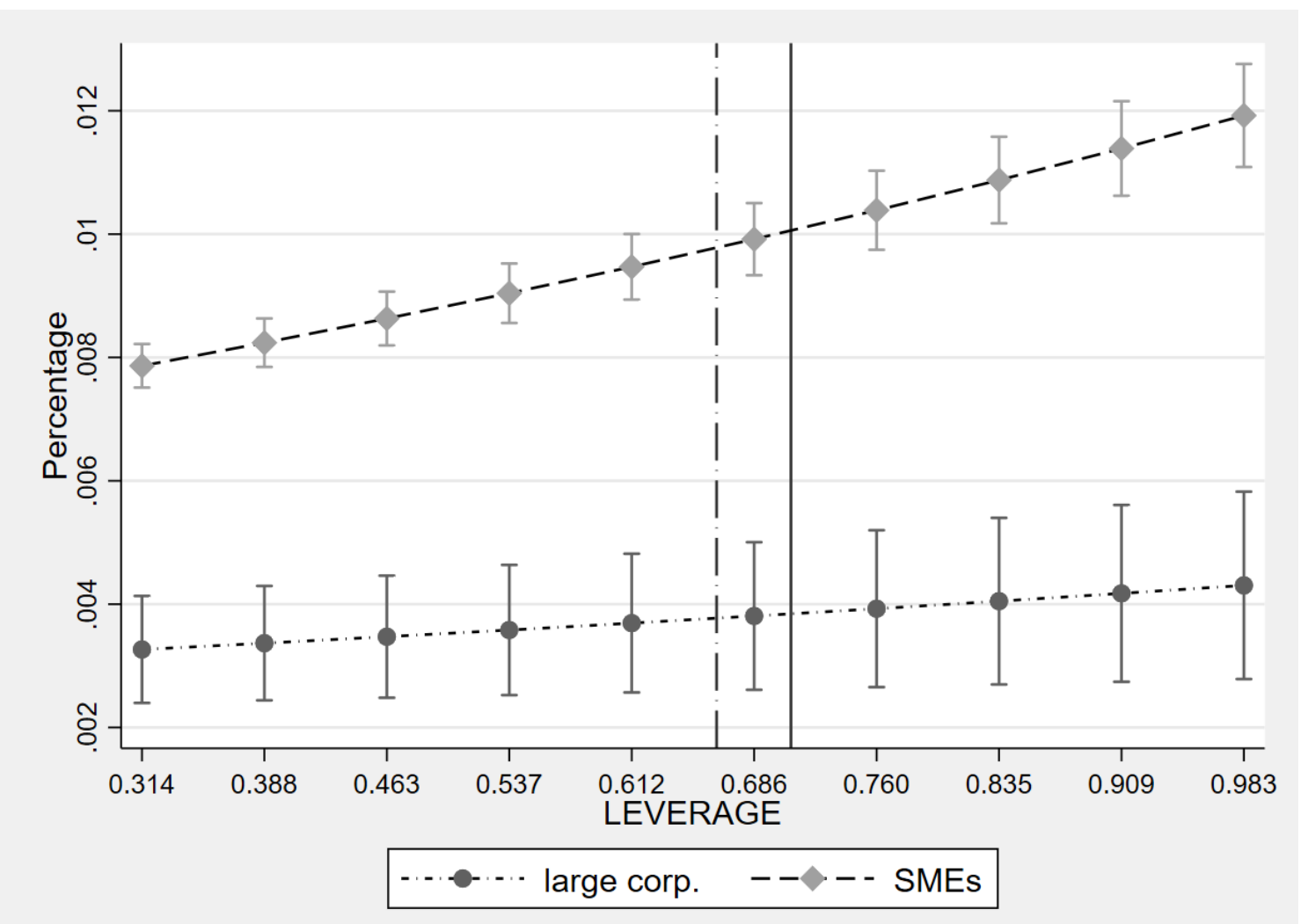




\section{Figure E.9: Additional Robustness}

This figure presents the marginal effects of LEVERAGE on the default probability of large corporations and SMEs computed using specification (2) of Equation 1, with control variables and their interaction with LEVERAGE added one at a time. Predicted probabilities are sorted according to different quartiles of LEVERAGE. LEVERAGE is the ratio of total liabilities to total assets; Small Business Act (SBA) is a dummy variable that identifies country-years where the number of SBA-related interventions is above the median number of interventions across all country-years in the sample; Partnerships/Sole Traders is a dummy variable that takes a value of 1 if a firm is not a partnerships or a sole trader; Financial Constraints is a dummy variable that takes a value of 1 if a firm has a probability of being financially constrained above the sample median probability; Net Income Growth is a dummy variable that takes a value of 1 if a firm's net income growth is above the sample's median net income growth; Asset Growth is a dummy variable that takes a value of 1 if a firm has an asset growth above the sample median asset growth; Secured Creditors and Absolute Priority is a dummy variable that takes a value of 1 if the legislation of the country mandates secured creditors to be paid first in case of default and Creditors' Restrictions on Reorganisation is a dummy variable that takes a value of 1 if the legislation of the country allows creditors to restrict reorganisation in cases of default. Vertical lines represent average LEVERAGE values for large corporations (dash-dotted lines) and SMEs (solid lines). Confidence intervals are reported at the $99 \%$ level.

(a) Small Business Act

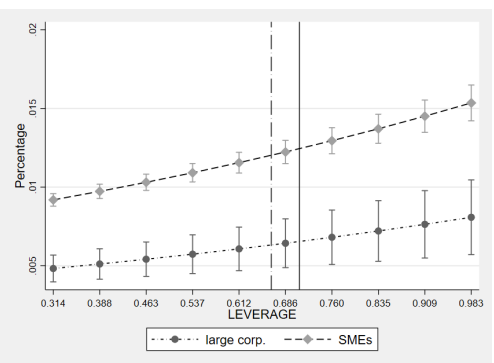

(d) Net Income Growth

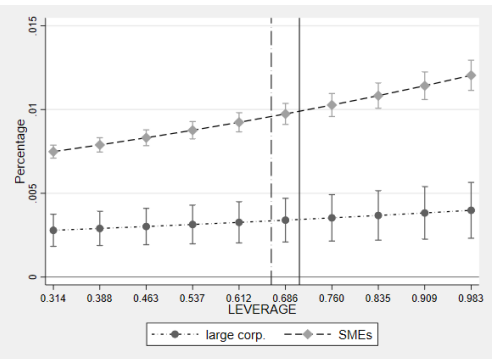

(b) Partnerships/Sole Traders

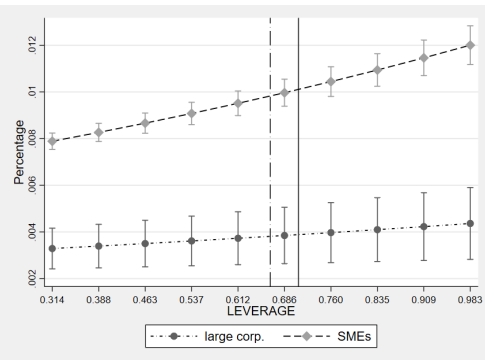

(e) Asset Growth

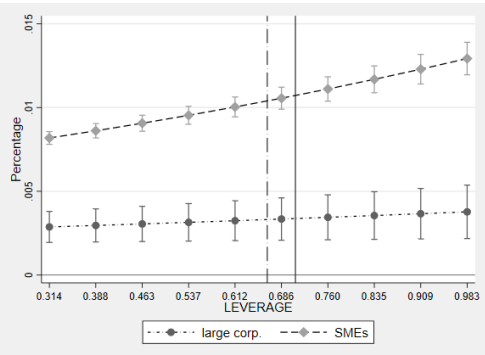

(g) Reorganization Restrictions

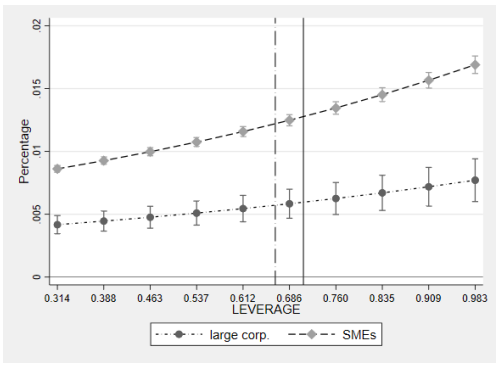

(c) Financial Constraints

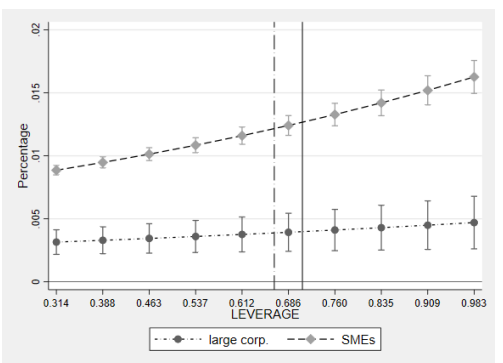

(f) Secured Creditor

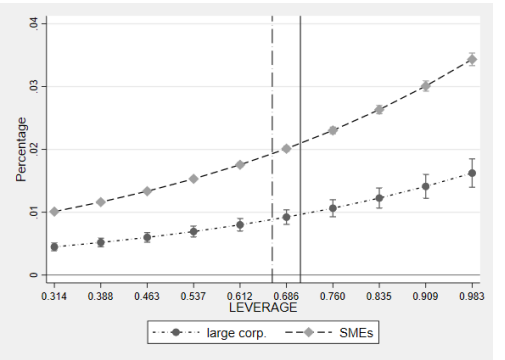




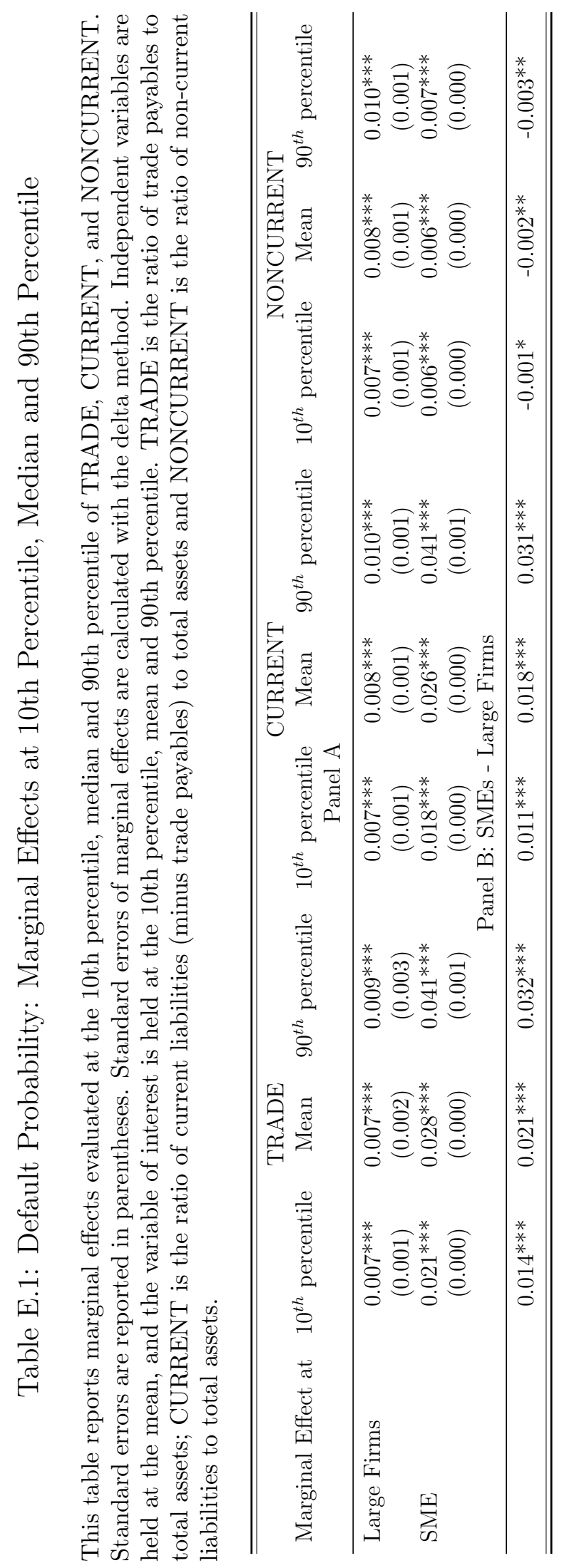


Table E.2: Additional Robustness: Predicted Default Probabilities

This table reports average predicted probabilities of default expressed as a percentage computed with specification (2) of Equation 1, adding control variables and their interaction with LEVERAGE one at a time. Predicted probabilities are sorted for different quartiles of LEVERAGE. LEVERAGE is the ratio of total liabilities to total assets; Small Business Act (SBA) is a dummy variable that we use to identify country-years in which the number of SBA-related interventions is above the median number of interventions across all country-years in the sample; Partnerships/Sole Traders is a dummy variable that takes a value of 1 if a firm is not a partnership or a sole trader; Financial Constraints is a dummy variable that takes a value of 1 if a firm has a probability of being financially constrained above the sample median probability; Net Income Growth is a dummy variable that takes a value of 1 if a firm's net income growth is above the sample median's net income growth; Assets Growth is a dummy variable that takes a value of 1 if a firm's asset growth is above the sample median's asset growth; Secured Creditors and Absolute Priority is a dummy variable that takes a value of 1 if the legislation of the country mandates that secured creditors to be paid first in case of default; and Creditors' Restrictions on Reorganisation is a dummy variable that takes a value of 1 if the legislation of the country allows creditors to restrict reorganisation in cases of default. ${ }^{* * *} \mathrm{p}<0.01 ; * * \mathrm{p}<0.05 ; * \mathrm{p}<0.1$.

\begin{tabular}{lccccc}
\hline \hline & First Quartile & Second Quartile & Third Quartile & Fourth Quartile & $\Delta_{\text {Fourth-First }}$ \\
\hline \multicolumn{5}{c}{ Panel A: Small Business Act (SBA) Interventions } \\
\hline \multicolumn{5}{c}{ Low Number of SBA Interventions } \\
\hline All Sample & $1.118^{* * *}$ & $1.523^{* * *}$ & $1.993^{* * *}$ & $4.154^{* * *}$ & $3.036^{* * *}$ \\
Large Firms & $0.593^{* * *}$ & $0.804^{* * *}$ & $1.133^{* * *}$ & $2.042^{* * *}$ & $1.449^{* * *}$ \\
SMEs & $1.144^{* * *}$ & $1.551^{* * *}$ & $2.022^{* * *}$ & $4.235^{* * *}$ & $3.092^{* * *}$ \\
\hline \multicolumn{5}{c}{ High Number of SBA Interventions } \\
\hline All Sample & $0.892^{* * *}$ & $1.343^{* * *}$ & $1.912^{* * *}$ & $3.922^{* * *}$ & $3.030^{* * *}$ \\
Large Firms & $0.494^{* * *}$ & $0.718^{* * *}$ & $1.060^{* * *}$ & $1.860^{* * *}$ & $1.366^{* * *}$ \\
SMEs & $0.915^{* * *}$ & $1.373^{* * *}$ & $1.948^{* * *}$ & $3.997^{* * *}$ & $3.082^{* * *}$ \\
\hline
\end{tabular}

High Number of SBA Interventions - Low Number of SBA Interventions

\begin{tabular}{lllll}
\hline All Sample & $-0.227^{* * *}$ & $-0.181^{* * *}$ & $-0.082^{* * *}$ & $-0.232^{* * *}$ \\
Large Firms & $-0.099^{* * *}$ & $-0.087^{* * *}$ & $-0.074^{* * *}$ & $-0.181^{* * *}$ \\
SMEs & $-0.229^{* * *}$ & $-0.178^{* * *}$ & $-0.074^{* * *}$ & $-0.238^{* * *}$ \\
\hline
\end{tabular}

Panel B: Partnerships/Sole Traders

Partnerships/Sole Traders

\begin{tabular}{llllll}
\hline All Sample & $0.832^{* * *}$ & $1.151^{* * *}$ & $1.536^{* * *}$ & $3.405^{* * *}$ & $2.573^{* * *}$
\end{tabular}




\begin{tabular}{|c|c|c|c|c|c|}
\hline & First Quartile & Second Quartile & Third Quartile & Fourth Quartile & $\Delta_{\text {Fourth-First }}$ \\
\hline Large Firms & $0.597 * * *$ & $0.754^{* * *}$ & $0.945^{* * *}$ & $1.971^{* * *}$ & $1.375^{* * *}$ \\
\hline SMEs & $0.847^{* * *}$ & $1.175^{* * *}$ & $1.561^{* * *}$ & $3.439 * * *$ & $2.592^{* * *}$ \\
\hline \multicolumn{6}{|c|}{ Other Firms } \\
\hline All Sample & $1.100^{* * *}$ & $1.466^{* * *}$ & $1.88^{* * *}$ & $3.494^{* * *}$ & $2.395^{* * *}$ \\
\hline Large Firms & $0.689^{* * *}$ & $0.863^{* * *}$ & $1.115^{* * *}$ & $1.853^{* * *}$ & $1.164^{* * *}$ \\
\hline SMEs & $1.121^{* * *}$ & $1.492^{* * *}$ & $1.913^{* * *}$ & $3.557^{* * *}$ & $2.436^{* * *}$ \\
\hline \multicolumn{6}{|c|}{ Other Firms - Partnerships/Sole Traders } \\
\hline All Sample & $0.268^{* * *}$ & $0.315^{* * *}$ & $0.348^{* * *}$ & $0.089^{* * *}$ & \\
\hline Large Firms & $0.092^{* * *}$ & $0.108^{* * *}$ & $0.170 * * *$ & $-0.118^{*}$ & \\
\hline SMEs & $0.274^{* * *}$ & $0.317^{* * *}$ & $0.353^{* * *}$ & $0.118^{* * *}$ & \\
\hline
\end{tabular}

Panel C: Financial Constraints

Less Likely Financially Constrained

\begin{tabular}{|c|c|c|c|c|c|}
\hline All Sample & $0.592^{* * *}$ & $0.932^{* * *}$ & $1.362^{* * *}$ & $3.022^{* * *}$ & $2.430^{* * *}$ \\
\hline Large Firms & $0.307^{* * *}$ & $0.431^{* * *}$ & $0.621^{* * *}$ & $1.197^{* * *}$ & $0.890^{* * *}$ \\
\hline SMEs & $0.604^{* * *}$ & $0.948^{* * *}$ & $1.386^{* * *}$ & $3.087^{* * *}$ & $2.483^{* * *}$ \\
\hline \multicolumn{6}{|c|}{ More Likely Financially Constrained } \\
\hline All Sample & $1.173^{* * *}$ & $1.598^{* * *}$ & $2.164^{* * *}$ & $4.564^{* * *}$ & $3.390^{* * *}$ \\
\hline Large Firms & $0.643^{* * *}$ & $0.816^{* * *}$ & $1.089^{* * *}$ & $2.144^{* * *}$ & $1.501^{* * *}$ \\
\hline SMEs & $1.221^{* * *}$ & $1.646^{* * *}$ & $2.216^{* * *}$ & $4.658^{* * *}$ & $2.483^{* * *}$ \\
\hline
\end{tabular}

More Likely Financially Constrained - Less Likely Financially Constrained

\begin{tabular}{lllll}
\hline All Sample & $0.582^{* * *}$ & $0.666^{* * *}$ & $0.802^{* * *}$ & $1.542^{* * *}$ \\
Large Firms & $0.336^{* * *}$ & $0.385^{* * *}$ & $0.468^{* * *}$ & $0.948^{* * *}$ \\
SMEs & $0.617^{* * *}$ & $0.698^{* * *}$ & $0.830^{* * *}$ & $1.572^{* * *}$ \\
\hline
\end{tabular}

Panel D: Net Income Growth

Slow Growing Net Income

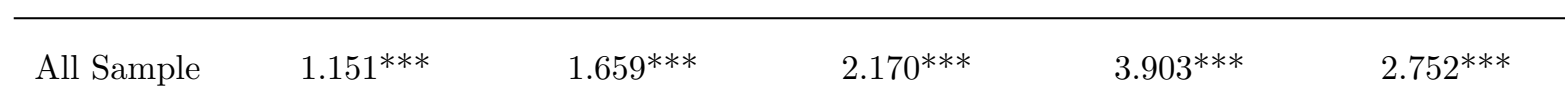




\begin{tabular}{|c|c|c|c|c|c|}
\hline & First Quartile & Second Quartile & Third Quartile & Fourth Quartile & $\Delta_{\text {Fourth-First }}$ \\
\hline Large Firms & $0.694^{* * *}$ & $0.921^{* * *}$ & $1.203^{* * *}$ & $1.893^{* * *}$ & $1.199^{* * *}$ \\
\hline SMEs & 1.176 & 1.692 & 2.209 & 3.975 & $2.799^{* * *}$ \\
\hline \multicolumn{6}{|c|}{ Fast Growing Net Income } \\
\hline All Sample & $0.878^{* * *}$ & $1.127^{* * *}$ & $1.502^{* * *}$ & $3.404^{* * *}$ & $2.526^{* * *}$ \\
\hline Large Firms & $0.575^{* * *}$ & $0.671^{* * *}$ & $0.897^{* * *}$ & $1.750^{* * *}$ & $1.175^{* * *}$ \\
\hline SMEs & $0.894^{* * *}$ & $1.147^{* * *}$ & $1.527 * * *$ & $3.478^{* * *}$ & $2.584^{* * *}$ \\
\hline \multicolumn{6}{|c|}{ Fast Growing Net Income - Slow Growing Net Income } \\
\hline All Sample & $-0.273^{* * *}$ & $-0.532^{* * *}$ & $-0.668^{* * *}$ & $-0.499 * * *$ & \\
\hline Large Firms & $-0.120^{* * *}$ & $-0.249 * * *$ & $-0.306^{* * *}$ & $-0.143^{* * *}$ & \\
\hline SMEs & $-0.282^{* * *}$ & $-0.545^{* * *}$ & $-0.682^{* * *}$ & $-0.496^{* * *}$ & \\
\hline \multicolumn{6}{|c|}{ Panel E: Assets Growth } \\
\hline \multicolumn{6}{|c|}{ Slow Growing Assets } \\
\hline All Sample & $1.240^{* * *}$ & $1.689^{* * *}$ & $2.220^{* * *}$ & $4.879^{* * *}$ & $3.639^{* * *}$ \\
\hline Large Firms & $0.785^{* * *}$ & $0.961^{* * *}$ & $1.267^{* * *}$ & $2.382^{* * *}$ & $1.597^{* * *}$ \\
\hline SMEs & $1.264^{* * *}$ & $1.718^{* * *}$ & $2.259^{* * *}$ & $4.987^{* * *}$ & $3.724^{* * *}$ \\
\hline \multicolumn{6}{|c|}{ Fast Growing Assets } \\
\hline All Sample & $0.742^{* * *}$ & $1.106^{* * *}$ & $1.537^{* * *}$ & $2.605^{* * *}$ & $1.863^{* * *}$ \\
\hline Large Firms & $0.464^{* * *}$ & $0.612^{* * *}$ & $0.827^{* * *}$ & $1.226^{* * *}$ & $0.762^{* * *}$ \\
\hline SMEs & $0.758^{* * *}$ & $1.128^{* * *}$ & $1.565^{* * *}$ & $2.652^{* * *}$ & $1.894^{* * *}$ \\
\hline
\end{tabular}

Fast Growing Assets - Slow Growing Assets

\begin{tabular}{lllll}
\hline All Sample & $-0.498^{* * *}$ & $-0.580^{* * *}$ & $-0.682^{* * *}$ & $-2.274^{* * *}$ \\
Large Firms & $-0.321^{* * *}$ & $-0.349^{* * *}$ & $-0.440^{* * *}$ & $-1.156^{* * *}$ \\
SMEs & $-0.505^{* * *}$ & $-0.590^{* * *}$ & $-0.694^{* * *}$ & $-2.335^{* * *}$ \\
\hline
\end{tabular}

Panel F: Secured Creditors and Absolute Priority

Secured Creditor Not Paid First

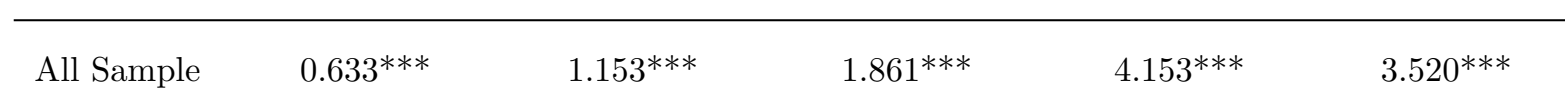




\begin{tabular}{|c|c|c|c|c|c|}
\hline & First Quartile & Second Quartile & Third Quartile & Fourth Quartile & $\Delta_{\text {Fourth-First }}$ \\
\hline Large Firms & $0.339^{* * *}$ & $0.657^{* * *}$ & $1.131^{* * *}$ & $2.424^{* * *}$ & $2.085^{* * *}$ \\
\hline SMEs & $0.645^{* * *}$ & $1.170^{* * *}$ & $1.884^{* * *}$ & $4.196^{* * *}$ & $3.551^{* * *}$ \\
\hline \multicolumn{6}{|c|}{ Secured Creditor Paid First } \\
\hline All Sample & $1.459^{* * *}$ & $1.656^{* * *}$ & $1.830^{* * *}$ & $3.125^{* * *}$ & $1.666^{* * *}$ \\
\hline Large Firms & $0.924^{* * *}$ & $0.961^{* * *}$ & $1.082^{* * *}$ & $1.560^{* * *}$ & $0.636^{* * *}$ \\
\hline SMEs & $1.515^{* * *}$ & $1.718^{* * *}$ & $1.893^{* * *}$ & $3.323^{* * *}$ & $1.808^{* * *}$ \\
\hline \multicolumn{6}{|c|}{ Secured Creditor Paid First - Secured Creditor Not Paid First } \\
\hline All Sample & $0.826^{* * *}$ & $0.503^{* * *}$ & $-0.031^{* * *}$ & $-1.028^{* * *}$ & \\
\hline Large Firms & $0.585^{* * *}$ & $0.304^{* * *}$ & $-0.049 * * *$ & $-0.865^{* * *}$ & \\
\hline SMEs & $0.870^{* * *}$ & $0.548^{* * *}$ & $0.009^{* * *}$ & $-0.873^{* * *}$ & \\
\hline \multicolumn{6}{|c|}{ Panel G: Creditors' Restrictions on Reorganization } \\
\hline \multicolumn{6}{|c|}{ Creditors Cannot Restrict Reorganization } \\
\hline All Sample & $0.863^{* * *}$ & $1.338^{* * *}$ & $1.895^{* * *}$ & $4.427^{* * *}$ & $3.563^{* * *}$ \\
\hline Large Firms & $0.516^{* * *}$ & $0.788^{* * *}$ & $1.177^{* * *}$ & $2.252^{* * *}$ & $1.737^{* * *}$ \\
\hline SMEs & $0.877^{* * *}$ & $1.356^{* * *}$ & $1.918^{* * *}$ & $4.510^{* * *}$ & $3.633^{* * *}$ \\
\hline \multicolumn{6}{|c|}{ Creditors Can Restrict Reorganization } \\
\hline All Sample & $1.275^{* * *}$ & $1.547^{* * *}$ & $1.903^{* * *}$ & $3.031^{* * *}$ & $1.756^{* * *}$ \\
\hline Large Firms & $0.740^{* * *}$ & $0.877^{* * *}$ & $1.084^{* * *}$ & $1.681^{* * *}$ & $0.940^{* * *}$ \\
\hline SMEs & $1.320^{* * *}$ & $1.592^{* * *}$ & $1.940^{* * *}$ & $3.081^{* * *}$ & $1.761^{* * *}$ \\
\hline \multicolumn{6}{|c|}{ Creditors Can Restrict Reorganization - Creditors Cannot Restrict Reorganization } \\
\hline All Sample & $0.412^{* * *}$ & $0.210^{* * *}$ & $0.008^{* * *}$ & $-1.395^{* * *}$ & \\
\hline Large Firms & $0.224^{* * *}$ & $0.090^{* * *}$ & $-0.093^{* * *}$ & $-0.572^{* * *}$ & \\
\hline SMEs & $0.444^{* * *}$ & $0.236^{* * *}$ & $0.022^{* * *}$ & $-1.429^{* * *}$ & \\
\hline
\end{tabular}


Table E.3: Loan Spreads: Equity Sensitivity Analysis

This table reports loan spreads when default probabilities are estimated using specification (4). "Lowleverage" firms belong to the first decile of our sample ranked according to leverage, whereas "Highleverage" firms belong to the tenth decile. SME (5M) denotes SMEs with annual sales below $€ 5$ million. PD is the probability of default; $d_{e l}$ is the expected loss component of the spread; $d_{u l}$ is the unexpected loss component of the spread; and $d_{e l}+d_{u l}$ is the total loan spread. In Panel A, cost of equity $\left(r_{e}\right)$ is $10 \%$. In Panel B, cost of equity $\left(r_{e}\right)$ is $15 \%$. All values are expressed as a percentage.

\begin{tabular}{|c|c|c|c|c|c|c|c|c|}
\hline & \multicolumn{3}{|c|}{ Low Leverage } & \multicolumn{3}{|c|}{ High Leverage } & \multicolumn{2}{|c|}{$\Delta_{\text {High-Low }}$} \\
\hline & Large & SMEs & $\Delta$ & Large & SMEs & $\Delta$ & Large & SMEs \\
\hline \multicolumn{9}{|c|}{ Panel A: $r_{e}=10 \%$} \\
\hline $\mathrm{PD}$ & 0.62 & 0.76 & 0.15 & 2.55 & 5.74 & 3.19 & 1.93 & 4.97 \\
\hline$d_{e l}$ & 0.12 & 0.15 & 0.03 & 0.50 & 1.13 & 0.63 & 0.38 & 0.98 \\
\hline$d_{u l}$ & 0.21 & 0.19 & -0.03 & 0.38 & 0.39 & 0.00 & 0.17 & 0.20 \\
\hline$d_{e l}+d_{u l}$ & 0.33 & 0.33 & 0.00 & 0.88 & 1.51 & 0.63 & 0.55 & 1.18 \\
\hline \multicolumn{9}{|c|}{ Panel B: $r_{e}=15 \%$} \\
\hline $\mathrm{PD}$ & 0.62 & 0.76 & 0.15 & 2.55 & 5.74 & 3.19 & 1.93 & 4.97 \\
\hline$d_{e l}$ & 0.12 & 0.15 & 0.03 & 0.50 & 1.13 & 0.63 & 0.38 & 0.98 \\
\hline$d_{u l}$ & 0.32 & 0.28 & -0.04 & 0.57 & 0.58 & 0.01 & 0.25 & 0.30 \\
\hline$d_{e l}+d_{u l}$ & 0.44 & 0.43 & -0.01 & 1.07 & 1.70 & 0.63 & 0.63 & 1.28 \\
\hline
\end{tabular}

